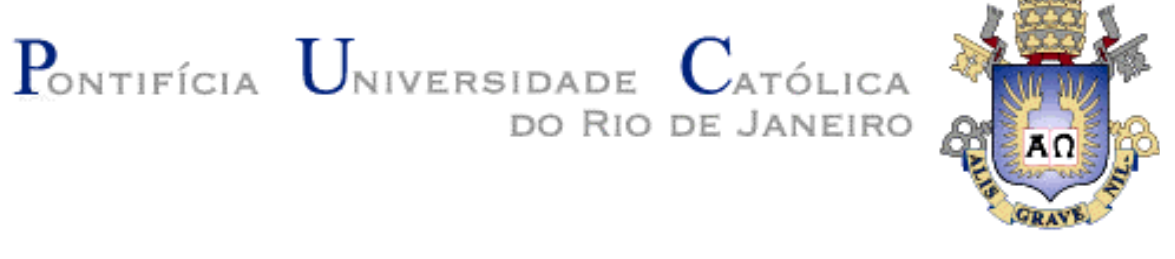

Sandra Milena Rosero Argote

\title{
Modelo Geomecânico Aplicado à Análise de Estabilidade de Poços com Ênfase em Folhelhos
}

\section{Dissertação de Mestrado}

Dissertação apresentada ao Programa de Pósgraduação em Engenharia Civil da PUC-Rio como requisito parcial para obtenção do título de Mestre em Engenharia Civil.

Orientador: Prof. Sergio A. B. da Fontoura 
Sandra Milena Rosero Argote

\section{Modelo Geomecânico Aplicado à Análise de Estabilidade de Poços com Ênfase em Folhelhos}

Dissertação apresentada ao Programa de Pósgraduação em Engenharia Civil da PUC-Rio como requisito parcial para obtenção do título de Mestre em Engenharia Civil. Aprovada pela Comissão Examinadora abaixo assinada.

Prof. Sergio Augusto Barreto da Fontoura Orientador Departamento de Engenharia Civil - PUC-Rio

Prof. Celso Romanel Departamento de Engenharia Civil - PUC-Rio

Prof. Ney Dumont Departamento de Engenharia Civil - PUC-Rio

Prof. Clemente José de Castro Gonçalves CENPES/PETROBRAS

Prof. José Eugenio Leal Coordenador Setorial do Centro Técnico Científico - PUC-Rio 
Todos os direitos reservados. É proibida a reprodução total ou parcial do trabalho sem autorização da universidade, do autor e do orientador.

\section{Sandra Milena Rosero Argote}

Graduou-se em Engenharia Civil pela Universidade de Nariño (San Juan de Pasto, Nariño, Colômbia - 2009) Ingressou em 2009 no curso de mestrado em Engenharia Civil na Pontifícia Universidade Católica do Rio de Janeiro, na área de Geotecnia, desenvolvendo dissertação de mestrado na linha de pesquisa de Geomecânica do Petróleo.

Ficha Catalográfica

Rosero Argote, Sandra Milena

Modelo geomecânico aplicado à análise de estabilidade de poços com ênfase em folhelhos / Sandra Milena Rosero Argote ; orientador: Sérgio A. B. da Fontoura. - 2012.

129 f. il. (color.) ; $30 \mathrm{~cm}$

Dissertação (mestrado)-Pontifícia Universidade Católica do Rio de Janeiro, Departamento de Engenharia Civil, 2012.

Inclui bibliografia

1. Engenharia civil - Teses. 2. Folhelho. 3. MEM. 4. TNP. 5. BDP. 6. Estabilidade de poços. I. Fontoura, Sérgio A. B. da. II. Pontifícia Universidade Católica do Rio de Janeiro. Departamento de Engenharia Civil. III. Título. 
Para meus amados pais Pilar e Anselmo;

E para meu querido irmão Christian. 


\section{Agradecimentos}

A Deus, por me ajudar nos momentos difíceis, por me dar a força para superar as dificuldades e terminar este trabalho e por todas as bençãos recebidas.

A CAPES pela concessão da bolsa de estudos e ao GTEP pelo apoio financeiro.

Ao professor Sérgio A. B. da Fontoura, meu profundo respeito e admiração profissional. Obrigada pelo seu apoio e paciência, pela confiança e incentivo constante, pela oportunidade de desenvolver este trabalho no GTEP e por todas as condições de infraestrutura oferecidas para o desenvolvimento deste trabalho.

Quero expressar a Vivian Marchesi, minha profunda admiração como profissional e como pessoa. Assim como, meu sincero agradecimento por sua importante contribuição e participação ativa no desenvolvimento desta dissertação. Obrigada por sua disposição e paciência, por todo seu apoio, por estar sempre o meu lado me incentivando, e pela valiosa amizade.

Aos meus pais, Pilar e Anselmo, e a meu irmão, Christian, por seu amor e apoio incondicional. Todos os meus logros são por e para vocês, hoje e sempre.

A Ana Liliana, por sua sincera amizade, por estar a meu lado nos dias de luta, por me alentar nos momentos difíceis e por celebrar meus sucessos como se fossem seus, obrigada por todos estes anos maravilhosos de amizade e por preencher minha vida de alegria com suas ocorrências.

Ao Luis Fernando Grijalba, pela imensa amizade que nos une desde a época do colégio e que tem tornado ainda mais forte ao longo destes anos todos. 
Ao Mario Morillo, por ser um grande amigo e colega, por me ter apoiado sempre e por estar presente nos momentos mais importantes da minha vida.

A Gricel e Fabricio, por todos os momentos que compartilhamos, por me apoiar, pela amizade e companheirismo incondicional, pelo convívio e aprendizado.

Aos amigos Leydi Silva, Andrés Gaona, José Miguel Mayta e Cristian Chacón, pela sua amizade e constante apoio durante todo o mestrado.

Aos colegas do GTEP, pela amizade e pelas gratas experiências vividas ao longo deste período.

A todos os professores e funcionários do Departamento de Engenharia Civil pelos ensinamentos e total apoio no decorrer deste trabalho.

Aos professores que participaram da Comissão Examinadora pelas sugestões feitas.

Finalmente, agradeço a todas as pessoas que contribuíram no desenvolvimento deste trabalho. 


\section{Resumo}

Rosero, Sandra Milena Argote; Fontoura, Sergio Augusto B. Modelo Geomecânico Aplicado à Análise de Estabilidade de Poços com Enfase em Folhelhos. Rio de Janeiro, 2012. 129p. Dissertação de Mestrado - Departamento de Engenharia Civil, Pontifícia Universidade Católica do Rio de Janeiro.

Frente à crescente complexidade dos cenarios de exploração de petróleo, as análises de estabilidade convencionais tornam-se insuficientes para determinar as condições reais dos poços. Assim, ciente destas limitações, a indústria do petróleo vem aplicando com mais frequência novos métodos como o modelo geomecânico denominado Mechanical Earth Model (MEM), pois permite gerar uma previsão da estabilidade do poço e ajuda a reduzir os riscos de perfuração. Neste sentido, o presente trabalho apresenta uma metodologia para estimar as condições da estabilidade de poços com ênfase nas formações de folhelhos, através da identificação e análise de problemas e eventos que revelem sinais de instabilidade geomecânica levantados nos dados de perfuração disponíveis. Boletins diários de perfuração e perfis elétricos de poços são as fontes de dados para análise de problemas de estabilidade que são os responsáveis pela maior parte dos tempos não produtivos, e consequentemente, de custos extras de perfuração. Por tanto, o estudo e o entendimento destes problemas contribuirá para a otimização do processo de perfuração, melhorando assim as práticas ou mitigando os efeitos severos das anormalidades.

\section{Palavras-chave}

Folhelho; Modelo Geomecânico; Tempo Não Produtivo; Boletins Diários de Perfuração; Estabilidade de poços. 


\section{Abstract}

Rosero, Sandra Milena Argote; Fontoura, Sergio Augusto B. (Advisor) Geomechanical Model Applied to the Stability Analysis of Wells with Enphasis on Shales. Rio de Janeiro, 2012. 129p. MSc. Dissertation Departamento de Engenharia Civil, Pontifícia Universidade Católica do Rio de Janeiro.

Facing the increasing complexity of scenarios for oil exploration, the conventional stability analysis became insufficient to determine the actual condition of the wells. Aware of these limitations, the oil industry has been applying new methods such as the geomechanical model named Mechanical Earth Model - MEM, which has been applied on the prediction of wellbore stability and drilling risks mitigation. In this sense, this work presents a methodology for estimating the wellbore stability conditions of wells with special emphasis on shale formations, through the identification and assessment of events which indicate geomechanical instability during drilling. These data are available from daily drilling reports and electric logs. Well Stability problems are responsible for most non-productive time, and consequently, the extra drilling costs. Therefore, the study and understanding of these problems contribute to the drilling optimization, thus improving the practices or mitigating the effects of severe abnormalities.

\section{Keywords}

Shales; Mechanical Earth Model; Non-Productive Time; Daily Drilling Report; Well stability. 


\section{Sumário}

$\begin{array}{ll}\text { 1. Introdução } & 17\end{array}$

$\begin{array}{ll}\text { 1.1. Motivação e objetivos } & 17\end{array}$

$\begin{array}{ll}\text { 1.2. Estrutura da dissertação } & 18\end{array}$

2. Revisão bibliográfica 20

2.1. Introdução 20

2.2. Histórico do modelo geomecânico - MEM. 21

2.3. Modelo Geomecânico aplicado para a estabilidade de poços. 21

2.4. Eventos e problemas de perfuração 25

2.4.1. Fechamento do poço 26

2.4.2. Desmoronamento do poço 27

2.4.3. Arraste e Torque $\quad 27$

2.4.4. Repasse 29

2.4.5. Limpeza do poço 30

2.5. Relação causa-consequência dos eventos e problemas $\begin{array}{ll}\text { de perfuração } & 31\end{array}$

2.6. Tempo Não-Produtivo (TNP) 38

2.7. Casos históricos da aplicação do MEM para a análise

de estabilidade de poços.

3 . Metodologia da modelagem geomecânica aplicada para a estabilidade de poços 48

3.1. Construção do MEM 48

3.2. Dados de Perfuração 50

3.2.1. Boletim Diário de Perfuração (BDP) 50

3.2.2. Dados da perfilagem 51

3.3. Metodologia para a construção do MEM 52

3.3.1. Auditoria de Dados 53

3.3.2. Retroanálise de Dados $\quad 54$

3.3.2.1. Análise do BDP 54 
3.3.3. Análise da estabilidade de poços

3.3.4. Modelagem tridimensional dos eventos de perfuração.

3.3.4.1. Estrutura do tratamento dos dados na modelagem geomecânica.

4. Resultados e Análise 82

4.1. Aquisição e Organização dos Dados 83

4.2. Análises dos Dados 83

4.2.1. Identificação dos eventos de instabilidade e construção das curvas de acompanhamento dos poços 83

5. Conclusões e sugestões. 110

6. Referências Bibliográficas 113

Apêndice A Gráficos de profundidade versus tempo 119

Apêndice B Gráficos para a análise do TNP 123

Apêndice C Janela Operacional 128 


\section{Lista de figuras}

Figura 2.1 - Integração de uma estrutura geológica e de um cubo sísmico 3D. 22 Figura 2.2 - Alguns tipos da instabilidade no poço. 26 Figura 2.3 - Classificação de cascalhos de folhelho,

A) cascalhos desmoronados, B) cascalhos lascados. 27

Figura 2.4 - Determinação dos esforços de arraste e torque. 28

Figura 2.5 - Repasse em um ambiente que contem uma concentração alta de cascalhos. $\quad 30$

Figura 2.6 - Formação e condição estável/instável dos cascalhos. 30

Figura 2.7 - Relações Causa-Consequência.

Figura 2.8 - Classificação do TNP nas operações de perfuração

de poços de petróleo e gás. 39

Figura 2.9 - Diagnóstico das condições da estabilidade de poço

em função dos "Quase-acidentes". 40

Figura 2.10 - Ações para eliminar os quase-acidente e o TNP

relacionados a instabilidade em cada fase do projeto e na execução do poço. 41

Figura 2.11 - Condição severa de instabilidade do poço Cusiana. 42

Figura 2.12 - Estabilidade das paredes do poço após a implementação

do MEM no campo Cusiana.. 43

Figura 2.13 - Curva de aprendizado no campo Cusiana. 44

Figura 2.14 - Acompanhamento do perfil caliper para a avaliação da integridade das paredes dos poços. $\quad 45$

Figura 2.15 - Experiência típica de perfuração antiga do campo.. 46

Figura 2.16 - Validação do modelo geomecânico. 47

Figura 2.17 - Experiência de perfuração do poço do projeto. 47

Figura 3.1 - Etapas envolvidas no fluxo de trabalho para o

diagnóstico das causas de problemas de perfuração. 53

Figura 3.2 - Metodologia para classificação e análise dos boletins. $\quad 54$

Figura 3.3 - Exemplo dos eventos de perfuração e das operações

de manobra plotados em um gráfico de profundidade versus tempo. $\quad 57$

Figura 3.4 - Influência do Tempo Não Produtivo (TNP) na curva

de perfuração. $\quad 58$

Figura 3.5 - Problemas de perfuração mapeados na trajetória do poço. 59 
Figura 3.6 - Gráfico de Pareto dos problemas encontrados

no poço em estudo.

Figura 3.7 - Problemas incidentes-GOM poços de gás

(poços perfurados 1993-2002; lâmina da água $\leq 600$ pés).

60

Figura 3.8 - Detalhes dos problemas incidentes-GOM

poços de gás- Companhia James K. Dodson. 60

Figura 3.9 - Módulo de Perfis. 62

Figura 3.10 - Método de Eaton para estimar a Pressão de Poros.. 64

Figura 3.11 - Relação entre E e $\mathrm{C}_{\mathrm{o}}$ para diversas litologias.. $\quad 67$

Figura 3.12 - Desmoronamentos e fraturas naturais no perfil de imagem. 72

Figura 3.13 - Breakouts e fraturas naturais e induzidas no perfil de imagem. 73

Figura 3.14 - Exemplo típico de janela operacional de um poço. 73

Figura 3.15 - Distribuição da pressão de poros a partir do centro

do poço caso o fluido seja não penetrante com descontinuidade

na parede do poço $\left(r=r_{w}\right) . \quad 76$

Figura 3.16 - Distribuição da pressão de poros a

partir do centro do poço caso o fluido seja penetrante. 76

Figura 3.17 - Etapas da construção do modelo 3D. 78

Figura 3.18 - Formato de apresentação dos dados discretos. 79

Figura 3.19 - formato de apresentação dos dados contínuos. 80

Figura 3.20 - correlação dos horizontes litológicos nos poços

analisados na janela bidimensional.. $\quad 81$

Figura 4.1 - Localização dos poços do estudo de caso. 82

Figura 4.2 - Gráfico de Perfuração versus Tempo do poço direcional P-004. 85

Figura 4.3 - Correlação da litologia, Trajetória, Perfil caliper e

Gráfico de Profundidade versus Tempo do poço P-004. 86

Figura 4.4 - Problemas de instabilidade ao longo da trajetória do poço P-004. 87

Figura 4.5 - Atividades principais do poço P-004. 88

Figura 4.6 - Discriminação do Tempo efetivo operacional e do TNP do poço. 89

Figura 4.7 - Detalhe dos eventos de instabilidade que contribuem no TNP. $\quad 89$

Figura 4.8 - Gráfico de Pareto poço P-004. 90

Figura 4.9 - Gráfico de Pareto dos poços analisados. 91

Figura 4.10 - Módulo de perfis - Perfis sintéticos de entrada do poço P-004. 94

Figura 4.11 - Módulo de perfis - Perfis sintéticos do poço P-004

calculados no SEST ${ }^{\odot}$. 
Figura 4.12 - Módulo de sobrecarga - Gradiente de sobrecarga

do poço P-004.

Figura 4.13 - Módulo de pressão de poros - Gradiente de pressão

de poros poço P-004.

Figura 4.14 - Módulo de pressão de propriedades mecânicas -

Propriedades mecânicas do poço P-004.

Figura 4.15 - Continuação Módulo de pressão de propriedades

mecânicas - Propriedades mecânicas do poço P-004.

Figura 4.16 - Continuação Módulo de pressão de propriedades

mecânicas - Propriedades mecânicas do poço P-004.

Figura 4.17 - Módulo de Tensões in-situ - Tensões in-situ do poço P-004. 100

Figura 4.18 - Módulo de Gradientes - Janela Operacional do poço P-004. 101

Figura 4.19 - Arquivo de importação dos repasses do poço P-004

como dado discreto.

102

Figura 4.20 - Arquivo de importação dos arrastes descendo

a coluna de perfuração do poço P-004 como dado contínuo.

102

Figura 4.21 - Correlação entre os arrombamentos e a coluna litológica

nos poços do estudo de caso a partir dos horizontes estratigráficos.

104

Figura 4.22 - Correlação entre os repasses e arrastes na descida

e retirada da coluna de perfuração com a coluna litológica nos poços

do estudo de caso a partir dos horizontes estratigráficos.

105

Figura 4.23 - Representação tridimensional dos arrombamentos nos poços do estudo de caso.

Figura 4.24 - Modelagem tridimensional dos horizontes litoestratigráficos em função dos arrombamentos nos poços do estudo de caso.

Figura 4.25 - Zonas de instabilidade em função dos arrombamentos

dos poços do estudo de caso.

Figura 4.26 - Zonas de maior instabilidade em função dos repasses nos poços do estudo de caso.

Fígura 4.27 - Modelagem tridimensional dos horizontes litoestratigráficos em função dos repasses nos poços do estudo de caso.

Figura 4.28 - Zonas de instabilidade em função dos repasses dos poços do estudo de caso..

Apêndice A.1 - Gráfico de profundidade versus tempo do poço P-001.

Apêndice A.2 - Gráfico de profundidade versus tempo do poço P-002.

Apêndice A.3 - Gráfico de profundidade versus tempo do poço P-003. 
Apêndice B.1 - Gráfico do tempo de perfuração das atividades principais do poço P-001.

Apêndice B.2 - Gráfico do Tempo produtivo (TP) e do Tempo Não

Produtivo (TNP) do poço P-001.

Apêndice B.3 - Gráfico dos problemas de instabilidade que geram o

Tempo Não Produtivo (TNP) do poço P-001.

Apêndice B.4 - Gráfico do tempo de perfuração das atividades principais do poço P-002.

Apêndice B.5 - Gráfico do Tempo produtivo (TP) e do Tempo Não

Produtivo (TNP) do poço P-002.

Apêndice B.6 - Gráfico do Tempo Não Produtivo (TNP) em função das atividades de perfuração do poço P-002.

Apêndice B.7 - Gráfico do tempo de perfuração das atividades principais do poço P-003.

Apêndice B.8 - Gráfico do Tempo produtivo (TP) e do Tempo Não Produtivo (TNP) do poço P-003.

Apêndice B.9 - Gráfico do Tempo Não Produtivo (TNP) em função das atividades de perfuração do poço P-003.

Apêndice C.1 - Janela operacional do poço P-001. 128

Apêndice C.2 - Janela operacional do poço P-002. 129

Apêndice C.3 - Janela operacional do poço P-003. 129 


\section{Lista de tabelas}

Tabela 2.1 - Fatores controláveis e não controláveis que influem na estabilidade do poço. $\quad 24$

Tabela 2.2 - Problema e principal agente causador. 32

Tabela 2.3 - Indicativos de ocorrência dos problemas. 32

Tabela 2.4 - Fatores associados à ocorrência de problemas geomecânicos. 33

Tabela 2.5 - Classificação Causa-efeito de Dificuldade de Avanço. 35

Tabela 2.6 - Classificação Causa-efeito de Dificuldade de Manobra. 36

Tabela 2.7 - Classificação Causa-efeito de Dificuldade por Prisão. 37

Tabela 3.1 - Resumo dos dados necessários para construir um

MEM e uma análise da estabilidade do poço. 49

Tabela 3.2 - Boletim diário de perfuração. $\quad 51$

Tabela 3.3 - Relações empíricas entre o angulo de fricção interna $(\Phi)$ e perfis. 68 Tabela 3.4 - Relações empíricas entre a resistência à compressão não-confinada (UCS) e outras propriedades físicas em folhelhos. 69 Tabela 4.1 - Poços analisados. 


\section{Lista de símbolos e siglas}

\begin{tabular}{ll}
$\Phi$ & Ângulo de atrito \\
BDP & Boletim Diário de Perfuração \\
$v$ & Coeficiente de Poisson \\
$\mathrm{C}_{\mathrm{o}}$ & Coesão \\
$\mathrm{dtc}$ & Tempo de trânsito da onda compressional \\
$\mathrm{dtmc}$ & Tempo de trânsito da onda compressional da matriz \\
$\mathrm{dtms}$ & Tempo de trânsito da onda cisalhante da matriz \\
$\mathrm{dts}$ & Tempo de trânsito da onda cisalhante \\
$\mathrm{ECD}$ & Densidade equivalente de circulação \\
$\mathrm{E}$ & Módulo de Young \\
$\mathrm{G}$ & Módulo de cisalhamento \\
$\mathrm{g}$ & Aceleração da gravidade \\
$\mathrm{K}$ & Razão entre as tensões principais efetivas \\
$\mathrm{K}_{\mathrm{b}}$ & Módulo de deformação volumétrica \\
$\mathrm{K}_{\mathrm{s}}$ & Módulo de compressibilidade dos grãos \\
$\mathrm{LOT}$ & Teste para determinar pressão de absorção \\
$M E M$ & Modelo Geomecânico \\
$\mathrm{\rho}_{\mathrm{f}}$ & Densidade da formação \\
$\mathrm{P}_{\mathrm{p}}$ & Pressão de poros \\
$\mathrm{ROP}$ & Taxa de penetração \\
$\mathrm{RPM}$ & Revoluções por minuto \\
$\mathrm{T}$ & Torque \\
$\mathrm{TNP}$ & Tempo Não Produtivo \\
$\mathrm{UCS}$ & Resistência à compressão simples \\
$\mathrm{WOB}$ & Peso sobre a broca de perfuração \\
$\sigma_{\mathrm{v}}$ & Tensão vertical \\
$\sigma_{\mathrm{h}}$ & Tensão horizontal menor \\
$\sigma_{\mathrm{H}}$ & Tempo horizontal maior \\
$\mathrm{v}_{\mathrm{p}}$ & Velocidade da onda compressional \\
$\mathrm{v}_{\mathrm{s}}$ & Velocidade da onda cisalhante \\
$\alpha$ & Coeficiente de Biot \\
$\mathrm{dt}$ & Tempo de trânsito \\
\hline
\end{tabular}




\section{1. Introdução}

\section{1. Motivação e objetivos}

A instabilidade em poços é um dos problemas frequentes que a indústria do petróleo tem enfrentado ao longo de várias décadas, sendo a instabilidade em folhelhos o maior item responsável pelo incremento do tempo perdido e dos custos operacionais extras durante a perfuração.

Nesse contexto, mesmo que nos últimos anos estes tipos de problemas tenham sido amplamente identificados, estudados e modelados, as análises de estabilidade convencionais tornaram-se insuficientes para determinar as condições de estabilidade reais dos poços, devido à crescente complexidade dos cenarios de exploração de petróleo e ao escasso conhecimento geomecânico do mesmo.

Estas constatações justificam muitos dos esforços que têm sido desenvolvidos na indústria para estabelecer metodologias capazes de reduzir os problemas de instabilidade e o Tempo Não-Produtivo (TNP) causado por esses.

Entre essas metodologias, a modelagem geomecânica (Mechanical Earth Model - MEM) se sobressai por permitir obter uma previsão da estabilidade do poço e a redução dos riscos de perfuração através da integração de um modelo geológico estrutural com todas as informações relevantes do poço, tais como, Boletins Diários de Perfuração (BDP), registros de perfis do poço, parâmetros de perfuração e sísmica (Plumb et al., 2000).

Neste contexto, este trabalho tem por objetivo propor uma metodologia que permite determinar por meio de uma modelagem geomecânica as condições de estabilidade de poços, através das análises dos dados de perfuração, isto é, $\mathrm{BDP}(\mathrm{s})$ e perfis dos poços, a partir da identificação dos eventos de perfuração particularmente relacionados aos problemas geomecânicos em folhelhos, os quais vêm a ser os responsaveis do TNP e custos extras na perfuração de poços. 


\section{2.}

\section{Estrutura da dissertação}

Este trabalho está dividido em seis capítulos e três apêndices. O capitulo 1 apresenta a introdução do tema em estudo, assim como a estrutura seguida ao longo da dissertação.

O Capítulo 2 inclui a revisão bibliográfica dos principais aspectos relacionados a uma análise da estabilidade de poços desenvolvida a partir de uma modelagem geomecânica com énfase particular em folhelhos. O estudo usa dados dos BDP(s) e de perfis dos poços, dos quais, apenas é apresentada a revisão dos eventos e problemas de natureza geomecânica pré-classificados dos BDP(s) como arrombamentos, fechamento do poço, repasses por instabilidade, arrastes descendo e retirando a coluna, topadas e peixe no poço. Estes eventos e problemas foram analisados e caracterizados tanto em função dos fatores que os geram quanto do TNP. Por último, são citados casos históricos em que se aplicou esta análise.

Após apresentados os aspectos gerais que envolvem a aplicação de uma modelagem geomecânica para avaliar a estabilidade de poços, dá-se inicio ao Capítulo 3 com a descrição da metodologia proposta em três estágios.

Inicialmente, apresenta-se a descrição dos dados disponíveis que foram utilizados na aplicação da metodologia proposta, isto é, BDP(s) e perfis dos poços. Também se inclui uma compilação das metodologias desenvolvidas por alguns autores para o tratamento e auditoria desses dados de perfuração em questão.

A seguir é apresentada a estrutura da metodologia proposta, descrevendo os critérios estabelecidos para o tratamento dos dados por meio de uma retroanálise individual e coletiva que permita a identificação dos problemas de perfuração e a estimação quantitativa do TNP.

Por último, inclue-se a descrição do processo para a análise de estabilidade dos poços feita particularmente para os trechos de folhelho com o apoio do software $\mathrm{SEST}^{\odot}$ - Sistema de ESTabilidade versão 5.72 desenvolvido pelo Grupo de Tecnologia em Engenharia de Petróleo (GTEP) da PUC-RIO em conjunto com a PETROBRAS. Do mesmo modo, foi usado o modelador computacional $\mathrm{PETREL}^{\odot}$ para o tratamento dos dados espacialmente dentro da modelagem tridimensional do campo. 
Uma vez apresentadas no Capítulo 3 as etapas da metodologia proposta, no Capítulo 4 é apresentado um estudo de caso utilizando a metodologia apresentada. Em seguida são apresentados os resultados obtidos.

No Capítulo 5 são apresentadas as conclusões e recomendações para trabalhos futuros.

No Capítulo 6 são apresentadas as referências bibliográficas citadas no trabalho e em seguida são apresentados três apêndices. O apêndice $A$ apresenta os gráficos de profundidade versus tempo dos poços analisados no estudo de caso. $O$ apêndice $B$ apresenta os gráficos para a análise do TNP causado pelos problemas e eventos de instabilidade. Finalizando, o apêndice $\mathrm{C}$ apresenta os gráficos correspondentes as janelas operacionais dos poços analisados no estudo de caso. 


\section{2. Revisão bibliográfica}

Este capítulo apresenta uma revisão dos conceitos e considerações de um modelo geomecânico aplicado à estabilidade de poços com ênfase em folhelhos, a fim de contextualizar a sua importância neste estudo. Em seguida, apresentam-se alguns estudos de casos que exemplificam a aplicação desta metodologia.

\section{1. \\ Introdução}

Manter as condições da estabilidade dos poços durante as operações de perfuração nos campos petrolíferos é muito importante, pois o indicador limitante do desempenho do poço é sua instabilidade (Dupriest et al., 2011).

Muitos estudos na área de instabilidade, particularmente os que se referem aos folhelhos, têm demostrado que as causas reais destes problemas ainda não são completamente entendidas e que maiores dificuldades operacionais são enfrentadas durante a perfuração quando o conhecimento dos parâmetros geomecânicos é limitado, pois é mais difícil prever os problemas de instabilidade do poço. Daqui que estas dificuldades tenham exigido o desenvolvimento de projetos em condições técnicas e economicamente desafiantes.

Nesse contexto, dependendo da severidade dos problemas de instabilidade encontrados nos poços, nem sempre estes podem ser solucionados através de uma análise convencional de estabilidade, razão pela qual novas metodologias têm sido desenvolvidas, como a modelagem geomecânica $M E M$, a qual já é reconhecida na indústria do petróleo como uma ferramenta versátil em menos de uma década de constituída, (Moazzeni et al., 2010). 


\section{2.}

\section{Histórico do modelo geomecânico - MEM.}

Segundo Plumb et al., (2000), a década dos anos 80 se caracterizou pela experiência teórica e prática que engenheiros e geólogos adquiriram na aplicação de técnicas de modelagem da estabilidade de poço de vários níveis de complexidade, pelo desenvolvimento de tecnologias computacionais, e pela melhoria de instrumentos de registro, tais como o perfil sônico e de imagem.

Já no início dos anos 90, com a identificação de graves problemas de instabilidade no campo de Cusiana, os autores demostraram que uma abordagem convencional para resolvê-los simplesmente não funcionaria, devido ao insuficiente conhecimento geomecânico do campo (Last et al., 1995).

A partir de tal constatação, os autores observaram a necessidade de criar um grupo multidisciplinar de especialistas que compilaram, por certo período de tempo, informações geomecânicas do campo suficientes para melhorar o desempenho da perfuração, sendo que tais informações constituem a fonte básica de informação usada para construir o MEM.

\section{3. \\ Modelo Geomecânico aplicado para a estabilidade de poços.}

Segundo Plumb et al., (2000), o MEM é uma representação numérica do estado de tensões e das propriedades mecânicas das rochas para uma seção estratigráfica específica em um campo ou bacia. $O$ modelo é ligado à estrutura geológica através da estratigrafia local e de um cubo de sísmica 3D.

Conforme os autores, basicamente o MEM é composto de vários conjuntos de dados de entrada, os quais podem ser distinguidos em quatro grupos principais, esses dados são: magnitude das tensões in-situ, direção das tensões in-situ, pressão de poros $\left(P_{p}\right)$ e propriedades elásticas das rochas. As tensões in-situ incluem: a tensão de sobrecarga $\left(\sigma_{v}\right)$, tensão horizontal mínima $\left(\sigma_{h}\right)$ e a tensão horizontal máxima $\left(\sigma_{H}\right)$. As propriedades elásticas incluem: módulo de Young (E), coeficiente de Poisson (v). Também se incluem os parâmetros de resistência à compressão da rocha (UCS), coesão (Co), ângulo de atrito ( $\phi)$, todos referentes à seção estratigráfica do local de estudo. 
Na Figura 2.1, estão apresentados os parâmetros geomecânicos típicos de um MEM.

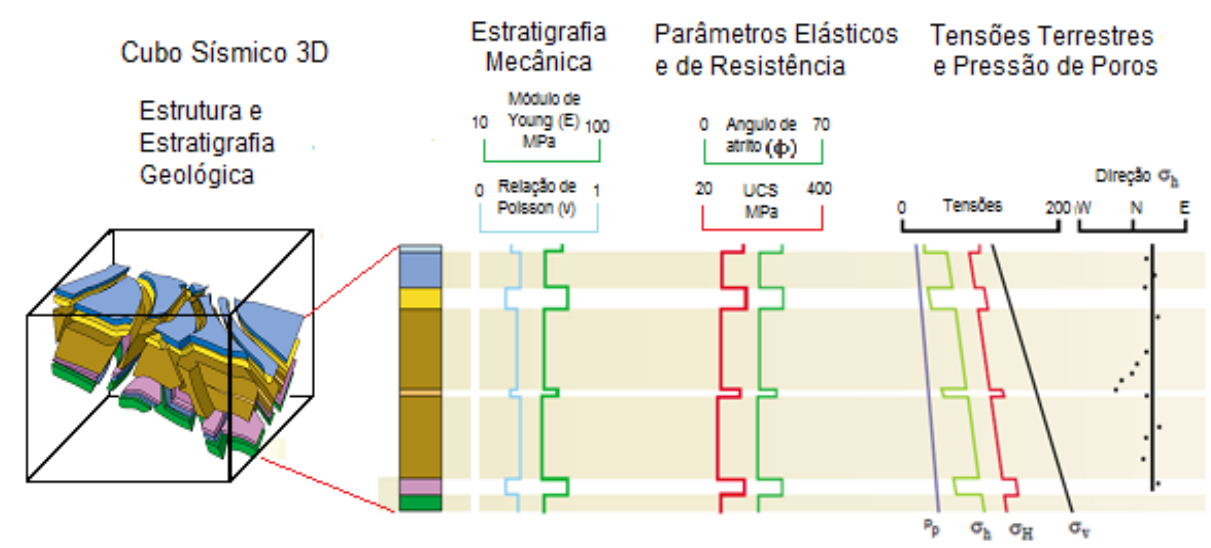

Figura 2.1 - Integração de uma estrutura geológica e de um cubo sísmico 3D (Modificada de Plumb et al., 2000).

Citam-se algumas vantagens oferecidas pelo $M E M$ como as seguintes:

- Visualização tridimensional integrada de dados de diversas fontes para fins da análise de estabilidade dos poços;

- Entendimento do campo como um todo;

- Identificação das causas dos problemas de instabilidade nos poços;

- Realce de possíveis regiões críticas no modelo, identificando onde, quando e porque ocorrem os problemas os eventos de perfuração;

- Reduzir o TNP causados pelos problemas na perfuração permitindo estabelecer uma previsão das experiências de perfuração de um poço em tempo real;

- Otimizar o tempo de perfuração;

- Obter uma boa taxa de penetração mantendo a estabilidade do poço;

- Adotar um peso de fluido de perfuração adequado;

- Melhorar o desempenho dos poços;

- Reduzir os custos.

Como foi mencionado no inicio, para efeitos da dissertação, o modelo geomecânico assim desenvolvido tem sido aplicado para o cálculo da estabilidade de poços com ênfase nos trechos de folhelhos, pois os problemas de instabilidade nestas formações são os que com mais frequência ocorrem na 
indústria do petróleo, sendo responsáveis pela maior parte do TNP e dos custos extras das operações.

Neste contexto, cabe destacar algumas características que fazem dos folhelhos uma formação instável, pois cerca de $75 \%$ das formações perfuradas em poços de petróleo contém folhelhos ativos e mais de $90 \%$ dos problemas de estabilidade das paredes do poço estão relacionados à inabilidade do fluido de perfuração em controlar esses folhelhos.

Segundo Fjær et al., (2002), nos últimos dez anos, aproximadamente, 5\% a $10 \%$ do tempo perdido e 20 a $30 \%$ dos custos extras ocorreram durante a perfuração em folhelhos.

Os folhelhos são rochas sedimentares, de granulação fina composta basicamente de minerais de argila. A baixa permeabilidade, a fissilidade e a facilidade de reagir quimicamente dos componentes da argila são características que conferem ao folhelho propriedades físico-químicas únicas, quando comparadas com outras rochas sedimentares.

Geralmente, os folhelhos estão compostos por quartzo, feldspato, calcita, e frações de argila em proporções variáveis; onde argilas susceptíveis a água, tais como a esmectita e ilita, podem constituir até $80 \%$ do peso total do folhelho (O’Brien \& Chenevert, 1973), conferindo-Ihe um elevado potencial de reatividade frente aos fluidos de perfuração à base água, desencadeando mecanismos de hidratação e dispersão, que podem chegar a causar problemas graves no poço com o passar do tempo.

Quando o poço é perfurado, o equilíbrio mecânico e físico-químico preexistente é perturbado, condicionando a estabilidade do poço à interação de diferentes fatores que controlam o comportamento do poço.

Mendoza (1987) cita, conforme Cheatham (1984), uma classificação dos fatores controláveis e não controláveis que influenciam a estabilidade de um poço segundo sua origem em: geomecânicos, geométricos e construtivos.

\section{Fatores geomecânicos}

Os fatores geomecânicos são dependentes diretamente das propriedades da formação. Eles incluem:

- Propriedades físico-químicas das rochas;

- Propriedades mecânicas da rocha intacta e das descontinuidades;

- Estado de tensões in-situ;

- Pressão do fluido de perfuração e;

- Variação da temperatura. 


\section{Fatores geométricos}

Os fatores geométricos estão relacionados com a forma, a direção e o mergulho do poço com respeito à distribuição da massa rochosa, incluindo:

- Diâmetro do poço e a profundidade de avaliação da estabilidade;

- Orientação e inclinação do poço e;

- Orientação relativa entre a direção das tensões principais e o eixo do poço.

\section{Fatores construtivos}

Os fatores construtivos estão ligados diretamente com as operações de perfuração, de instalação do revestimento e de produção. Os principais fatores deste tipo são os seguintes:

- Tipo e peso do fluido de perfuração;

- Forças geradas pela broca;

- Tipo de revestimento e cimentação;

- Forças e modificações das tensões durante a fase de produção.

Segundo Chen (2001), alguns fatores que induzem a ruptura do poço podem ser controlados, enquanto outros são impossíveis de controlar por serem propriedades intrínsecas da formação.

Os principais fatores que afetam a estabilidade do poço estão listados na Tabela 2.1

Tabela 2.1 - Fatores controláveis e não controláveis que influem na estabilidade do poço. (Editada de Chen, 2001).

\begin{tabular}{|l|l|}
\hline \multicolumn{1}{|c|}{ FATORES CONTROLÁVEIS } & \multicolumn{1}{c|}{ FATORES INCONTROLÁVEIS } \\
\hline Pressão no poço & Tensões in-situ \\
\hline Tipo de fluido de perfuração & Litologia das rochas \\
\hline $\begin{array}{l}\text { Composição química do fluido de } \\
\text { perfuração }\end{array}$ & Composição química do fluido dos poros \\
\hline $\begin{array}{l}\text { Orientação e direção relativa ao campo de } \\
\text { tensões }\end{array}$ & $\begin{array}{l}\text { Porosidade da rocha/ Permeabilidade } \\
\text { original/Compressibilidade }\end{array}$ \\
\hline Temperatura de lama & Temperatura inicial da rocha \\
\hline Tamanho do poço & Resistência da rocha \\
\hline Tamanho do tubo de perfuração & Propriedades mecânicas da rocha \\
\hline Vazão & Poro pressão inicial \\
\hline Tempo do poço aberto & Fraturas naturais \\
\hline $\begin{array}{l}\text { Operações de perfuração (perfuração, } \\
\text { cimentação, etc.) }\end{array}$ & $\begin{array}{l}\text { Propriedades térmicas das rochas } \\
\text { Gradiente Geotérmico }\end{array}$ \\
\hline
\end{tabular}


Dependendo da interação desses fatores, existem diferentes tipos de problemas de instabilidade os quais serão tratados no item a seguir.

\section{4. \\ Eventos e problemas de perfuração}

Chipindu (2010) cita, conforme Cerqueira (1997), que problema é qualquer resultado indesejável de uma atividade ou processo. Para qualquer estudo de problemas o mais importante é saber identificar sua natureza (tipo) e como se manifesta (sintomas).

Rabelo (2008) considera que:

Todo tipo de problema dever ser averiguado, não ficando restrito a eventos mais sérios como prisões de coluna e kicks. Registros de repasses (realizados com frequência) e arrastes elevados durante as manobras de descida de revestimento também devem ser tratados como anormalidades, já que podem evidenciar ocorrências de problemas geomecânicos.

Os tipos de problemas e eventos de instabilidade em folhelhos podem ser do tipo intrínseco como os relacionados com a interação físico-química do folhelho com o fluido de perfuração, à ruptura da rocha ou, do tipo operacional.

En vista disso, a seguir é apresentada uma breve descrição de alguns problemas de instabilidade que podem ser identificados no BDP e que podem estar relacionados à instabilidade de poços durante a perfuração em trechos de folhelhos.

Oort (1994) classificou em dois tipos os problemas intrínsecos dos folhelhos no campo: problemas de instabilidade em cascalhos e, no poço.

Os problemas de instabilidade nos cascalhos envolvem os processos de hidratação e expansão dos minerais de argila presentes no folhelho ao entrarem em contato com o fluido de perfuração base água, resultando em um carregamento de sólidos no fluido de perfuração que provoca um aumento da viscosidade, dificulta a execução da limpeza e causa problemas operacionais como prisão da coluna de perfuração.

No que se refere à instabilidade de poços durante a perfuração com fluidos a base água, os fatores que causam os problemas de instabilidade podem ser classificados com base nos diferentes efeitos sobre a alteração da pressão dos poros e das tensões que atuam no folhelho, em mecânicos e físico-químicos, os quais têm sido discutidos por vários autores tais como Bradley (1979a). 
Entre os problemas de perfuração mais frequentes nos poços citam-se os seguintes (Bradley, 1979a; Bradley 1979b):

- Fechamento do poço

- Alargamento do poço

- Limpeza ineficiente do poço

- Prisão da coluna de perfuração

Entre os eventos de perfuração citam-se os seguintes:

- Repasses

- Arrastes e torques elevados

\subsection{1.}

\section{Fechamento do poço}

Consiste na redução da seção transversal do poço provocada pela ruptura por compressão de acordo com o comportamento dúctil ou frágil das rochas perfuradas, tal como são representados na Figura 2.2.

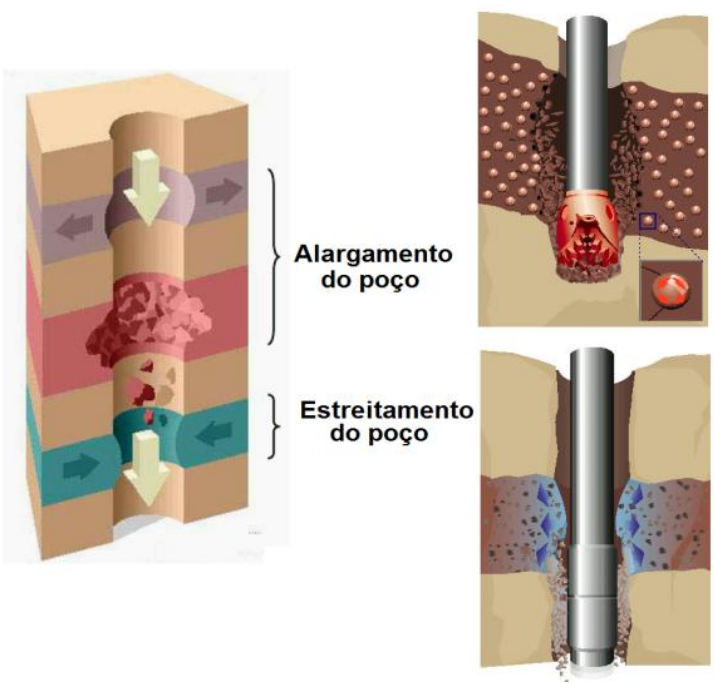

Figura 2.2 - Alguns tipos da instabilidade no poço (Modificada de Last et al.,1995).

No caso particular dos folhelhos, o fechamento do poço pode ocorrer devido ao inchamento dos minerais de argila por hidratação, produzindo o aprisionamento das ferramentas de perfuração, altos torques e os repasses repetitivos experimentados durante a retirada da coluna de perfuração. 


\subsection{2.}

\section{Desmoronamento do poço}

Chama-se de desmoronamento as quedas de cascalhos ou blocos de rocha que formam parte das paredes do poço, o qual pode ser provocado pela pressão hidrostática insuficiente no interior do poço para superar a pressão dos poros da rocha, pela ação mecânica da coluna de perfuração sobre as paredes do poço ou por ruptura à compressão normalmente caracterizada por rupturas diametralmente opostas.

Uma análise das características dos cascalhos provenientes do poço tais como tamanho, formato e quantidade é uns dos meios para se detectar a causa do desmoronamento.

Os cascalhos dos folhelhos se ajustam bem a este tipo de análise, pois eles podem dar uma boa indicação das condições de estabilidade das paredes do poço Figura 2.3 (Rocha \& Azevedo, 2007).

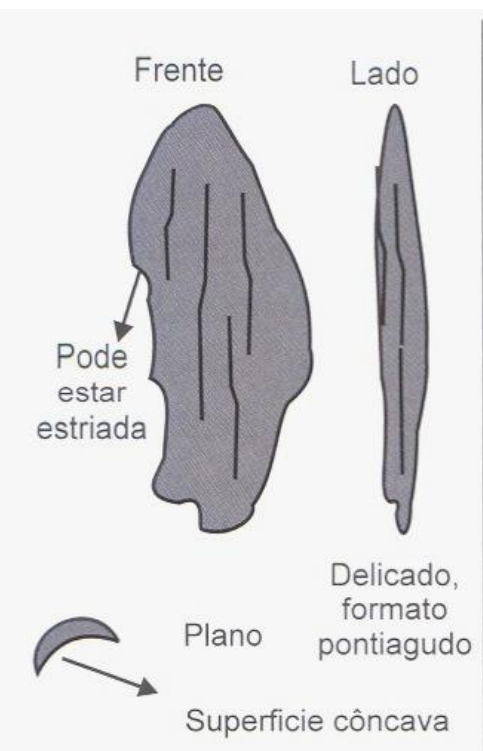

(A)

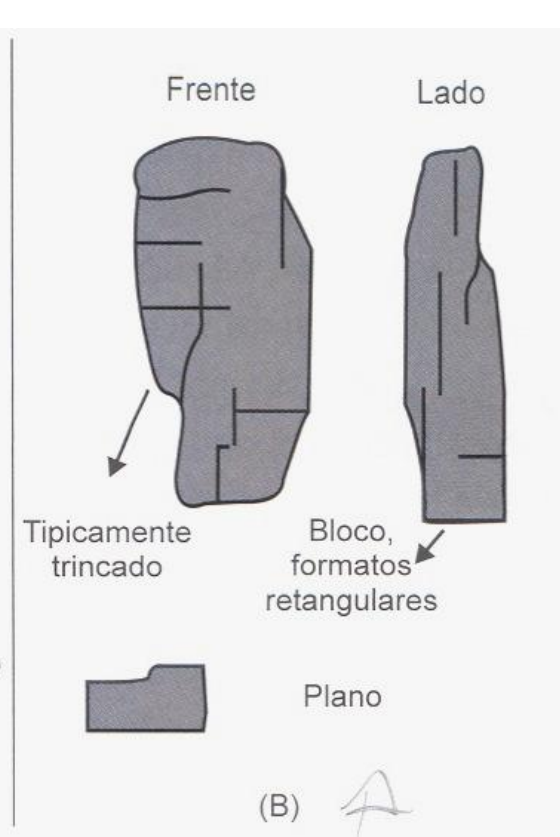

(B)

Figura 2.3 - Classificação de cascalhos de folhelho, A) cascalhos desmoronados, B) cascalhos lascados, (Tomada de Rocha \& Azevedo, 2007).

\subsection{3.}

\section{Arraste e Torque}

Segundo Idagawa (1990), o diagnóstico de problemas na perfuração pode ser baseado na análise de esforços de torque (momento necessário para girar a coluna) e arraste (esforço adicional para a movimentação axial da coluna devido 
a forças de atrito), os quais são frequentemente associados entre si durante as movimentações de colunas de perfuração ou de revestimentos no interior do poço.

O mesmo autor afirma que o diagnóstico de problemas na perfuração de poços direcionais pode ser feito com base na avaliação de esforços de torque e arraste registrados nas movimentações da coluna de perfuração ou de revestimento no interior do poço, pois com o aumento da inclinação do poço, maior é a parcela da coluna de perfuração que passa a se apoiar nas paredes do poço (podendo variar significativamente dependendo da trajetória do poço e da composição da coluna) resultando em maiores torques e arrastes durante as manobras.

Por último, o autor afirma que a avaliação destes parâmetros é importante, pois permite o conhecimento das condições mecânicas das paredes do poço, fazendo com que seja possível identificar, a tempo, problemas como, por exemplo, prisão de coluna ou do cabo de perfilagem.

Obtêm-se boas estimativas de torque e arraste, multiplicando-se o fator de atrito pela força normal da coluna sobre as paredes do poço como é representado da Figura 2.4, os quais podem ser usados para diagnosticar problemas no poço quando combinados com outros parâmetros tais como: variação da pressão de bombeio, pistoneios, amostras de calha, repassamentos, entre outros.

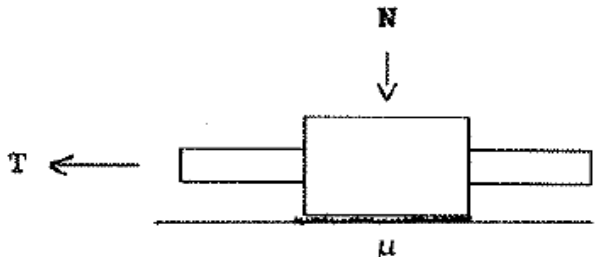

$\mu=\frac{T}{N}$

onde:
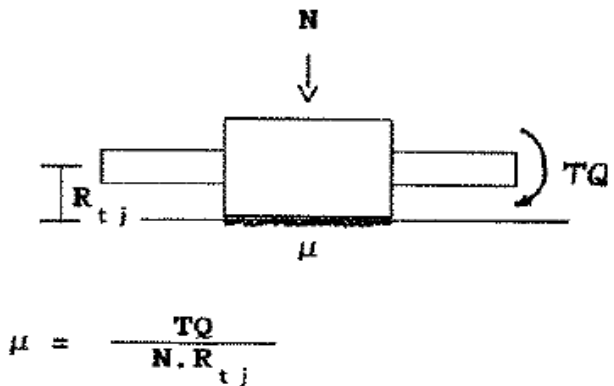

Figura 2.4 - Determinação dos esforços de arraste e torque (Tomada de Idagawa, 1990).

O monitoramento combinado de torque, arraste e da densidade equivalente de circulação (ECD) fornecem informações adicionais sobre as condições da limpeza do poço. A técnica também permite otimizar a programação dos repasses para que eles sejam feitos corretamente somente quando são necessários (Vos, 2000). 


\subsection{4. \\ Repasse}

Segundo Chipindu (2010), os repasses são feitos para manter em boas condições as paredes dos poços para que os revestimentos, perfis elétricos, colunas de pescaria e demais componentes da coluna de perfuração possam passar sem problemas nos diâmetros planejados no projeto de poço.

Os repasses podem causar problemas ao invés de resolvê-los, se não forem feitos com suficiente cuidado, comprometendo o funcionamento do poço pela geração de uma grande quantidade de cascalhos e/ou cavings que podem chegar a causar problemas de estabilidade, aumento do ECD e prisões na coluna de perfuração.

Yarim et al., (2010) afirmam que alguns operadores consideram que o tempo adicional que requerem as operações de repasse é TNP.

Os autores afirmam que as operações de repasses são utilizadas para:

- Evitar a condição de fechamento do poço.

- Limpeza do poço eliminando os cascalhos e cavings.

Tavares (2006) considera necessárias as operações de repasse:

- Na retirada da coluna de perfuração quando houver indícios de resistência (por exemplo, acunhamento);

- Na descida da coluna de perfuração quando há intervalos que ofereçam resistência (por exemplo: topamento);

- Quando há ameaça de prisão;

- Para cortar a pega de cimento.

As operações de repasse em formações instáveis, que são sensíveis à agitação mecânica, tais como folhelhos fraturados, podem ter um efeito negativo para a integridade do poço, devido à transmisão de vibrações por parte da coluna de perfuração ao folhelho fraturado, causando alargamento no diâmetro do poço e mais sólidos por remover, tal como se observa na Figura 2.5 (Yarim et al., 2010). 
Operação de repasse em um ambiente que contem una concentração alta de cascalhos

Restrição no anular devido à grande quantidade de cascalhos, provocando:

- Alta flutuação da pressão nas bombas

- Alta flutuação do torque

- Alta flutuação dos repasses

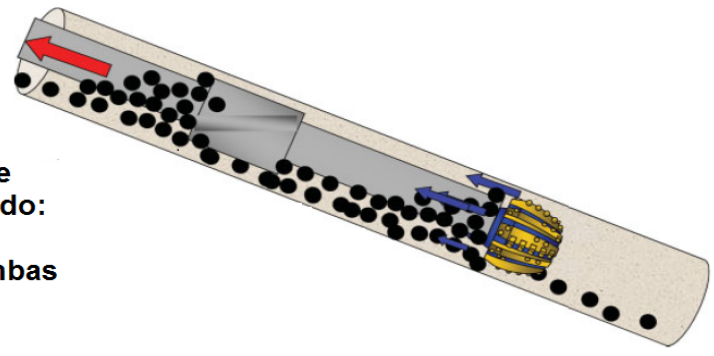

Figura 2.5 - Repasse em um ambiente que contem uma concentração alta de cascalhos.

(Modificada de Yarim et al., 2010).

\subsection{5.}

\section{Limpeza do poço}

Durante a perfuração de um poço, os cascalhos gerados pela broca são removidos para a superfície pelo fluido circulando no poço. Quando se utiliza uma vazão insuficiente ou quando as propriedades do fluido são inadequadas, os cascalhos não são removidos totalmente, e vão se acumulando no espaço anular podendo resultar na prisão de coluna.

Segundo Yarim et al., (2010), a limpeza de poços se apresenta como um problema comum e custoso na perfuração direcional e horizontal. A limpeza inadequada de poços horizontais pode causar problemas como rápido desgaste da broca, baixas taxas de perfuração, altos valores de torque e arraste, e até a prisão da coluna de perfuração.

Se a situação não for tratada da maneira correta, podem ocorrer desvios na trajetória ou até mesmo a perda do poço. Em poços direcionais, os cascalhos formam um leito na parte inferior das paredes do poço dificultando ainda mais a sua remoção, como o apresentado na Figura 2.6.

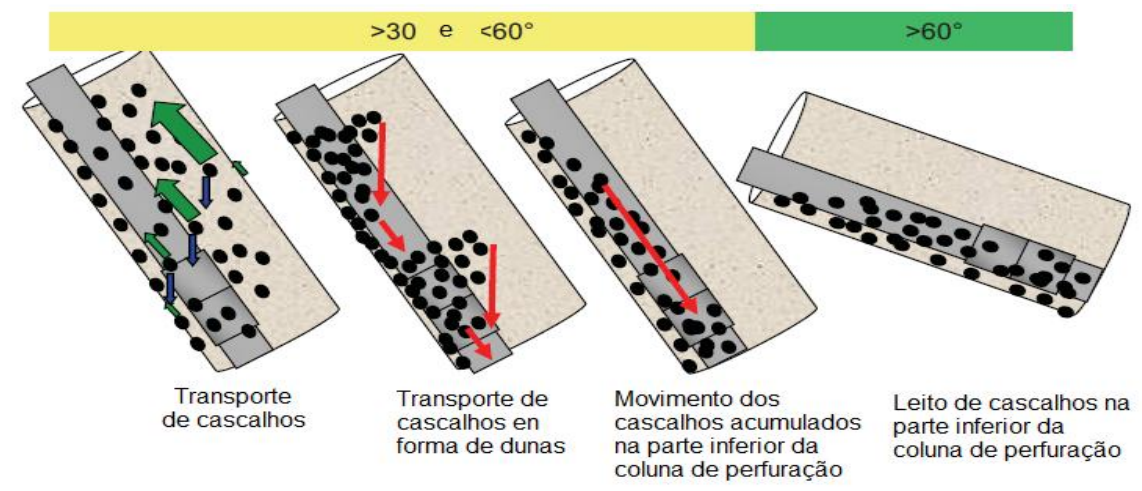

Figura 2.6 - Formação e condição estável/instável dos cascalhos. (Modificada de Yarim et al., 2010). 
Ainda existem outras situações em que a vazão ótima é limitada pela capacidade dos equipamentos de bombeio. Outra limitação ocorre em poços com variações grandes de geometria como mudança nominal do diâmetro do poço, alargamentos, etc.

\section{5 .}

\section{Relação causa-consequência dos eventos e problemas de perfuração}

Conforme Tavares (2006), algumas situações dos problemas mencionados, possuem relação de causa e consequência entre si. A Figura 2.7 apresenta algumas das relações que podem ser explicitadas.

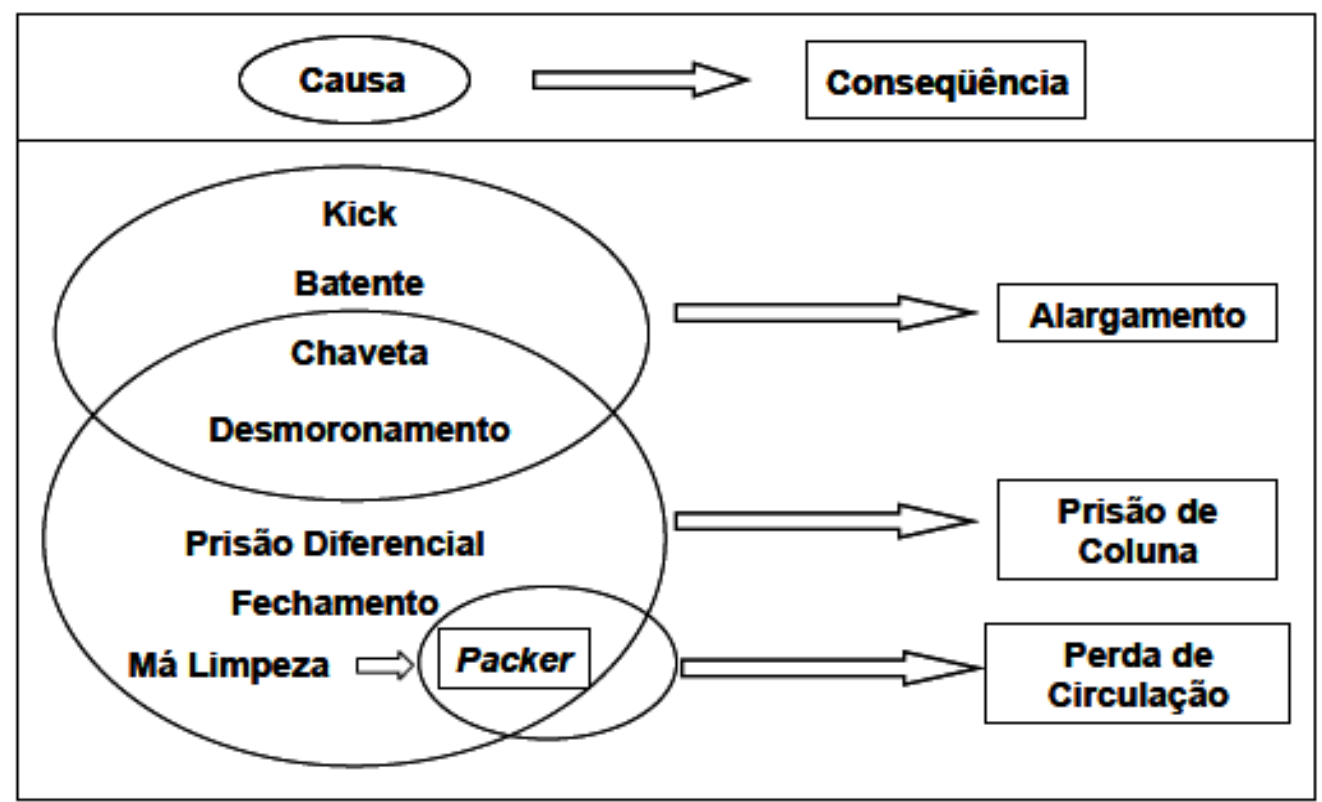

Figura 2.7 - Relações Causa-Consequência (Modificada de Tavares, 2006).

O autor analisou as situações dos problemas descritos e considerou o mecanismo responsável pela ocorrência em cada caso, concluindo que é possível mapear para a maioria dos problemas um principal agente causador.

De acordo com a classificação apresentada na Tabela 2.2 são quatro os principais agentes causadores de problemas de perfuração: Fluido de Perfuração, Geometria do Poço, Características da Formação e Parâmetros Mecânicos. 
Tabela 2.2 - Problema e principal agente causador (Modificada de Tavares, 2006).

\begin{tabular}{|c|c|c|}
\hline Problema & Principal agente Causador & Parâmetro \\
\hline Perda de Circulação & Fluido de Perfuração & $E C D>P_{F}$ \\
\hline Prisão Diferencial & Fluido de Perfuração & $E C D>>P_{p}$ \\
\hline $\begin{array}{l}\text { Desmoronamento / } \\
\text { Alargamento de Poço }\end{array}$ & Fluido de Perfuração & $\mathrm{ECD}<\mathrm{P}_{\mathrm{c}}$ \\
\hline $\begin{array}{c}\text { Má Limpeza do Poço/ } \\
\text { Packer Hidráulico (Pack- } \\
\text { off) }\end{array}$ & Fluido de Perfuração & Baixa $\mu_{\text {fluido }} \mathrm{e} / \mathrm{ou}$ Baixa $\mathrm{V}_{\text {fluido }}$ \\
\hline Chavetas & Geometria do Poço & Dogleg $>5^{\circ}$ \\
\hline Kick & Fluido de Perfuração & $\mathrm{ECD}<\mathrm{P}_{\mathrm{p}}$ \\
\hline Batente & $\begin{array}{l}\text { Características da } \\
\text { Formação }\end{array}$ & Formações duras \\
\hline Fechamento de Poço & $\begin{array}{l}\text { Características da } \\
\text { Formação }\end{array}$ & Hidratação de argila / movimento de sal \\
\hline $\begin{array}{l}\text { Vibração (Quebra de } \\
\text { BHA) }\end{array}$ & Parâmetros Mecânicos & $\begin{array}{c}\text { Rotação e/ou peso sobre broca } \\
\text { inadequado }\end{array}$ \\
\hline
\end{tabular}

Onde: $P_{F}$ (Pressão de fratura da formação), $P_{P}$ (Pressão de poros da formação), $P_{C}$ (Pressão mínima para evitar o colapso da formação), $\mu_{\text {fluido }}$ (Viscosidade do Fluido de Perfuração), $V_{\text {Fluido }}$ (Velocidade de Carreamento do Fluido de Perfuração).

Finalmente o autor concluiu de acordo com a classificação apresentada na Tabela 2.2, que o fluido de perfuração está relacionado a diversos problemas de perfuração. Na Tabela 2.3 apresenta as observações de superfície que poderiam ser interpretadas como indícios de problemas no poço.

Tabela 2.3 - Indicativos de ocorrência dos problemas (Modificada de Tavares, 2006).

\begin{tabular}{|c|c|c|}
\hline Problema & Fluido de perfuração & Indicios \\
\hline Perda de Circulação & Peso excessivo de fluido & $\begin{array}{l}\text { Reduzida vazão de retorno } \\
\text { Perda de volume nos tanques }\end{array}$ \\
\hline Prisão Diferencial & Peso excessivo de fluido & $\begin{array}{l}\text { Aumento do Torque } \\
\text { Aumento do Arraste } \\
\end{array}$ \\
\hline $\begin{array}{l}\text { Desmoronamento de } \\
\text { Poço/ Alargamento de } \\
\text { Poço }\end{array}$ & Peso insuficiente de fluido & $\begin{array}{c}\text { Aumento no retorno de cascalhos } \\
\text { Cascalhos maiores e irregulares } \\
\text { Aumento do Arraste } \\
\text { Aumento do Torque }\end{array}$ \\
\hline $\begin{array}{c}\text { Má Limpeza do Poço / } \\
\text { Packer Hidráulico (Pack- } \\
\text { off) }\end{array}$ & Propriedades inadequadas & $\begin{array}{c}\text { Aumento da Pressão de Bombeio } \\
\text { Aumento do Arraste } \\
\text { Aumento do Torque }\end{array}$ \\
\hline Kick & Peso insuficiente de fluido & $\begin{array}{l}\text { Aumento da vazão de retorno } \\
\text { Ganho de volume nos tanques }\end{array}$ \\
\hline
\end{tabular}


Conforme Rabelo (2008), a maioria dos problemas de perfuração está associada a causas de natureza geomecânica. Na Tabela 2.4, apresenta-se uma caracterização dos principais fatores relacionados com a ocorrência dos problemas descritos.

Tabela 2.4 - Fatores associados à ocorrência de problemas geomecânicos (Modificada de Rabelo, 2008).

\begin{tabular}{|c|c|c|}
\hline PROBLEMAS & CAUSAS & EFEITOS OBSERVADOS \\
\hline Alargamento & $\begin{array}{l}\text { - Pressão hidráulica excessiva (vazão de bombeio) } \\
\text { - Ação mecânica da coluna (BHA) } \\
\text { - Reatividade da formação x fluido (tipo de fluido) } \\
\text { - Desmoronamentos (regime de tensões) }\end{array}$ & $\begin{array}{l}\text { - Topadas durante manobras } \\
\text { - Maior volume de retorno de } \\
\text { cascalho }\end{array}$ \\
\hline Batentes & $\begin{array}{l}\text { - Intercalações entre formações moles e duras de } \\
\text { pequena espessura (litologia) }\end{array}$ & $\begin{array}{l}\text { - Choques na passagem da } \\
\text { coluna pelo trecho } \\
\text { - Dificuldade de descida de } \\
\text { revestimentos }\end{array}$ \\
\hline Chavetas & $\begin{array}{l}\text { - Atrito da coluna com a parede do poço em } \\
\text { trechos com desvio acentuado (inclinação) }\end{array}$ & $\begin{array}{l}\text { - Dificuldade na manobra do } \\
\text { BHA }\end{array}$ \\
\hline Desmoronamento & $\begin{array}{l}\text { - Pressão hidrostática insuficiente (peso de } \\
\text { fluido/regime de tensões) } \\
\text { - Ação mecânica da coluna (BHA) } \\
\text { - Pressão hidráulica excessiva (vazão de bombeio) } \\
\text { - Dissolução de domos salinos (litologia) }\end{array}$ & $\begin{array}{l}\text { - Maior volume de retorno de } \\
\text { cascalho } \\
\text { - Drags elevados na manobra } \\
\text { - Cascalhos com tamanho } \\
\text { maior que o normal }\end{array}$ \\
\hline Fechamento & $\begin{array}{l}\text { - Reatividade da formação x fluido (tipo de fluido) } \\
\text { - Formações com mobilidade (ex: sais) (litologia) } \\
\text { - Pressão hidrostática insuficiente (peso de fluido) }\end{array}$ & $\begin{array}{l}\text { - Drags elevados na manobra } \\
\text { - Dificuldade na descida do } \\
\text { revestimento } \\
\text { - Ameaças de prisão }\end{array}$ \\
\hline Kick & $\begin{array}{l}\text { - Pressão hidrostática insuficiente (peso de } \\
\text { fluido/pressão da formação) } \\
\text { - Pistoneio (operação) } \\
\text { - Perda de circulação (característica da } \\
\text { formação/peso de fluido) }\end{array}$ & $\begin{array}{l}\text { Indícios primários: } \\
\text { - Aumento do volume de lama } \\
\text { nos tanques } \\
\text { - Aumento da vazão de retorno } \\
\text { - Fluxo com bombas } \\
\text { desligadas }\end{array}$ \\
\hline $\begin{array}{l}\text { Perda de } \\
\text { circulação }\end{array}$ & $\begin{array}{l}\text { - Existência de fraturas na formação (característica } \\
\text { da formação) } \\
\text { - Formações com alta permeabilidade e } \\
\text { porosidade (característica da formação) } \\
\text { - Peso de fluido excessivo em zonas depletadas } \\
\text { ou com baixo gradiente de fratura (peso de fluido) }\end{array}$ & $\begin{array}{l}\text { - Redução do volume de lama } \\
\text { nos tanques }\end{array}$ \\
\hline $\begin{array}{l}\text { Prisão por } \\
\text { diferencial }\end{array}$ & $\begin{array}{l}\text { - Grande diferencial de pressão lama x formação } \\
\text { (permeável). É preciso ainda que a coluna esteja } \\
\text { em contato com a parede do poço (peso de } \\
\text { fluido/pressão da formação) } \\
\text { - Tipo de fluido inadequado (com grande } \\
\text { quantidade de filtrado) (tipo de fluido) }\end{array}$ & $\begin{array}{l}\text { - Aumento do drag e torque } \\
\text { - Perda do movimento da } \\
\text { coluna }\end{array}$ \\
\hline
\end{tabular}

Já Chipindu (2010) baseado no trabalho de Tavares (2006), quem determinou um modelo para a identificação de problemas de perfuração, descrevendo como indício da ocorrência destes, o comportamento de alguns parâmetros mecânicos e hidráulicos, classificou os problemas por ocorrência como dificuldade de avanço (DA), dificuldade de manobra (DM) e prisão $(P)$. Estas dificuldades foram definidas assim:

- Dificuldades de Avanço (DA): compreendem todas as anormalidades que ocorrem durante o aumento da profundidade medida no poço e outras a ela associadas. 
- Dificuldades de Manobra (DM): compreendem todas as anormalidades que ocorrem durante as operações de descida e retirada da coluna para efetuar conexões, descida de revestimento, manobra curta e/ou troca de equipamento.

- Dificuldades por Prisão $(P)$ : entende-se toda perda total ou parcial de movimentos axiais da coluna de perfuração ou da ferramenta de perfilagem a cabo.

O mesmo autor analisou o comportamento dos parâmetros mecânicos e hidráulicos (aumento, redução e constante) em associação com as demais informações que auxiliam na determinação das causas dos problemas pela ocorrência de DA, DM e $P$ em função da litologia, tectonismo e outras causas operacionais, tal como são apresentadas na Tabela 2.5, Tabela 2.6 e Tabela 2.7 respectivamente. 
Tabela 2.5 - Classificação Causa-efeito de Dificuldade de Avanço. (Tomada de Chipindu, 2010).

\begin{tabular}{|c|c|c|c|c|c|c|c|c|}
\hline & \multicolumn{4}{|c|}{ Litologia } & \multicolumn{3}{|c|}{ Vibrações } & \multirow{2}{*}{\begin{tabular}{|c|} 
Outras falhas \\
$\begin{array}{c}\text { Mecânicas/pro- } \\
\text { cedimentais }\end{array}$ \\
\end{tabular}} \\
\hline Parâmetros & $\begin{array}{c}\text { Enc } \\
\text { Broca }\end{array}$ & F. Abrasivas & $\begin{array}{c}\text { F. } \\
\text { Duras }\end{array}$ & F. Poço & Bit Bounce & Stick slip & Whirl & \\
\hline Vazão (V) & $\downarrow$ & - & - & $\downarrow$ & - & - & - & - \\
\hline Pressão (P) & $\uparrow$ & - & - & $\uparrow$ & - & - & - & - \\
\hline Torque (T) & $\downarrow$ & $\downarrow$ & - & $\uparrow$ & $\downarrow \uparrow \downarrow \uparrow \downarrow$ & $\downarrow \uparrow \downarrow \uparrow \downarrow$ & $\downarrow \uparrow \downarrow \uparrow \downarrow$ & - \\
\hline Drag (Drag) & $\downarrow$ & $\uparrow$ & - & $\uparrow$ & $\uparrow$ & $\uparrow$ & $\uparrow$ & - \\
\hline Rotação da coluna (RPM) & $\uparrow$ & $\uparrow$ & - & $\downarrow$ & $\downarrow \uparrow \downarrow \uparrow \downarrow$ & $\downarrow \uparrow \downarrow \uparrow \downarrow$ & $\downarrow \uparrow \downarrow \uparrow \downarrow$ & - \\
\hline Taxa de penetração (ROP) & $\downarrow$ & $\downarrow$ & $\downarrow$ & $\downarrow$ & $\downarrow$ & $\downarrow$ & $\downarrow$ & nula \\
\hline Peso sobre a broca (WOB) & Exc. & - & - & - & Baixo peso & Exc. Peso & Baixo peso & - \\
\hline \multicolumn{9}{|c|}{ Informação Adicional } \\
\hline Caliper & - & $\downarrow$ & - & & - & - & - & - \\
\hline Fm. argilosa (margas/folhelhos) & SIM & - & - & & - & - & - & - \\
\hline Tipo de fluido & WBM & - & - & & - & - & - & - \\
\hline Intercalações de rochas duras/moles & - & - & - & & Fav & Fav & Fav & - \\
\hline Desgaste da broca (cod. IADC) & - & SIM & - & & $\uparrow$ & $\uparrow$ & $\uparrow$ & - \\
\hline
\end{tabular}

\begin{tabular}{|ll|}
\hline Cte - Constante & Exc - Excessivo LEGENDA \\
$\downarrow-$ Redução & Fav - favorece a ocorrência do tipo de vibração em análise \\
$\uparrow$ - Aumento & $\downarrow \varnothing \varnothing$ - Redução do diâmetro interno \\
$\downarrow \uparrow \downarrow \uparrow \downarrow-$ Oscilações & SIM - informação relevante para causa em análise \\
WBM - fluido de perfuração base água & \\
\hline
\end{tabular}


Tabela 2.6 - Classificação Causa-efeito de Dificuldade de Manobra. (Tomada de Chipindu, 2010).

\begin{tabular}{|c|c|c|c|c|c|c|c|c|c|c|}
\hline \multirow{3}{*}{ Parâmetros } & \multicolumn{6}{|c|}{ Litologia } & \multirow{3}{*}{\begin{tabular}{|c|} 
Tectonismo \\
$\begin{array}{l}\text { Demoro- } \\
\text { namento }\end{array}$
\end{tabular}} & \multicolumn{3}{|c|}{ Outras Falhas } \\
\hline & \multirow{2}{*}{ Batente } & \multirow{2}{*}{$\begin{array}{l}\text { P. Dife- } \\
\text { rencial }\end{array}$} & \multicolumn{4}{|c|}{ Fechamento do Poço } & & \multirow{2}{*}{$\begin{array}{c}\text { Má } \\
\text { limpeza }\end{array}$} & \multirow{2}{*}{$\begin{array}{l}\text { Dog leg } \\
\text { severo }\end{array}$} & \multirow{2}{*}{ Chavetas } \\
\hline & & & argilas & sal & fm.a. & e.r. & & & & \\
\hline Vazão (V) & Cte & Cte & $\downarrow$ & $\downarrow$ & $\downarrow$ & $\downarrow$ & $\downarrow$ & $\downarrow$ & Cte & Cte \\
\hline Pressão (P) & Cte & Cte & $\uparrow$ & $\uparrow$ & $\uparrow$ & $\uparrow$ & $\uparrow$ & $\uparrow$ & Cte & Cte \\
\hline Torque (T) & $\downarrow$ & $\uparrow$ & $\uparrow$ & $\uparrow$ & $\uparrow$ & $\uparrow$ & $\uparrow$ & $\uparrow$ & 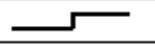 & Cte \\
\hline Drag (Drag) & $\downarrow$ & $\uparrow$ & $\uparrow$ & $\uparrow$ & $\uparrow$ & $\uparrow$ & $\uparrow$ & $\uparrow$ & 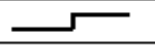 & $\uparrow \uparrow$ \\
\hline Rotação da coluna (RPM) & $\uparrow$ & $\uparrow$ & $\downarrow$ & $\downarrow$ & $\downarrow$ & $\downarrow$ & $\downarrow$ & $\downarrow$ & -5 & Cte \\
\hline Posição da Catarina (Pc) & 1 & $\$$ & 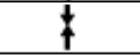 & $\ddagger$ & 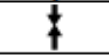 & $\ddagger$ & $\$$ & $\$$ & - & 2 \\
\hline \multirow{2}{*}{\multicolumn{11}{|c|}{ Taxa de penetração (ROP) }} \\
\hline & & & & & & & & & & \\
\hline Caliper & इ & & $\downarrow \varnothing$ & $\downarrow \varnothing$ & $\downarrow \varnothing$ & $\downarrow \varnothing$ & $\uparrow \varnothing$ & Sim & Sim & Sim \\
\hline Reatividade das Argilas & & & Sim & & & & & & & \\
\hline Fluência da formação (sal) & & & & Sim & & & & & & \\
\hline Volume de Cascalhos & & & & & & & $\uparrow$ & $\downarrow$ & & \\
\hline Formato de Cascalhos & & & & & & & Lascado & & & \\
\hline Permeabilidade da formação & & Sim & & & & Sim & & & & \\
\hline Tipo de fluido & & & WBM & & & & & & & \\
\hline Intercalações de rochas duras/moles & Sim & & & & & & & & & \\
\hline Desgaste da broca (cod. IADC) & & & & & Sim & Não & & & & \\
\hline Trajetória & & & & & & & & 3 & 4 & \\
\hline
\end{tabular}

Trajetória

\section{LEGENDA}

Cte - Constante

$\downarrow$ - Redução

$\uparrow$ - Aumento; $\uparrow \uparrow$ - Aumento excessivo

\$ - Posição da catarina travada

† - Aumento do diâmetro interno do poço

ЦØ - Redução do diâmetro interno do poço

巨్ - Formato das paredes do poço
1 - Topamento da coluna de perfuração

2 - Acunhamento da coluna de perfuração

3 - Inclinação de $45+/-15^{\circ}$ crítica para limpeza do poço

4 - Mais de 3 pontos consecutivos com inclinação superior a $5^{\circ}$ por cada 100 pés perfurado pode causar acunhamento argilas - por inchamento de argilas sal - por fluência de sal

fim. a - devido a formação abrasiva

e.r. - por espessamento do reboco

$\leftarrow$ Sobe e atinge patamar

WBM - Fluido de perfuração base água

Sim - Inform. relevante para causa em análise 
Tabela 2.7 - Classificação Causa-efeito de Dificuldade por Prisão. (Tomada de Chipindu, 2010).

\begin{tabular}{|l|c|c|c|c|c|c|}
\cline { 2 - 7 } \multicolumn{1}{c|}{} & \multicolumn{2}{c|}{ Litologia } & \multicolumn{2}{c|}{ Tectonismo } & \multicolumn{2}{c|}{ Outras falhas operacionais } \\
\hline Parâmetros & P. diferencial & Fechamento poço & Desmoronamento & Packoff & Chavetas & Outras \\
\hline Vazão(V) & - & - & - & - & - & - \\
\hline Pressão (P) & $\uparrow$ & $\uparrow$ & $\uparrow$ & $\uparrow$ & - & - \\
\hline Torque (T) & $\uparrow$ & $\uparrow$ & $\uparrow$ & $\uparrow$ & $\uparrow$ & - \\
\hline Drag (Drag) & $\uparrow$ & $\uparrow$ & $\uparrow$ & $\uparrow$ & $\uparrow$ & - \\
\hline Rotação da coluna (RPM) & Nula & Nula & Nula & Nula & Nula & Nula \\
\hline Taxa de penetração (ROP) & Nula & Nula & Nula & Nula & Nula & Nula \\
\hline Peso sobre a broca (WOB) & $-\quad$ & - & - & - & - & - \\
\hline & \multicolumn{2}{|c|}{ Informação Adicional } & \multicolumn{5}{|c|}{} \\
\hline Caliper & - & $\downarrow \emptyset$ & $\uparrow \emptyset$ & - & - & - \\
\hline Parada e comandos (zona permeável) & Sim & - & - & - & - & - \\
\hline Parada de circulação & - & - & - & Sim & - & - \\
\hline Tipo de fluido & - & WBM & - & - & - & - \\
\hline Relatos no BDP (cascalho desmoronado) & - & - & Sim & - & - & - \\
\hline Trajetória (poço direcional) & - & - & - & - & Sim & - \\
\hline
\end{tabular}

\begin{tabular}{|ll|}
\hline & LEGENDA \\
\hline SIM - Informação sem relevância para causa em análise & \\
$\downarrow-$ Redução & $\downarrow \emptyset$ - Redução do diâmetro interno do Poço \\
$\uparrow$ - Aumento & $\uparrow \emptyset$ - Alargamento do diâmetro interno do Poço \\
\hline
\end{tabular}




\section{6.}

\section{Tempo Não-Produtivo (TNP)}

Segundo Dupriest et al., (2011), problemas de instabilidade como o alargamento ou colapso do poço geram altos TNP, desvios, e a redução da eficiência no transporte dos cascalhos à superficie, causando significativas consequências econômicas.

Neste contexto, estes tipos de problemas que demandam a inversão de tempos extras não programados são chamados de TNP, o qual é definido como o "tempo no qual a perfuração cessa ou a taxa de penetração é muito baixa" (Moazzeni et al., 2010).

Entre as ocorrências que levam à perda de tempo de perfuração, citam-se as seguintes (Moazzeni et al., 2010):

- Perda de circulação;

- Prisão da coluna de perfuração;

- Ocorrência de kicks;

- Instabilidade do poço;

- Fratura da formação;

- Baixa taxa de penetração em formações duras;

- Tropeços devido à mudança de brocas;

- Operações de pescaria;

- Operações corretivas de cimentação;

O Impacto qualitativo do TNP pode ser classificado nestes quatro itens:

- Perda ou dano de equipamentos;

- Perda financeira;

- Questões de saúde, segurança e meio ambiente;

- Espera de equipamentos e aplicações de novas técnicas.

Segundo Miura et al., (2009), a maior parte do TNP nas operações de perfuração deve-se aos problemas classificados por ocorrência como dificuldade de manobra (DM), dificuldade de avanço (DA) e prisão (P). 
Segundo Moazzeni et al., (2010), o período do tempo de perfuração de poços pode ser classificado em diferentes etapas, tais como as apresentadas na Figura 2.8.

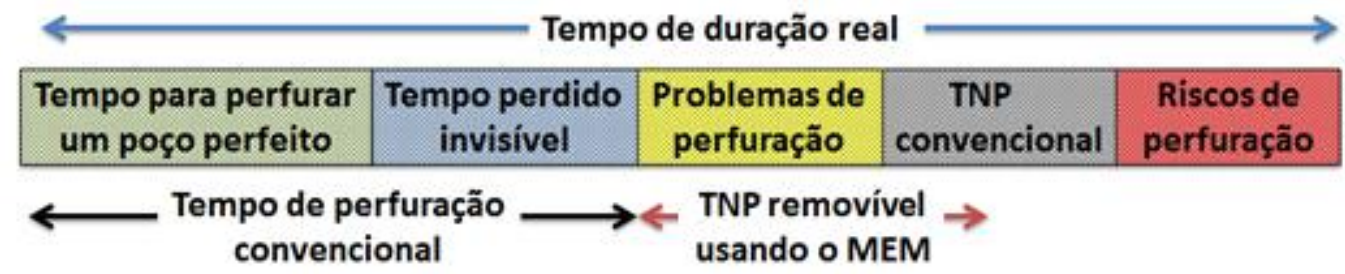

Figura 2.8 - Classificação do TNP nas operações de perfuração de poços de petróleo e gás. (Modificada de Moazzeni et al., 2010).

Significando que o tempo para perfurar um poço perfeito (quadro verde), corresponderia ao tempo em que se esperaria que o poço fosse finalizado normalmente.

O tempo perdido invisível (quadro azul) é controlado pelos operários da perfuração.

Já o quadro amarelo, que corresponde à ocorrência dos problemas de perfuração, inclui as causas relacionadas diretamente à geração do TNP, o qual pode ser classificado como tempo de perda da circulação, tempo de remoção de kick e tempo gasto para liberar a coluna presa de perfuração.

O TNP convencional (quadro cinza) corresponde ao limite da capacidade das ferramentas, transporte das ferramentas e condições climáticas.

Por último, os riscos de perfuração incluem questões relacionadas à saúde, segurança e meio ambiente.

Desta classificação pode se dizer que o MEM tenta resolver o TNP gerado pela ocorrência dos problemas de perfuração, e envolve também os aspectos relacionados ao limite da capacidade das ferramentas, pois uma das possíveis alternativas para mitigar os problemas de instabilidade pode ser modificar alguma ferramenta.

Dupriest et al., (2011) observaram através de um estudo detalhado de poços com altos TNP, que praticamente todos os problemas severos de instabilidade foram precedidos por "quase-acidentes" ou eventos de instabilidade, tais como: repasses, arrastes, prisões da coluna de perfuração, entre outros. 
A identificação destes "quase-acidentes" ou eventos de instabilidade tem se convertido em uma ferramenta útil para avaliar as condições de estabilidade dos poços.

Uma possivel análise destes eventos de instabilidade pode ser feita aplicando um conceito semelhante ao da pirâmide de segurança (Heinrich, 1931), onde vários níveis de "quase-acidentes" podem ser identificados e tratados.

Na Figura 2.9 apresenta-se um exemplo do processo para a avaliação das condições da estabilidade do poço em função da identificação dos "quaseacidentes".

Aqui se evidencia que o tratamento dos "quase-acidentes" nos níveis inferiores da piramide, em um processo de planejamento e execução dos poços, contribui com a diminuição dos custos extras de perfuração, com o aumento da metragem da perfuração e o tratamento dos eventos de instabilidade, que permitem por último, a redução do o TNP.

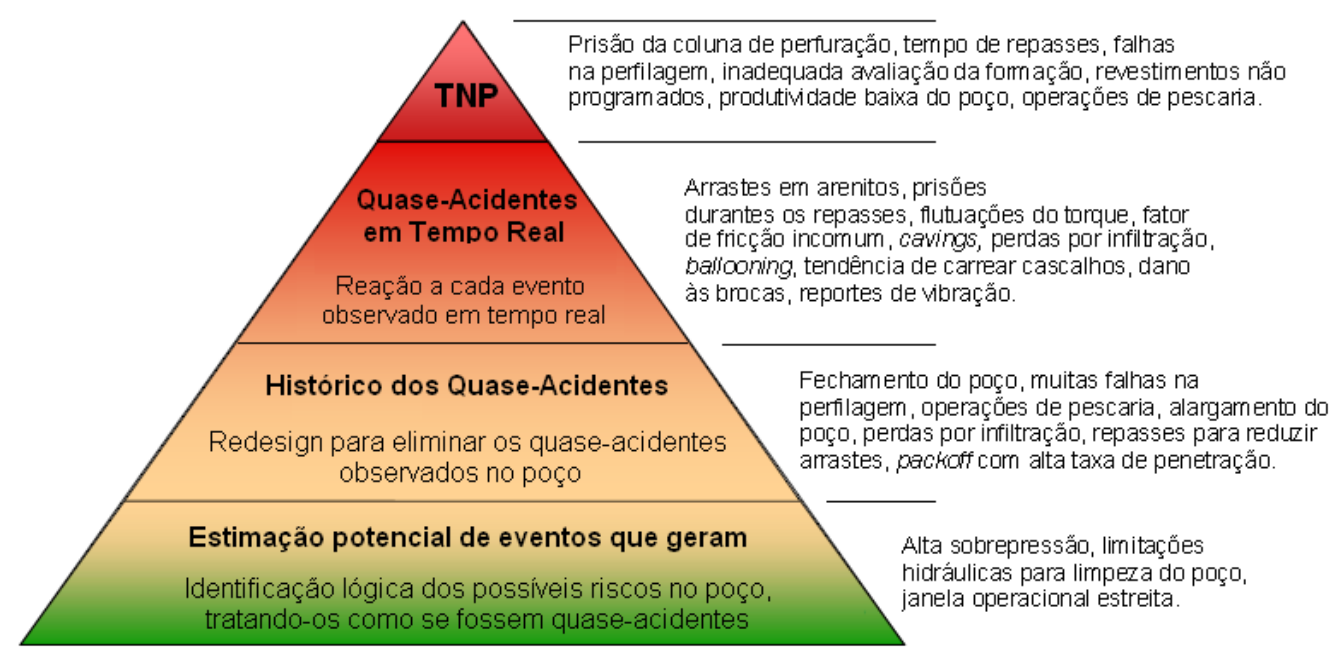

Figura 2.9 - Diagnóstico das condições da estabilidade de poço em função dos "Quase-acidentes" (Modificada de Dupriest et al., 2011). 
Na Figura 2.10 é apresentado um exemplo das ações que podem ser tomadas em cada nível da pirâmide aplicada para a estabilidade do poço.

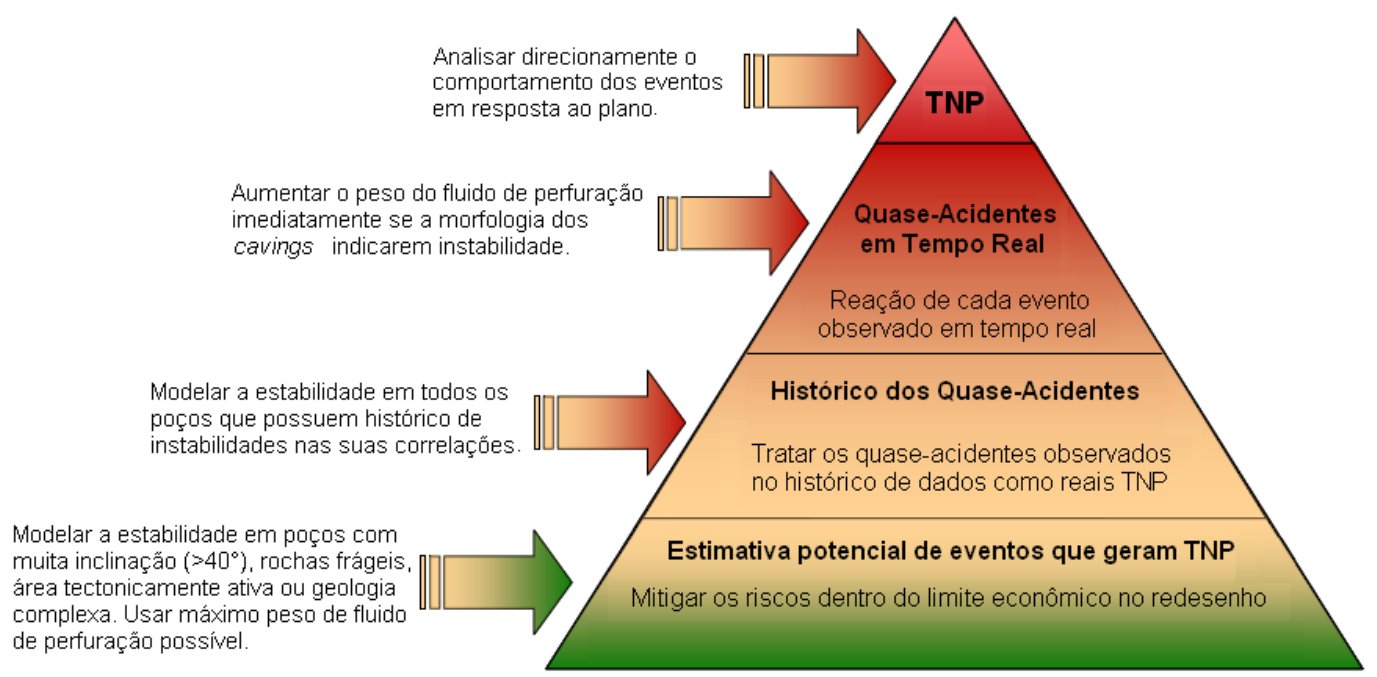

Figura 2.10 - Ações para eliminar os quase-acidente e o TNP relacionados a instabilidade em cada fase do projeto e na execução do poço. (Modificada de Dupriest et al., 2011).

Dupriest et al., (2011) consideraram que os problemas de instabilidade mais frequentes giram em torno do alargamento do poço ou breakouts, os quais tem impacto na hidráulica, na limpeza e no retorno das perdas do poço.

\section{7. \\ Casos históricos da aplicação do MEM para a análise de estabilidade de poços.}

Conforme Plumb et al., (2000), um modelo geomecânico é construído e usado para gerar uma previsão da estabilidade do poço que ajude a reduzir os riscos de perfuração.

No entanto, a magnitude e intensidade dos problemas de instabilidade são imprevisíveis no mundo e ainda são responsáveis por gerar TNP excessivos e custos altos que podem ficar ainda mais severos sob a influência de tectonismo.

Last et al., (1995) constataram esse cenário de instabilidade no campo Cusiana da bacia dos Llanos, localizado em uma zona tectonicamente ativa da Cordilheira Este na Colômbia.

$\mathrm{Na}$ Figura 2.11, observa-se a condição severa de instabilidade e uma constante deterioração dos poços do campo Cusiana durante as operações de perfuração. 
Os alargamentos, a cimentação inadequada e os desvios no poço, consideraram-se como os problemas de instabilidade mais severos devido ao aumento considerável de cavings gerados, pois esses foram responsáveis pela maioria das prisões da coluna durante a perfuração e dos repasses para o condicionamento do poço.

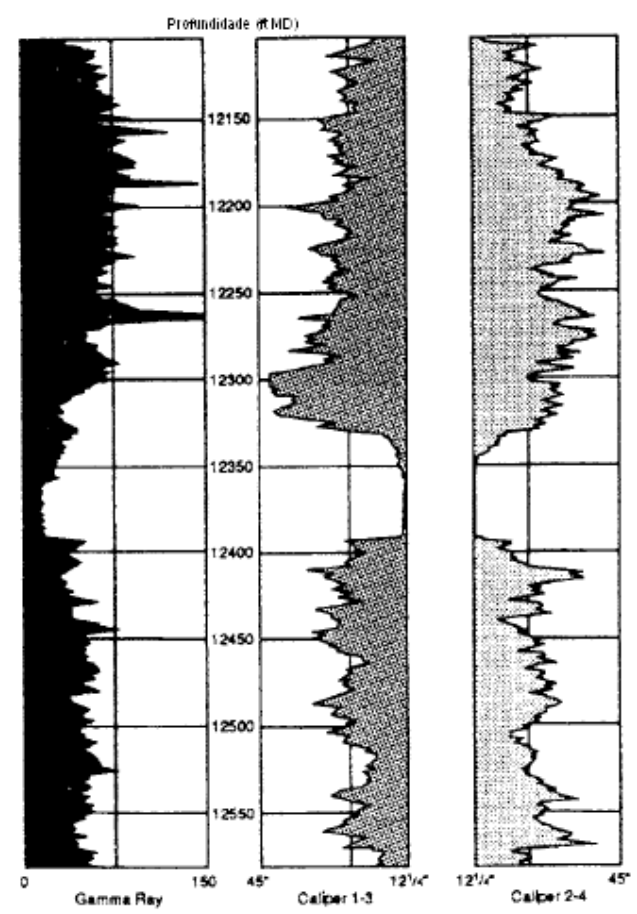

Figura 2.11 - Condição severa de instabilidade do poço Cusiana (Modificada de Last et al., 1995).

Adicionalmente, pela rugosidade severa do poço, observaram-se percalços durante as operações de revestimento e perfilagem nas intercalações de areiafolhelho, exigindo varias operações de repasses para o condicionamento do poço.

Pelas evidências anteriores de problemas por instabilidade e pelas fracassadas tentativas para solucioná-los, os autores concluíram que uma abordagem convencional para resolver esses problemas de instabilidade simplesmente não funcionaria devido ao insuficiente conhecimento geomecânico do campo.

Basicamente por essa escassa informação geomecânica do campo, um grupo interdisciplinar de especialistas foi conformado para recompilar os dados de perfuração necessários que permitissem obter uma análise de estabilidade representativa do campo. Desta experiência, obteve-se como subproduto a metodologia do MEM. 
Conforme os resultados obtidos, após a implementação progressiva das recomendações e os procedimentos para melhorar as condições de estabilidade dos poços sugeridas pelo $M E M$, os autores concluíram que houve um impacto significativo na redução do TNP gerado pelas prisões da coluna de perfuração e dos repasses realizados, produto da minimização dos cavings, assim como pode ser observado na Figura 2.12.

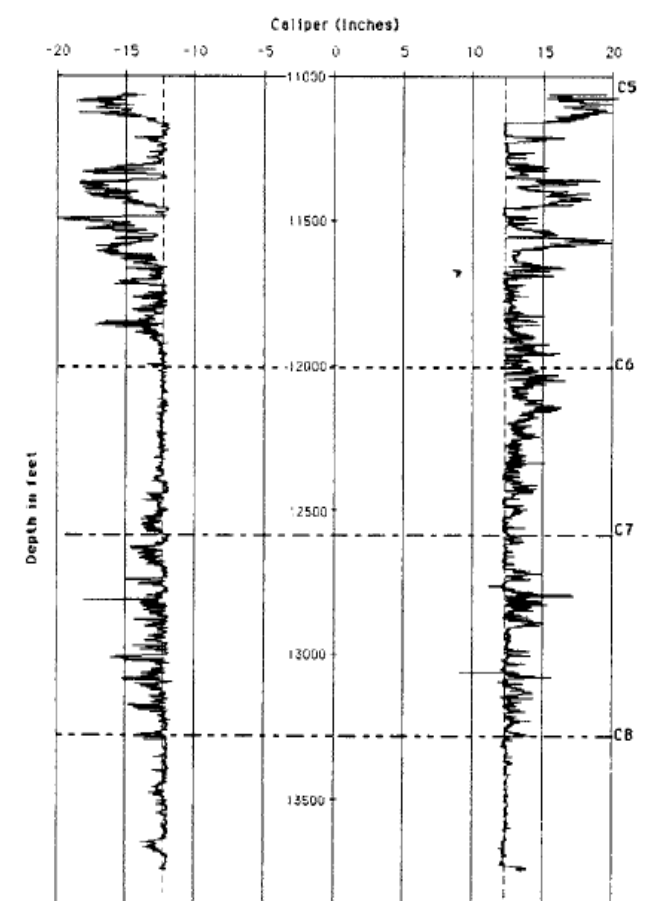

Figura 2.12 - Estabilidade das paredes do poço após a implementação do MEM no campo Cusiana (Modificada de Last et al. 1995).

Do mesmo modo, como apresentado na Figura 2.13, o MEM influiu também no desenvolvimento de novos poços no campo, pois estes foram perfurados em menos tempo que o previsto, mantendo as condições dos poços no que se refere às práticas e procedimentos para melhorar tanto as condições de estabilidade do poço quanto às estratégias de perfuração. 


\section{Cusiana Tempo x Curva de Aprendizado}

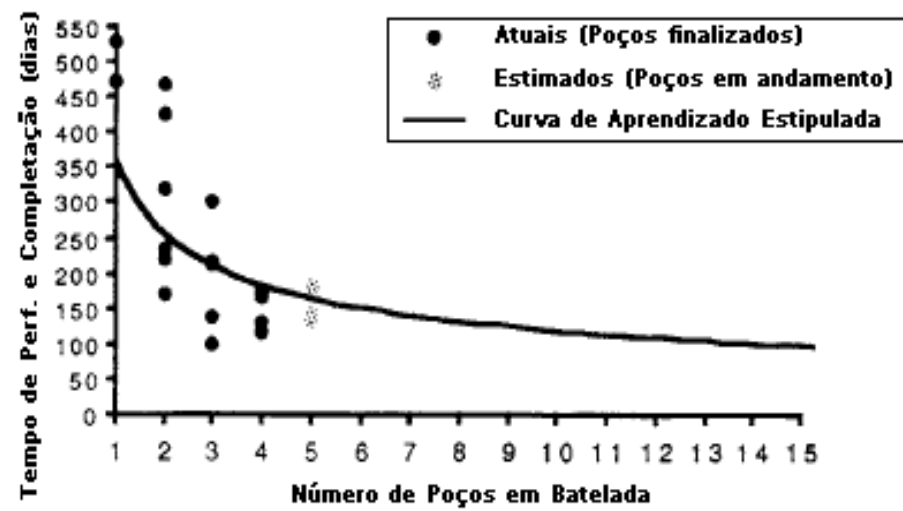

Figura 2.13 - Curva de aprendizado no campo Cusiana (Modificada de Last et al. 1995).

Pelos bons resultados obtidos após a aplicação do $M E M$ no campo de Cusiana, vários campos de petróleo tem adotado seu procedimento, entre os quais, citam-se os seguintes casos:

Segundo Lee et al., (2003), a auditoria dos eventos de perfuração do MEM realizada no campo San Martin (Perú) permitiu identificar que os problemas de instabilidade, tais como: reatividade dos folhelhos, perda do fluido de perfuração, e má limpeza do poço eram os maiores contribuintes do TNP.

Neste campo, a determinação das magnitudes das tensões horizontais na área de estudo foi uma das principais incertezas, pois uma análise prévia dos poços não foi conclusiva o suficiente para identificar as tensões relacionadas à ruptura por cisalhamento causado pelos efeitos físico-químicos e/ou mecânicos.

Por outro lado, a ocorrência do alargamento no poço, verificado tanto pelo perfil caliper quanto pela presencia de cavings angulares nas profundidades do alargamento, foi relacionado às propriedades do fluido de perfuração, incapaz de controlar argilas reativas presentes na formação perfurada.

Tendo em conta estas observações, a análise do MEM previu um breakout mínimo na formação através da determinação da tensão horizontal mínima calibrada a partir do Teste da Integridade da Formação (FIT).

Além disso, o MEM permitiu determinar uma estratégia para reduzir a instabilidade do poço devido à reatividade da argila, sugerindo usar fluidos inibidores (glicol, potássio) para que essas fossem mais adequadamente tratadas do que por apenas um simples aumento do peso de fluido de perfuração. 
Por último, o MEM previu corretamente as tensões relacionadas à falha por cisalhamento na parte inferior do poço, permitindo que o poço fosse perfurado em condições próximas ao limite da estabilidade.

Em uma experiência similar na Bacia Austral no sul da Argentina Fontana et al., (2007), observaram que, problemas de estabilidade relacionados à formação de cavings em folhelhos micro fraturados, tais como prisão da coluna, arrastes elevados, repasses, entre outros, geram um TNP superior a $25 \%$ do tempo total de perfuração programado.

O MEM aplicado no campo permitiu compreender as causas e os mecanismos da instabilidade dos folhelhos naturalmente fraturados dos poços e sugerir três estratégias de mitigação, tais como: a diminuição do peso do fluido de perfuração, a utilização de aditivos inibidores no fluido de perfuração para selar as fraturas naturais e modificar os componentes da coluna de perfuração para minimizar as vibrações laterais sob a formação.

Na Figura 2.14 através de um acompanhamento do perfil caliper, pode-se observar a drástica melhora na qualidade das paredes do poço após a aplicação do MEM.

EVOLUÇÃO DO PERFIL CALIPER - (de izquerda a direita)

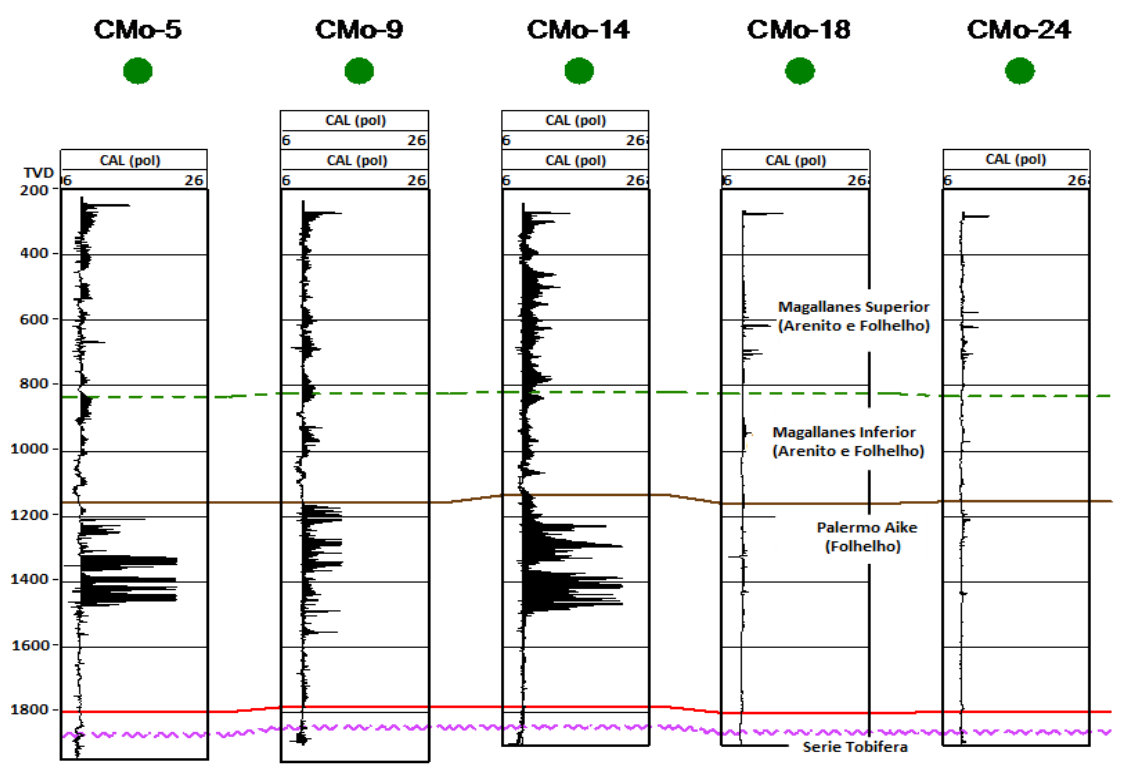

Figura 2.14 - Acompanhamento do perfil caliper para a avaliação da integridade das paredes dos poços (Modificada de Fontana et al., 2007).

Araujo et al., (2009) estenderam a aplicação do MEM a poços de gás na bacia de Neuquén Argentina, com o fim de otimizar o tempo de perfuração do campo, tentando reduzir os riscos da ocorrência dos problemas de instabilidade 
que geram o TNP com uma boa taxa de penetração, mantendo a estabilidade do poço.

Esse MEM foi construído usando um conjunto de dados que incluiu perfis do poço, boletins diários de perfuração, perfis de imagem, medidas de pressão de poros e testes de micro fraturas.

A Figura 2.15 apresenta as curva de perfuração de um poço que experimentou problemas de fechamento de poço e prisão da coluna de perfuração que requerem de operações de repasses e de pescaria, gerando atrasos no programa de perfuração.

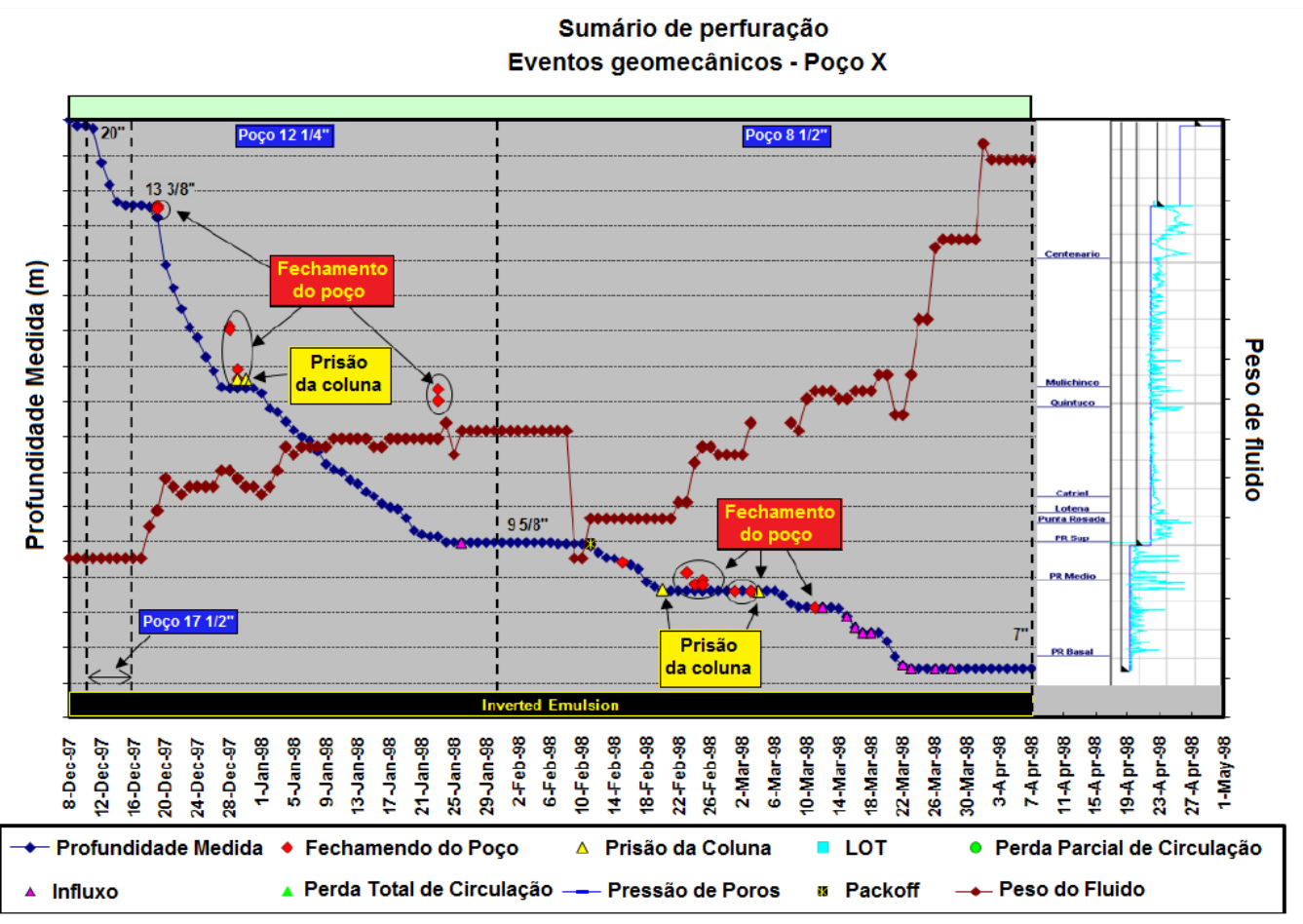

Figura 2.15 - Experiência típica de perfuração antiga do campo (Modificada de Araujo et al., 2009).

Na Figura 2.16 a validação de um peso de fluido de perfuração para um novo poço do campo foi feita com o fim de reproduzir os problemas experimentados nas mesmas profundidades e litologias nos poços perfurados (Araujo et al., 2009). 


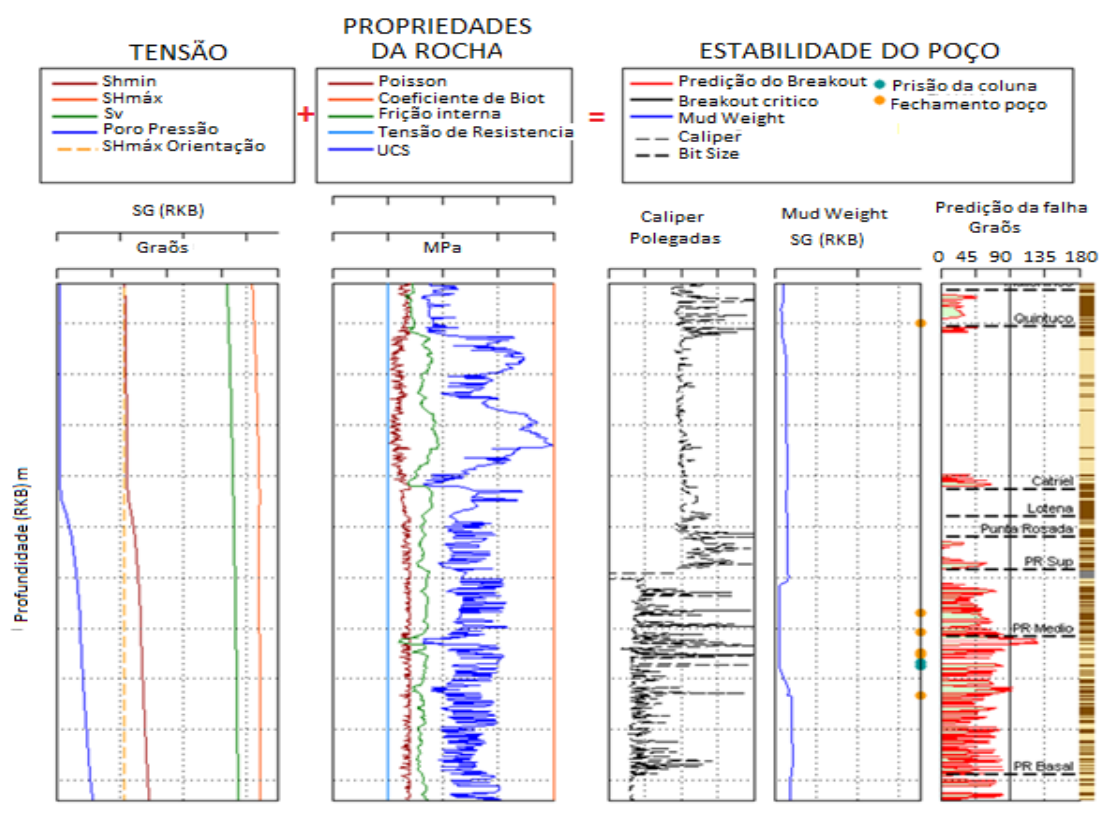

Figura 2.16 - Validação do modelo geomecânico (Modificada de Araujo et al., 2009).

Os mesmos autores confirmaram que, na bacia de Neuquén após a perfuração de um novo poço usando $\circ$ peso do fluido de perfuração recomendado pelo $M E M$, poucos fechamentos do poço e quase nenhuma prisão da coluna e influxo de gás foram experimentados nas profundidades e litologias onde esses tinham sido observados no passado, diminuindo a necessidade de operações de repasses e limpeza no poço, e consequentemente, do TNP, como observado na Figura 2.17.

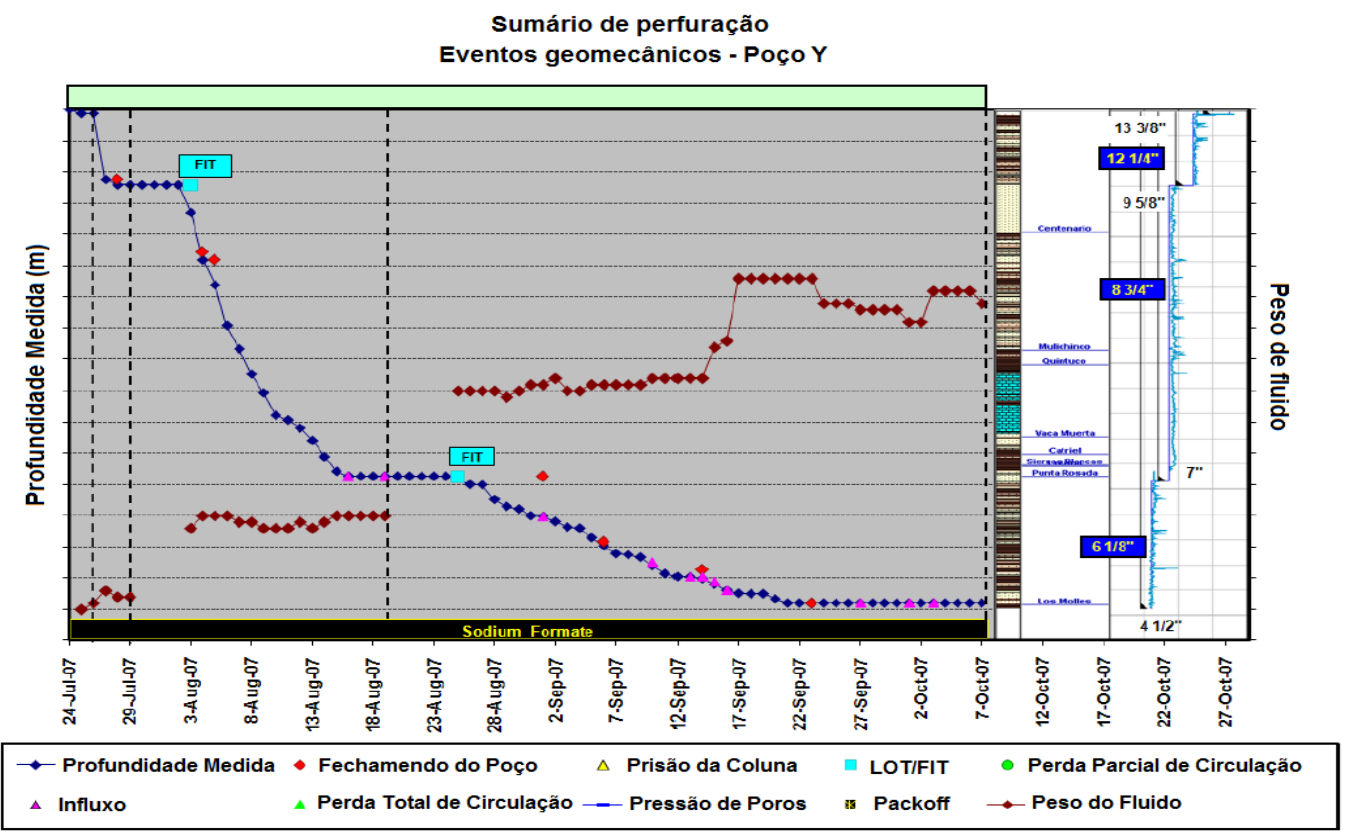

Figura 2.17 - Experiência de perfuração do poço do projeto (Modificada de Araujo et al., 2009). 


\section{3. \\ Metodologia da modelagem geomecânica aplicada para a estabilidade de poços}

Este capítulo tem por finalidade apresentar de forma metódica, uma estrutura de trabalho que permita identificar os problemas geomecânicos de poços em um campo de estudo, cujos mecanismos de instabilidade estejam relacionados aos folhelhos.

\section{1.}

\section{Construção do MEM}

A construção de um MEM permite obter o conhecimento geral do campo, integrando um modelo geológico estrutural com todas as informações relevantes do poço, tais como, registros de perfis do poço e boletins diários de perfuração, sísmica (Araújo et al., 2010).

Dessa forma, a equipe de perfuração pode compreender os riscos potenciais de perfuração, planejar estratégias e agir rapidamente, caso necessário, para mitigá-los (Lee et al., 2003).

Plumb et al., (2000) apresentam na Tabela 3.1, o conjunto de dados ideal para iniciar a construção do MEM aplicado à análise da estabilidade do poço.

Amani et al., (2010), conforme o trabalho de Plumb et al., (2000), sugerem que, a construção do MEM usado para prever a estabilidade dos poços deve considerar duas etapas:

A primeira etapa inclui a construção do MEM para um poço do campo, baseado na informação geológica e mecânica das rochas.

A segunda etapa consiste em demonstrar a utilidade do MEM para explicar os problemas relacionados à estabilidade dos poços encontrados durante a perfuração e predizer um peso de fluido seguro e estável para evitar tais problemas nos novos poços do campo.

Esta previsão da estabilidade resume o desempenho esperado na perfuração em função da profundidade medida no poço (Plumb et al., 2000). 
Tabela 3.1 - Resumo dos dados necessários para construir um MEM e uma análise da estabilidade do poço (Modificada de Plumb et al., 2000).

\begin{tabular}{|c|c|c|}
\hline $\begin{array}{c}\text { DADOS } \\
\text { REQUERIDOS }\end{array}$ & PERFIS & OUTROS \\
\hline \multirow{4}{*}{$\begin{array}{l}\text { Estratigrafia } \\
\text { mecânica }\end{array}$} & - Gamma Ray & - Cascalhos \\
\hline & - Densidade & Cavings \\
\hline & - Resistividade & - Seqüência estratigráfica \\
\hline & - Sônico (Vp) & \\
\hline \multirow{3}{*}{$\begin{array}{l}\text { Pressão de } \\
\text { Poros (Pp) }\end{array}$} & · Sônico $(\mathrm{Vp})$ & - velocidade intervalar (sísmica) \\
\hline & - Check shot surver & Testes de formação \\
\hline & - Resistividade & - Boletins diários de perfuração (BDP) \\
\hline $\begin{array}{c}\text { Tensão de } \\
\text { Sobrecarga (Sv) }\end{array}$ & - Densidade volumétrica & - Cascalhos \\
\hline \multirow{4}{*}{$\begin{array}{l}\text { Direção das } \\
\text { tensões }\end{array}$} & - Caliper orientado & - Mapas estruturais \\
\hline & Imagem do poço & - Sísmica 3D \\
\hline & $\begin{array}{l}\text { Orientação da velocidade } \\
\text { de propagação de ondas } \\
\text { acústicas }\end{array}$ & \\
\hline & Anisotropia & \\
\hline \multirow{8}{*}{$\begin{array}{c}\text { Tensão } \\
\text { horizontal } \\
\text { mínima }(\sigma \mathrm{h})\end{array}$} & · Sônico (Vp \& Vs) & $\cdot \mathrm{Pp}$ \\
\hline & wireline stress tool & Leak-Off Test (LOT) \\
\hline & & Extended Leak-Off Test (ELOT) \\
\hline & & Microfraturas \\
\hline & & - Testes de injeção Step-rate \\
\hline & & Base de dados \\
\hline & & - Boletins diários de perfuração (BDP) \\
\hline & & - Modelagem \\
\hline \multirow{3}{*}{$\begin{array}{c}\text { Tensão } \\
\text { horizontal } \\
\text { máxima }(\sigma \mathrm{H})\end{array}$} & Imagem do poço & $\cdot \mathrm{Pp}$ \\
\hline & $\begin{array}{l}\text { Modelo de tensões do } \\
\text { poço }\end{array}$ & $\sigma h$ \\
\hline & & $\begin{array}{l}\text { - Resistência da rocha } \\
\text { - Base de dados }\end{array}$ \\
\hline \multirow{3}{*}{$\begin{array}{l}\text { Parâmetros } \\
\text { elásticos } E, G, v\end{array}$} & · Sônico (Vp \& Vs) & Base de dados \\
\hline & - Densidade volumétrica & Testes de laboratório \\
\hline & & Cavings \\
\hline \multirow{3}{*}{$\begin{array}{l}\text { Parâmetros de } \\
\text { resistência da } \\
\text { rocha (UCS, } \phi)\end{array}$} & · Sônico (Vp \& Vs) & Base de dados \\
\hline & - Densidade volumétrica & - Testes de laboratório \\
\hline & Estratigrafia mecânica & Cavings \\
\hline \multirow{2}{*}{$\begin{array}{c}\text { Mecanismos de } \\
\text { falha }\end{array}$} & Imagem do poço & - Boletins diários de perfuração (BDP) \\
\hline & - Caliper orientado & - Cavings (imagem digitais) \\
\hline
\end{tabular}

Segundo Plumb et al., (2000), a classificação das etapas para a construção do MEM esta composta por mais três etapas, além das duas anteriores, aplicáveis a poços inclinados e de grande alcance. Estas são

A validação do MEM como parte da terceira etapa, através do monitoramento dos dados durante a perfuração em tempo real para testar a previsão das anormalidades no modelo. Anormalidades na predição indicam falhas nos dados ou no MEM.

Já na quarta etapa, estas anomalias são analisadas para determinar a(s) fonte(s) de erro. Se a ação imediata é necessária na plataforma, pode ser com base em decisões informadas.

E por último, na quinta etapa, os autores sugerem corrigir o MEM. A correção do MEM pode ser feita antes que as decisões sejam tomadas ou também podem ser feita off-line, se a geologia ou as tensões mudam drasticamente. 
No entanto, a metodologia estabelecida nesta dissertação a partir de dados de perfuração, isto é, dados dos $\mathrm{BDP}$ (s) e perfis dos poços, compreende apenas as duas primeiras etapas para a construção do $M E M$, pois a partir da terceira etapa é inevitável o monitoramento de dados de perfuração de um poço em tempo real para validar a previsão da estabilidade estimada nas duas primeiras etapas, estando fora do alcance deste trabalho.

\section{2.}

\section{Dados de Perfuração}

\subsection{1.}

\section{Boletim Diário de Perfuração (BDP)}

O Boletim Diário de Perfuração (BDP) é um registro diário que apresenta descritivamente informações sobre a sequência das atividades e procedimentos que ocorrem em cada fase durante a perfuração.

Nele são registrados, por exemplo, o tempo e a profundidade do início e do término de cada atividade à medida que a perfuração vai avançando. Por esta razão, o BDP é uma fonte que fornece informações importantes para a elaboração de uma retroanálise.

Basicamente as informações que compõem o BDP são as seguintes:

- Comentários operacionais;

- Data;

- Duração das atividades (inicio - fim em termos de horas);

- Profundidade inicial;

- Profundidade final;

- Descrição das atividades;

- Descrição das operações;

- Descrição das etapas de perfuração. 
Na Tabela 3.2, é representada uma configuração típica de BDP.

Tabela 3.2 - Boletim diário de perfuração (Tomada de Tavares, 2006).

\begin{tabular}{|c|c|c|c|c|c|c|}
\hline $\begin{array}{l}\text { Data do } \\
\text { Relatório }\end{array}$ & $\begin{array}{c}\text { Inicio } \\
\text { (h) }\end{array}$ & $\begin{array}{c}\text { Duração } \\
\text { (h) }\end{array}$ & $\begin{array}{l}\text { Prof. } \\
\text { Inicial } \\
\text { (m) }\end{array}$ & $\begin{array}{l}\text { Prof. } \\
\text { Final } \\
\text { (m) }\end{array}$ & Descrição & $\begin{array}{c}\text { Etapa } \\
\text { (Subcode) }\end{array}$ \\
\hline $08 / 09$ & $14: 30$ & 2 & 2741 & 2749 & Perfurando orientado & $\begin{array}{c}\text { Perfurando } \\
\text { orientado }\end{array}$ \\
\hline $08 / 09$ & $16: 30$ & 0.5 & 2749 & 2754 & Perfurando com rotação da coluna & $\begin{array}{c}\text { Perfurando } \\
\text { rotativo }\end{array}$ \\
\hline $08 / 09$ & $17: 00$ & 1 & 2754 & 2762 & Perfurando orientado & $\begin{array}{c}\text { Perfurando } \\
\text { orientado }\end{array}$ \\
\hline $09 / 09$ & $18: 00$ & 24 & 2762 & 2925 & $\begin{array}{l}\text { Perfurando com rotação da coluna e orientado, } \\
\text { fazendo back reaming antes da conexão e após } \\
\text { perfurar trecho orientado. ( } 20 / 35 \mathrm{kip}, 130 / 170 \\
\text { rpm, } 450 \mathrm{gpm} \text { pela coluna e } 200 \mathrm{gpm} \text { pela } \\
\text { booster line, } 3350 / 3420 \mathrm{psi} \text {, tpm }=6,8 \mathrm{~m} / \mathrm{h})\end{array}$ & $\begin{array}{c}\text { Perfurando } \\
\text { orientado }\end{array}$ \\
\hline $10 / 09$ & $18: 00$ & 5 & 2925 & 2961 & $\begin{array}{l}\text { Perfurando com rotação da coluna e orientado, } \\
\text { fazendo back reaming antes da conexão e após } \\
\text { perfurar trecho orientado. (20/35kip, } 130 / 170 \\
\text { rpm, } 450 \mathrm{gpm} \text { pela coluna e } 200 \mathrm{gpm} \text { pela } \\
\text { booster line, } 3350 / 3420 \mathrm{psi} \text {, tpm }=7,2 \mathrm{~m} / \mathrm{h} \text { ) }\end{array}$ & $\begin{array}{c}\text { Perfurando } \\
\text { orientado }\end{array}$ \\
\hline
\end{tabular}

\subsection{2. \\ Dados da perfilagem}

Segundo Tavares (2005), o procedimento de identificação de problemas de perfuração se dá por indícios no comportamento de alguns parâmetros, tais como: parâmetros mecânicos (torque, rotação, peso sobre a broca (WOB)) e, hidráulicos (vazão, pressão de bombeio e de injeção).

O controle desses parâmetros é muito importante durante a perfuração de um poço, pois garante o sucesso operacional e a previsão em tempo oportuno de eventuais anormalidades.

Neste sentido, faz-se necessária uma revisão dos perfis do poço para identificar a possível variação, ou não, destes registros em função da ocorrência dos eventos de perfuração em trechos de folhelho.

Uma configuração básica dos parâmetros perfilados pode ser a seguinte:

- Perfil caliper;

- Perfis radioativos (Raios Gamma (GR));

- Perfis acústicos (Perfis sónico);

- Bit Size;

- Tempo de trânsito da onda compressional (dtc);

- Parâmetros de perfuração (WOB, taxa de penetração (ROP), Revoluções por minuto (RPM), Torque, Vazão, Densidade, Pressão da injeção). 


\section{3. \\ Metodologia para a construção do MEM}

Apresenta-se a seguir alguns trabalhos da literatura que desenvolveram distintas metodologias aplicáveis para o tratamento dos dados de perfuração disponíveis para a construção do MEM neste trabalho.

Rabelo (2008) descreve uma metodologia para a análise de dados de perfuração obtidos a partir de operações de campo, com o objetivo de estudar o comportamento dos problemas de poços e transformar os dados gerados em informações que permitam aos projetistas um melhor conhecimento das peculiaridades do campo analisado a fim de proporcionar um melhor desempenho na execução das operações futuras.

Mcintyre et al., (2009) descrevem como uma análise dos eventos de perfuração pode ser útil para refinar o modelo geomecânico, fornecendo insumos-chaves para otimizar o planejamento dos poços e adaptar as práticas de perfuração às condições adversas do campo.

Por último, Chipindu (2010), apresentou três procedimentos para a identificação das causas dos problemas de instabilidade com o fim de caracterizar os mais variados problemas que ocorrem durante a perfuração de um poço, através da pré-classificação das ocorrências em: dificuldade de manobra, dificuldade de avanço e prisão.

No estudo desenvolvido pelos autores, os dados usados para caracterizar estes tipos de problemas através das dificuldades mencionadas, constaram de dados de BDP(s) dos poços, dados de mudlogging, dados da perfilagem, e outros dados, tais como: o fluido de perfuração utilizado, a configuração da composição de fundo, o desgaste de broca, o gráfico do caliper, litologia e trajetória do poço.

Dessa forma, possibilitou-se 0 entendimento aprofundado dos sintomas/causas e dos domínios em que estes problemas ocorrem, contribuindo para a maximização da eficiência na perfuração através da minimização e/ou eliminação do TNP.

Unanimemente, os autores destacam a importância do tratamento e organização dos dados adquiridos nas fases de auditoria de dados, pois os dados de entrada insuficientes ou errôneos prejudicam os resultados das análises de estabilidade de poços, mesmo quando utilizando modelos de análise avançados. Esta é a razão pela qual a auditoria de dados é um primeiro passo crítico para análise de estabilidade do poço. 
Nesse contexto, a metodologia proposta foi estruturada em três etapas: auditoria de dados, retroanálise, e modelagem tridimensional dos eventos de perfuração.

Na Figura 3.1 é apresentada a estrutura da metodologia proposta, em função dos trabalhos mencionados acima.

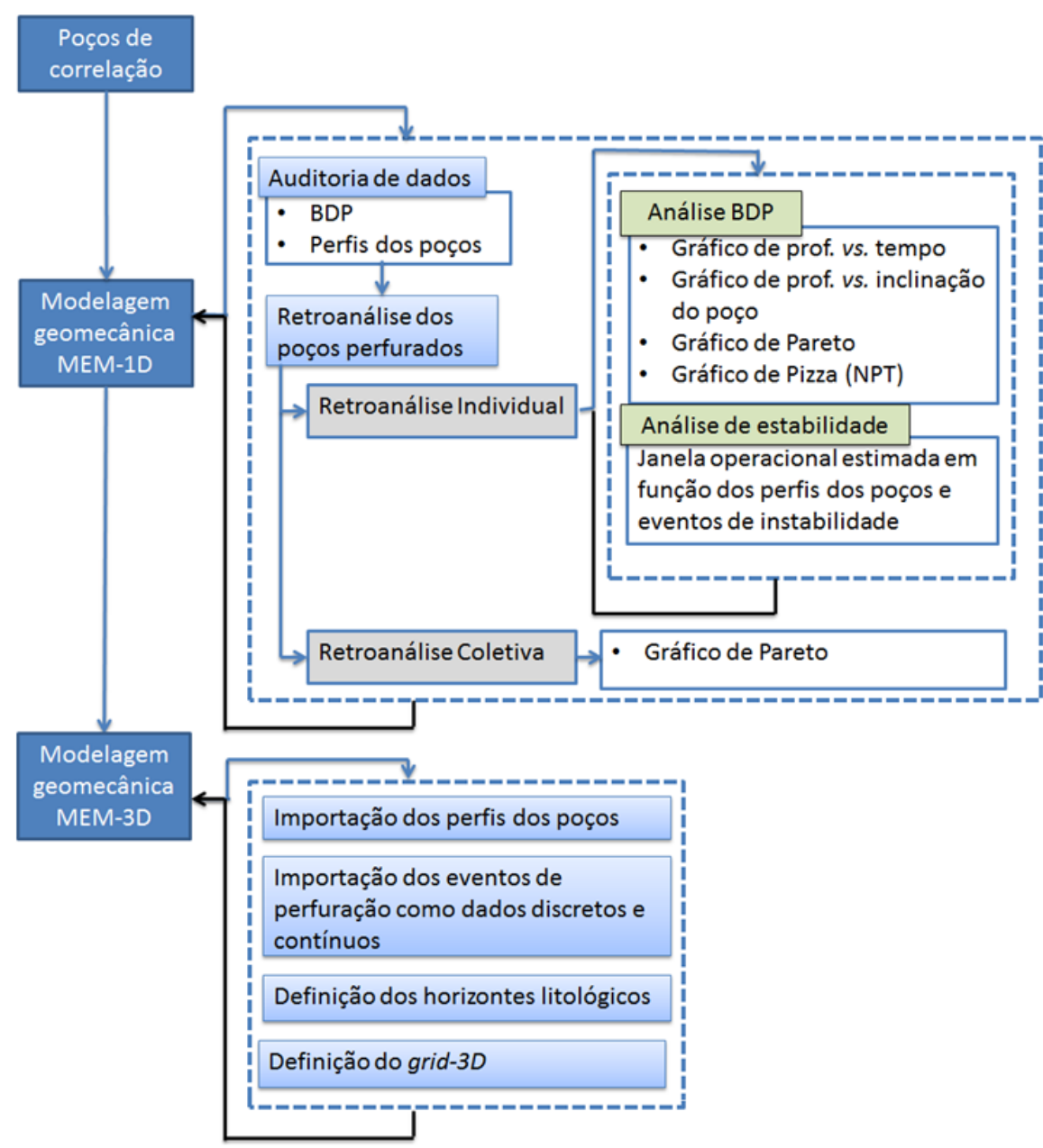

Figura 3.1 - Etapas envolvidas no fluxo de trabalho para o diagnóstico das causas de problemas de perfuração.

\subsection{1.}

\section{Auditoria de Dados}

$\mathrm{Na}$ fase de auditoria de dados, os dados relevantes para um estudo geomecânico devem ser reunidos, organizados e selecionados.

Geralmente, a coleta inclui um grande volume de informações de diferentes fontes como os $\operatorname{BDP}(s)$, perfis dos poços, dados e relatórios geológicos, interpretações petrofísicas, dados sísmicos e, em geral, informação do campo (Qiu et al., 2008; White et al., 2007). 


\subsection{2.}

\section{Retroanálise de Dados}

Considerou-se uma retroanálise individual e coletiva dos dados disponíveis nos poços de correlação para um melhor aproveitamento da informação contida nestes. A finalidade é obter dados importantes que permitam calibrar o modelo geomecânico aplicado à estabilidade de poços.

\subsubsection{1.}

\section{Análise do BDP}

A revisão dos eventos de instabilidade durante a perfuração e as ações adotadas pela equipe de perfuração fornecem informações importantes para uma análise de estabilidade.

$\mathrm{Na}$ literatura existem diversas metodologias para a identificação de problemas de perfuração a partir do estudo dos $\mathrm{BDP}(\mathrm{s})$ dos poços analisados.

Uma delas, apresentada no trabalho de Miura et al., (1991; 2003) propõe uma metodologia de aquisição de conhecimento a partir do estudo de textos do BDP, cuja finalidade é a exploração do grande potencial de informação contida nos mesmos para gerar o conhecimento sobre questões relativas aos problemas que ocorreram durante a perfuração.

Na Figura 3.2 são apresentadas as seis etapas da metodologia proposta no trabalho de Miura et al.. (2003).

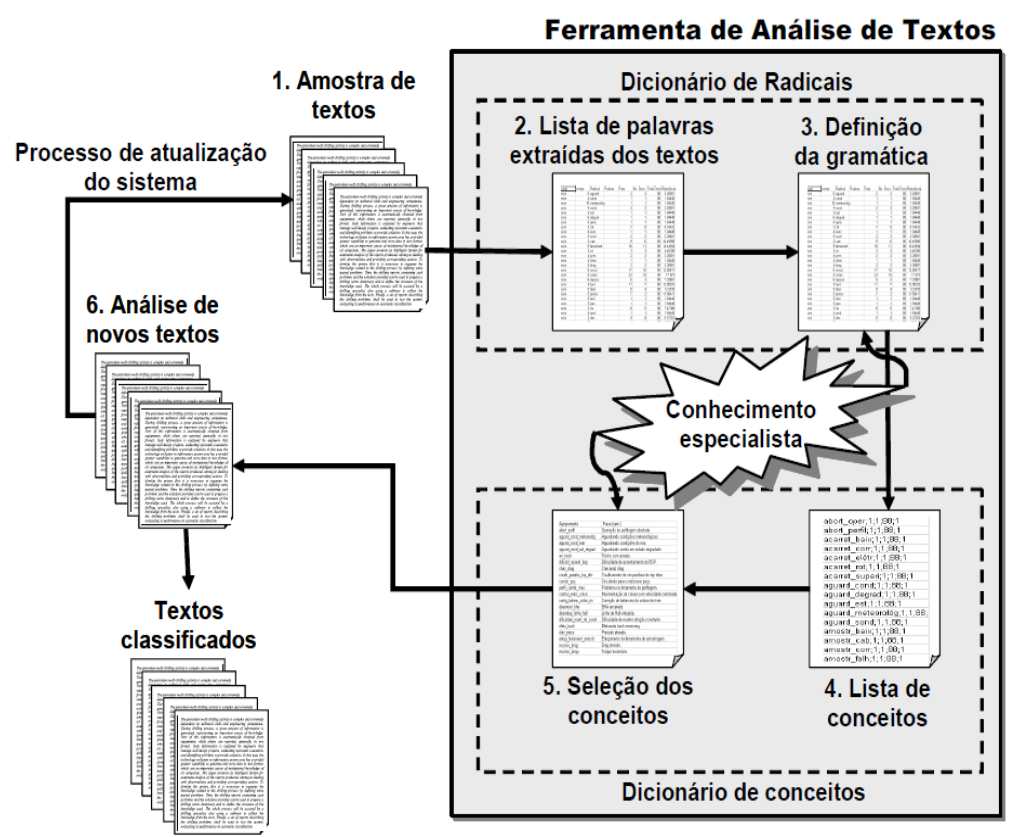

Figura 3.2 - Metodologia para classificação e análise dos boletins (Tomada de Miura et al., 2003). 
Já Rabelo (2008) como extensão do trabalho de Miura et al., (1991; 2003), propôs uma metodologia para a classificação automatizada dos textos de $\operatorname{BDP}(\mathrm{s})$, através da elaboração de um dicionário de problemas que contenha todas as anormalidades que podem ocorrer durante a perfuração de um poço, com o fim de otimizar o tempo gasto no processo de identificação dos mesmos.

Uma pré-classificação dos procedimentos definidos como dificuldade de manobra (DM), dificuldade do avanço (DA) e prisão (P) da coluna para o diagnóstico das causas dos problemas de perfuração, é outra das metodologias para uma análise preliminar das informações do BDP apresentada por Chipindu (2010).

O autor sugere que seja feita uma revisão dos dados registrados no BDP para identificar tanto a ocorrência dos eventos como os eventos posteriores que se apresentem como uma consequência da anormalidade assinalada.

Alguns exemplos do autor para a identificação destas dificuldades no BDP se apresenta a seguir:

Pré-classificação de DM:

Em uma sequência intercalada de calcilutitos, margas, arenitos e folhelhos: descendo a coluna com barrilete de testemunhagem, coluna topando a 2726 metros (duração 30 minutos)", o evento a seguir, é descrito como "conectando o Kelly e repassando para eliminar as restrições (duração 1 hora).

\section{Pré-classificação de DA:}

Perfurando, orientando com dificuldade de avanço, ou sem êxito de avanço", ou em outro exemplo verificando-se a DA devido a um problema de enceramento da broca poderia estar relatado o seguinte: "Bombeando $50 \mathrm{bbl}$ de colchão para desenceramento da broca e trabalhando com rotação da coluna (duração 2 horas)". Nos trechos imediatamente a seguir é relatado que "tentando desencerar broca sem sucesso (duração 1 hora)". E por fim, "Reparando a bomba de lama, (duração 3 horas).

\section{Pré-classificação de P:}

Preparando para pescar ferramenta da Schlumberger que ficou presa após término do último pré-teste do RFT a 3071 metros, no topo do reservatório (duração 6 horas)" "Descendo coluna de HW + DP, com overshot da Schlumberger para pescar ferramenta de perfilagem, é uma operação demorada por ter que passar o cabo da Schlumberger por dentro de cada seção descida (duração 10 horas).

Segundo Qiu et al., (2008), embora a descrição dos eventos de instabilidade no BDP possa ser ambígua, quando comparada com dados geomecânicos, perfis caliper e de imagem, eles podem destacar áreas de risco e ajudar a distinguir diferentes mecanismos de deformação através do sentido de ação e reação do poço frente a estas ocorrências, validando assim a interpretação da análise geomecânica. 
Neste contexto, um dos primeiros tópicos a ser estudado dentro de qualquer análise geomecânica compreende a reconstrucão do histórico de perfuração como parte da análise Post Mortem dos poços de correlação onde os eventos de perfuração ocorreram (Mcintyre et al., 2009).

$\mathrm{Na}$ análise Post Mortem, um gráfico da profundidade versus tempo do poço, chamado por alguns autores como Gráfico de Acompanhamento Diário do Poço é elaborado a partir dos dados registrados no BDP para visualizar os eventos geomecânicos importantes que sejam observados no poço, auxiliando, posteriormente ou paralelamente, um estudo de estabilidade.

Para construir este gráfico, os registros referentes às experiências de perfuração, eventos ou "quase-acidentes" operacionais, ações corretivas e lições aprendidas devem ser sistematicamente coletadas e utilizadas para gerar um banco de dados de risco de perfuração.

Este gráfico permite que as experiências de perfuração sejam apresentadas de forma estruturada e organizada em função da profundidade perfurada (MD, TVD) além de estabelecer uma ligação entre as experiências de perfuração de poços com formações específicas, práticas e atividades de perfuração.

Neste sentido, a identificação dos eventos de perfuração no gráfico da profundidade versus tempo do poço é uma ferramenta ideal para:

- Identificar a falha de um poço em particular, pois os eventos de perfuração revelam especificamente dentro de quais formações e a que profundidades estão ocorrendo as falhas no poço;

- Distinguir os problemas relacionados com as práticas de perfuração inadequadas daqueles que são afetados pela instabilidade da formação, sendo que estes últimos requerem de uma análise geomecânica detalhada focada para a modelagem de estabilidade no poço para analisar a razão pela qual esses poços são instáveis;

- Revelar quando e durante quais atividades de perfuração esses eventos ocorrem, como, por exemplo, durante a perfuração, perfilagem, entre outras.

Alguns autores além de representar no gráfico da profundidade versus tempo os problemas e eventos de perfuração identificados em torno das profundidades, litologias e principais atividades do poço, representam também 
as manobras tanto na subida quanto na descida da coluna de perfuração tal como o apresentado na Figura 3.3.

Isto é feito com o fim de analisar o efeito destas nas intensidades dos problemas e eventos de instabilidade, tais como, os arrastes, pois geralmente estes são mais altos na retirada da coluna de perfuração.

No entanto, para efeito deste trabalho, não foram incluídas as manobras da coluna devido ao risco da poluição do gráfico que possa dificultar sua interpretação.

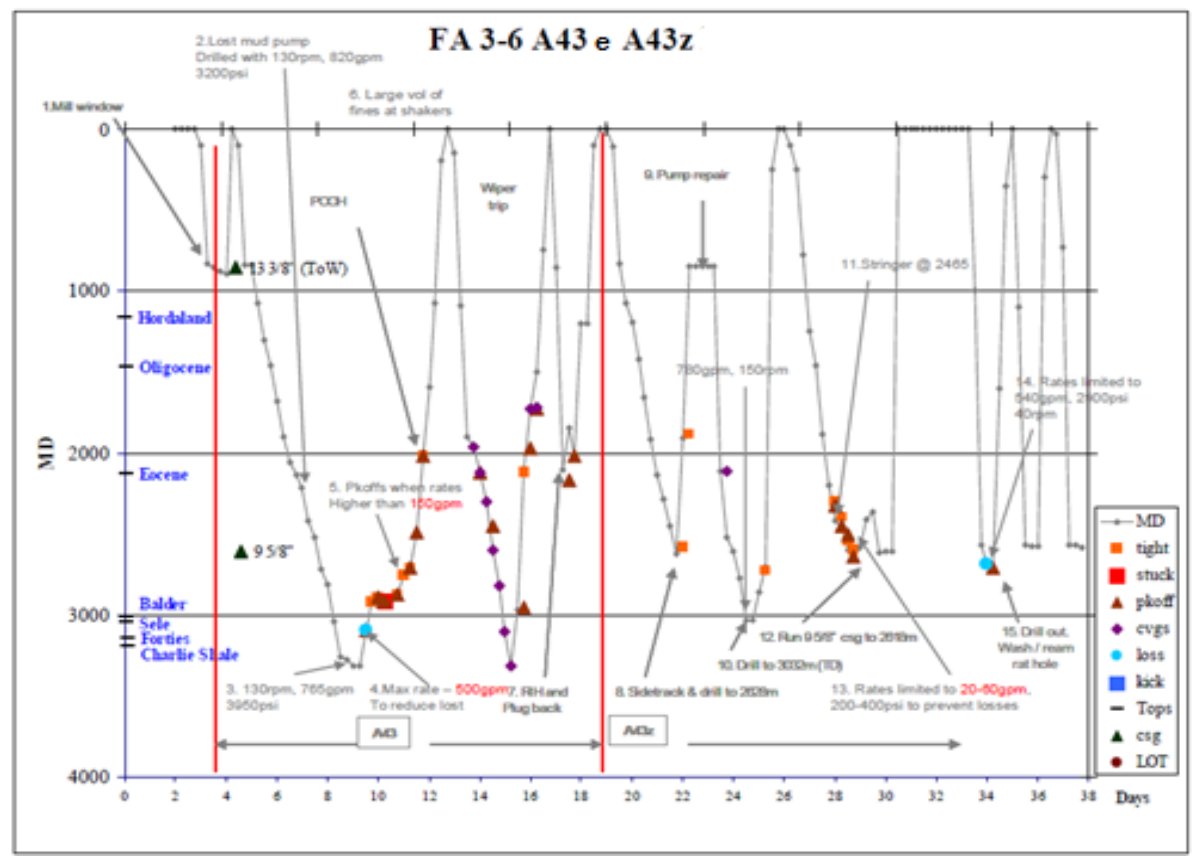

Figura 3.3 - Exemplo dos eventos de perfuração e das operações de manobra plotados em um gráfico de profundidade versus tempo (Tomada de Mcintyre et al., 2009).

Segundo Mcintyre et al., (2009), em geral, o gráfico de profundidade versus tempo é a maneira mais sistemática e rigorosa de como os problemas de perfuração podem ser abordados, pois permite o tratamento isolado dos eventos de perfuração que estejam relacionados com as práticas de perfuração e atividades deficientes daqueles que são geologicamente induzidos pela instabilidade natural da formação, tal como acontece no caso dos folhelhos.

Segundo Reid et al., (2006), o gráfico da profundidade versus tempo do poço nem sempre representa o tempo programado de perfuração, pois a ocorrência dos eventos de perfuração em zonas problemáticas geram TNP.

Na Figura 3.4, observa-se como a ocorrência do TNP influi nas curvas de perfuração, destacando uma parcela onde ocorre a perda "invisível" do tempo 
(uma redução da eficiência da perfuração), e outra parcela onde é representado o tempo utilizado para tal zona problemática.

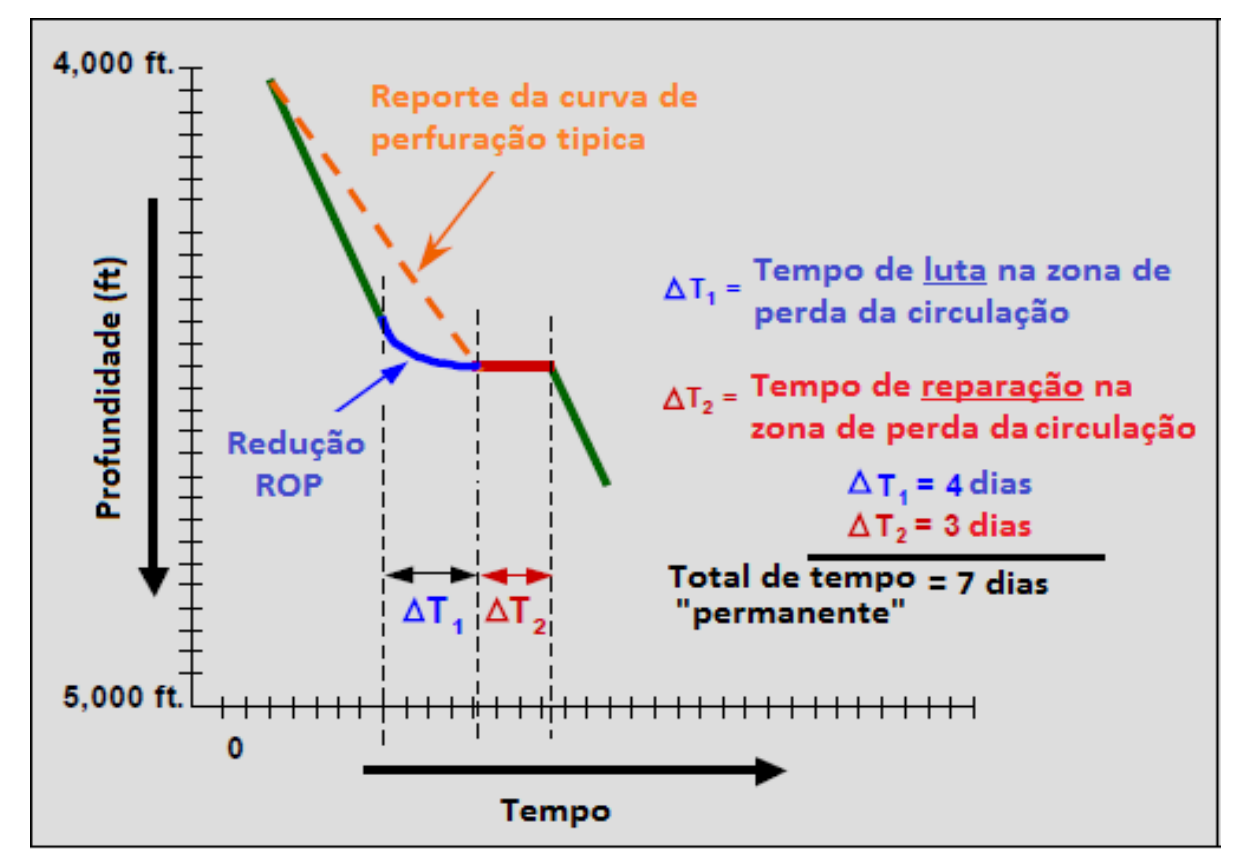

Figura 3.4 - Influência do Tempo Não Produtivo (TNP) na curva de perfuração. (Modificada de Reid et al., 2006).

Neste exemplo, visualiza-se como a curva de perfuração real se afasta da curva teórica que deveria seguir dado o caso da não ocorrência dos eventos de perfuração.

Segundo Rabelo (2006), aí está a importância (no caso de ter disponíveis os dados de projeto) da comparação das curvas Projetada versus Realizada a fim de verificar onde ocorre defasagem entre as duas para investigar as possíveis causas do atraso.

Outra análise que pode ser feita a partir do estudo dos dados do BDP é a relação da ocorrência dos eventos de perfuração em função da inclinação do poço.

O gráfico de profundidade versus inclinação Figura 3.5, pode evidenciar a possível influência do ganho do ângulo no poço como o fator determinante da instabilidade do poço, mesmo que as condições de deposição de litologia e da configuração do fluido de perfuração sejam supostamente ideais. 


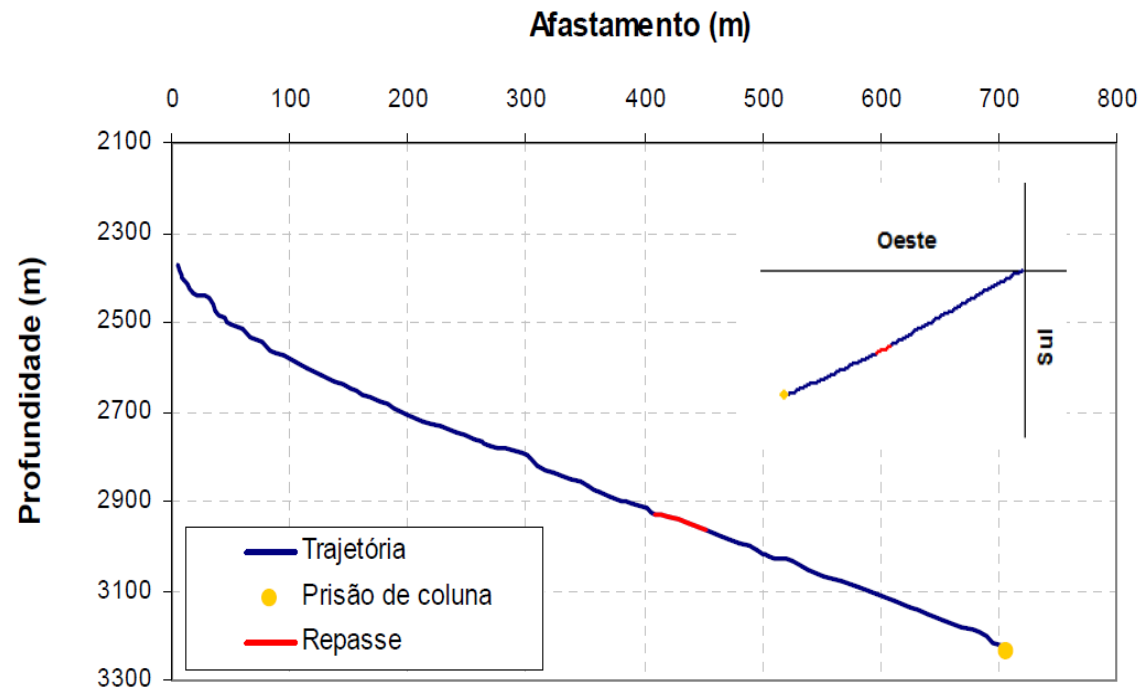

Figura 3.5 - Problemas de perfuração mapeados na trajetória do poço. (Tomada de Rabelo, 2006).

Já no gráfico de Pareto, outro subproduto da análise do(s) $\operatorname{BDP}(\mathrm{s})$, é possível estimar quantitativamente a frequência da ocorrência desses problemas e eventos de perfuração nos poços, como o apresentado na Figura 3.6.

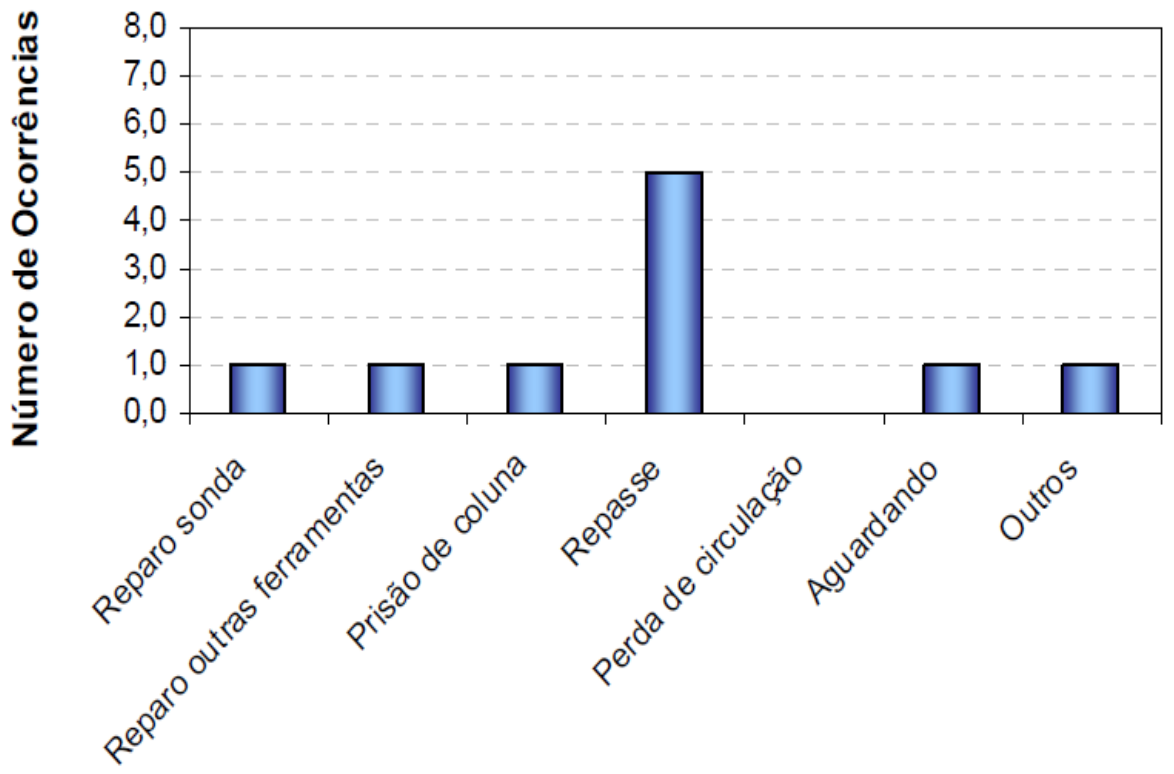

Figura 3.6 - Gráfico de Pareto dos problemas encontrados no poço em estudo. (Tomada de Rabelo, 2006).

No que se refere ao tratamento e a análise do TNP, esses podem ser muito bem representados em gráficos de pizza, tal como foi proposto no trabalho de Dodson (2004). 
O autor determinou a partir de um estudo de 1700 poços de gás perfurados no Golfo do México, que os eventos especiais de perfuração geraram um TNP de 24\% (ver Figura 3.7).

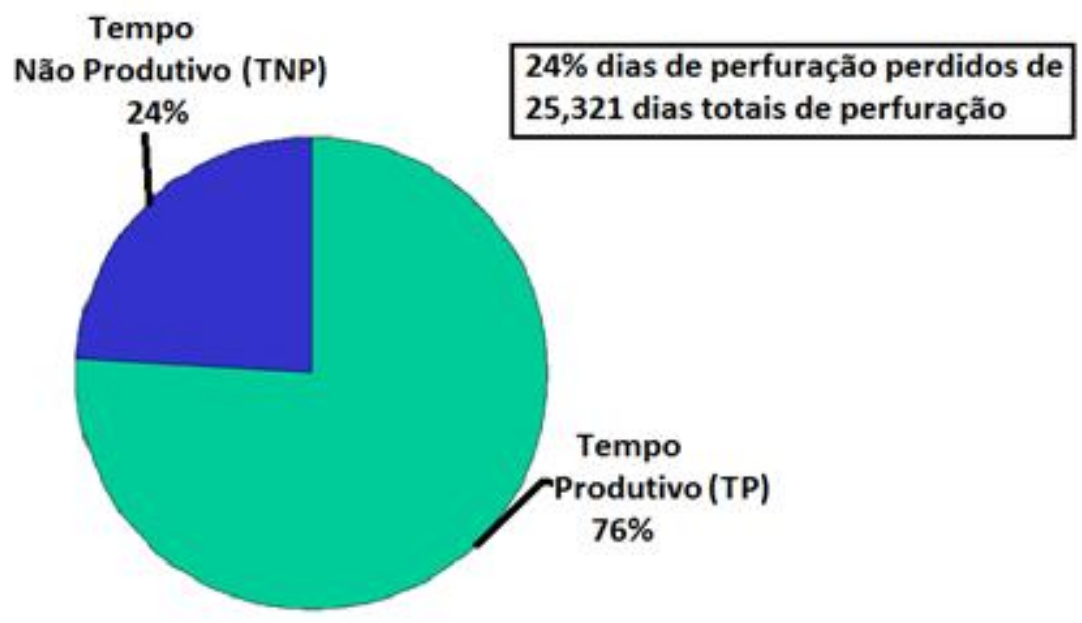

Figura 3.7 - Problemas incidentes-GOM poços de gás (poços perfurados 1993-2002; lâmina da água $\leq 600$ pés) (Modificada de Reid et al., 2006).

Esse gráfico de pizza para a análise do TNP pode ainda ser detalhado para explicar problemas específicos, como aqueles causados por instabilidade do poço, como é apresentado detalhadamente na Figura 3.8, onde são observados kicks, fluxos de gás, fluxos de água rasos, perdas da circulação, instabilidades de poço, e prisões de coluna, tal como o apresentado na Figura 3.7.

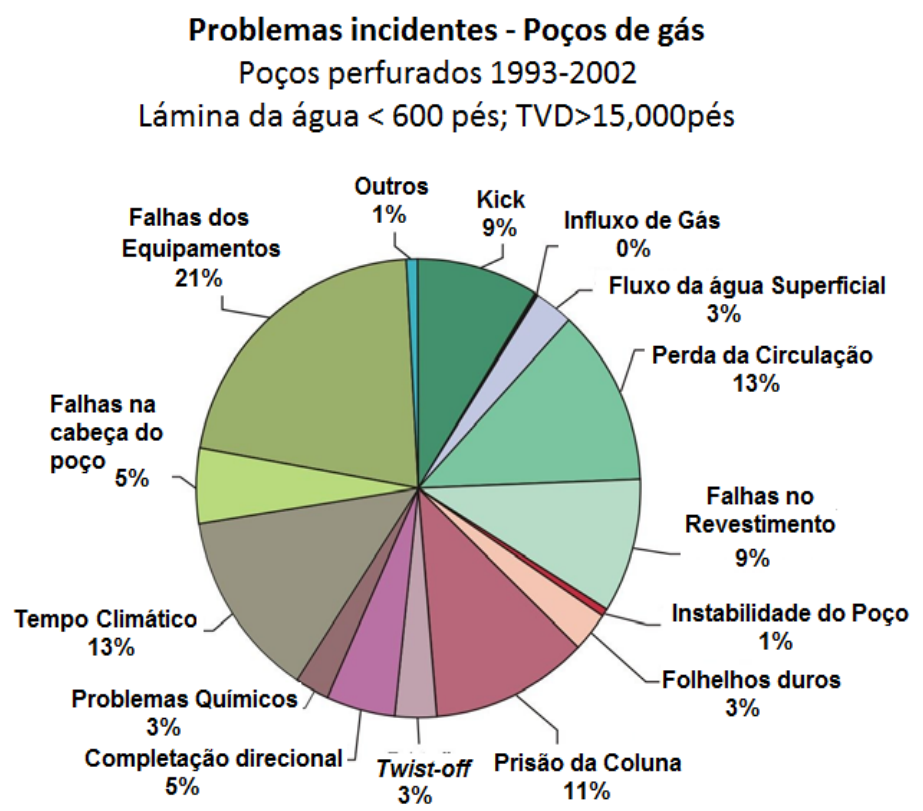

Figura 3.8 - Detalhes dos problemas incidentes-GOM poços de gás- Companhia James K. Dodson (Modificada de Reid et al., 2006). 


\subsection{3.}

\section{Análise da estabilidade de poços}

Conforme citado anteriormente, a construção de um MEM parte da revisão das experiências de perfuração no campo com o fim de identificar os problemas geomecânicos.

Em seguida, esses problemas e eventos de instabilidade, devem ser incorporados para calibrar e validar as análises de estabilidade de poços ao longo do processo do modelo geomecânico, com o fim de fornecer os dados chave para programar estratégias de perfuração mais apropriadas para cada poço.

Neste contexto, a análise de estabilidade dos poços foi determinada seguindo a sequência de cálculo dos módulos estabelecidos na estrutura do software de Sistema de estabilidade de poços SEST ${ }^{\odot}$ (Sistema de ESTabilidade versão 5.72) criado pelo GTEP da PUC-RIO em conjunto com a PETROBRAS, definidos como: Perfis, Sobrecarga, Pressão de Poros, Propriedades Mecânicas, Tensões In-Situ e Gradientes, para o cálculo de perfis não disponíveis, tais como: o gradiente de sobrecarga, o gradiente de pressão de poros, a estimativa das propriedades mecânicas, estimativa das tensões in-situ e os gradientes de colapso e fratura, respectivamente.

O SEST ${ }^{\odot}$ tem por objetivo principal a avaliação da janela operacional de peso do fluido de perfuração para o projeto de poços através dos gradientes de pressão de poros, colapso e fratura (inferiores e superiores).

O processo começa com a determinação do módulo de perfis. Neste módulo, os perfis dos poços, que podem ser do tipo elétrico e/ou acústico, são carregados no $\mathrm{SEST}^{\odot}$ para estimar por meio de correlações e relações estabelecidas na literatura, as informações iniciais para o cálculo dos parâmetros necessários para obter a janela operacional de estabilidade. Em continuação definem-se os perfis usados no SEST ${ }^{\odot}$ :

- $\quad$ Tempo de trânsito da onda compressional (dtc);

- $\quad$ Tempo de trânsito da onda cisalhante (dts);

- $\quad$ Tempo de trânsito da onda compressional da matriz (dtmc);

- $\quad$ Tempo de trânsito da onda cisalhante da matriz (dtms);

- Resistividade;

- Raios Gamma;

- Volume de argila;

- $\quad$ Densidade dos grãos; 
- $\quad$ Porosidade e

- $\quad$ Densidade (da formação) quando disponível.

Na Figura 3.9 se apresenta a visualização do modulo de perfis no SEST ${ }^{\odot}$.

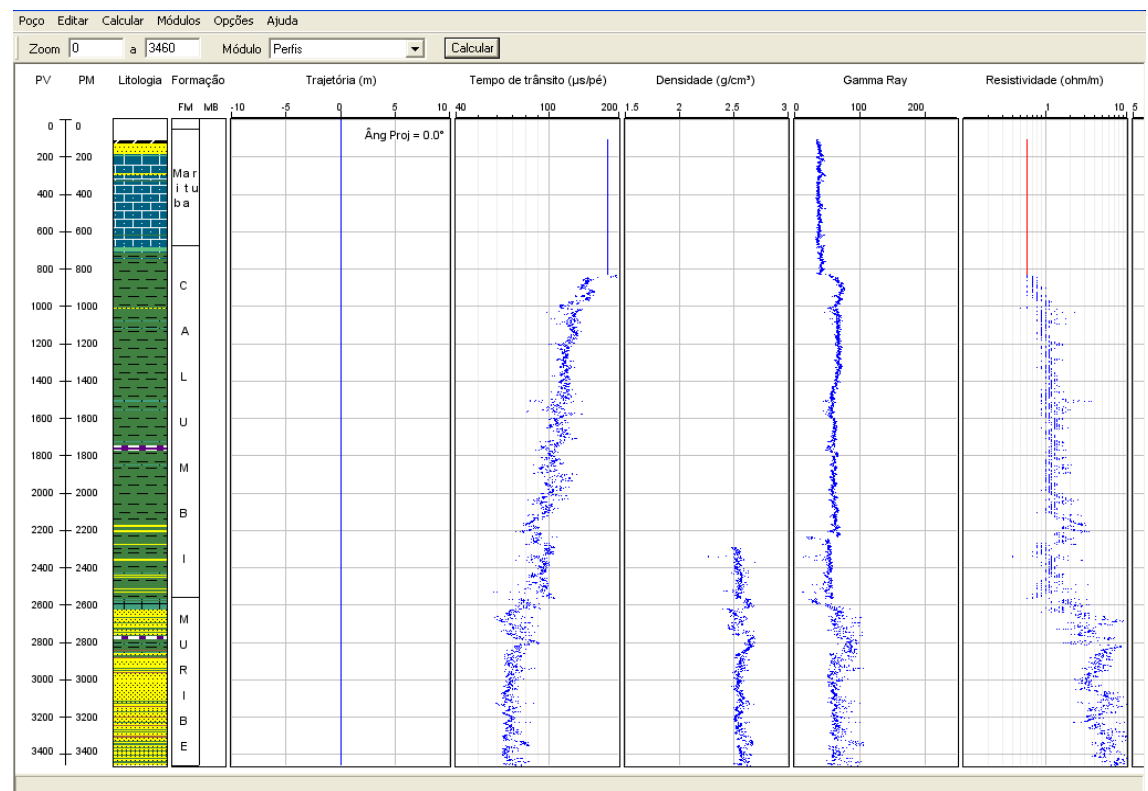

Figura 3.9 - Módulo de Perfis (Tomada do SEST ${ }^{\odot}, 2012$ ).

O módulo de sobrecarga tem por objetivo calcular o gradiente de sobrecarga.

Em poços verticais, a tensão de sobrecarga é considerada igual à tensão vertical e, pode ser calculada em função das densidades das camadas sobrejacentes à formação a certa profundidade. Esta tensão vem a ser geralmente, a maior tensão atuante na formação.

Do mesmo modo, a orientação desta tensão coincide com o eixo $z$ em um sistema de coordenadas, e sua magnitude pode ser obtida a partir da integração do perfil de densidade da formação com a profundidade, conforme eq. (3.1):

$$
\sigma_{o v}=\int_{0}^{z} \rho g d D
$$

Onde:

$\sigma_{o v}=$ Tensão de sobrecarga.

$\rho=$ Densidade das camadas sobrepostas.

$g=$ Constante gravitacional .

$z$ =profundidade desejada.

$d D=$ Variação da profundidade . 
Quando não se tem disponível o perfil de densidade da formação, a tensão de sobrecarga pode ser calculada usando correlações propostas na literatura, a partir do tempo de trânsito ou velocidade com a densidade, tais como: Gardner (1975) e Bellotti \& Giacca (1978).

Bellotti \& Giacca (1978) correlacionaram a densidade com o tempo de trânsito da formação e da matriz da rocha.

Os autores consideraram para formações cimentadas e compactadas um (dtc $\leq 100.0$ ), assumindo o valor do tempo compressional da matriz para folhelho: $\mathrm{dtmc}=47.0 \mu \mathrm{s} / \mathrm{pé}$.

Para formações cimentadas e compactadas (dtc $\leq 100)$, conforme eq. (3.2):

$$
\rho_{f}=3,28-(d t c / 89,0)
$$

Para formações não cimentadas ( $d t c>100)$, conforme eq. (3.3):

$$
\rho_{f}=2,75-2,11(d t c-d t m c) /(d t c+200)
$$

Onde:

$\rho_{f}=$ densidade da formação $\left(\mathrm{gr} \backslash \mathrm{cm}^{3}\right)$.

Segundo Gardner (1974), é um dos métodos para estimativa de densidade das formações mais usados na indústria do Petróleo devido à sua simplicidade pois necessita apenas dos dados acústicos para estimar a densidade.

A equação de Gardner para folhelhos do Golfo do México usa duas constantes empíricas, a e b, as quais devem ser calibradas para a área em estudo. Neste segundo modo, as constantes da fórmula devem ser calibradas para cada local. No Golfo do México estas constantes a e b foram estimadas em 0.23 e 0.25 respectivamente, conforme eq. (3.4):

$$
\rho_{f}=a\left(\frac{10^{6}}{d t c}\right)^{b}
$$

Outro parâmetro sumamente importante, calculado no módulo de pressão de poros em função dos perfis dos poços, é o gradiente de pressão de poros.

Geralmente, a pouca influência sofrida de outros fenômenos diagenéticos que ocorrem após o processo de compactação torna as formações 
impermeáveis, como os folhelhos e argilas, rochas bem apropriadas para a estimativa de pressão de poros.

No entanto, considerando a baixa permeabilidade dos folhelhos e argilas, pode ocorrer que a certa profundidade, a taxa de soterramento e a taxa da redução do volume poroso passem a ser maiores que o escape do fluido contido dentro dos poros gerando uma possível retenção de fluidos durante o processo de compactação, o que é chamado de subcompactação. No processo de subcompactação há um aumento da pressão dos poros e a pressão da sobrecarga passa a atuar sob eles.

Existem na literatura várias correlações para obter o gradiente de poros, entre as quais, o método de Eaton é amplamente utilizado no meio, sendo que o fundamento principal deste método é o processo de subcompactação.

O método de Eaton por sua vez, pode estimar o gradiente de pressão de poros tanto de perfis da onda de trânsito como pelo perfil de resistividade traçando uma linha de tendência sob o perfil para estimar o valor da porosidade em condições normais e de observação.

Tal como se observa na Figura 3.10, em um gráfico semi-logarítmico do perfil de tempo de trânsito com a profundidade, em condições normais de compactação esta linha de tendência tem um comportamento linear, o que significa a redução da porosidade à medida em que aumenta a tensão de sobrecarga. Dessa forma, é muito facilmente reconhecida uma zona anormalmente compactada.
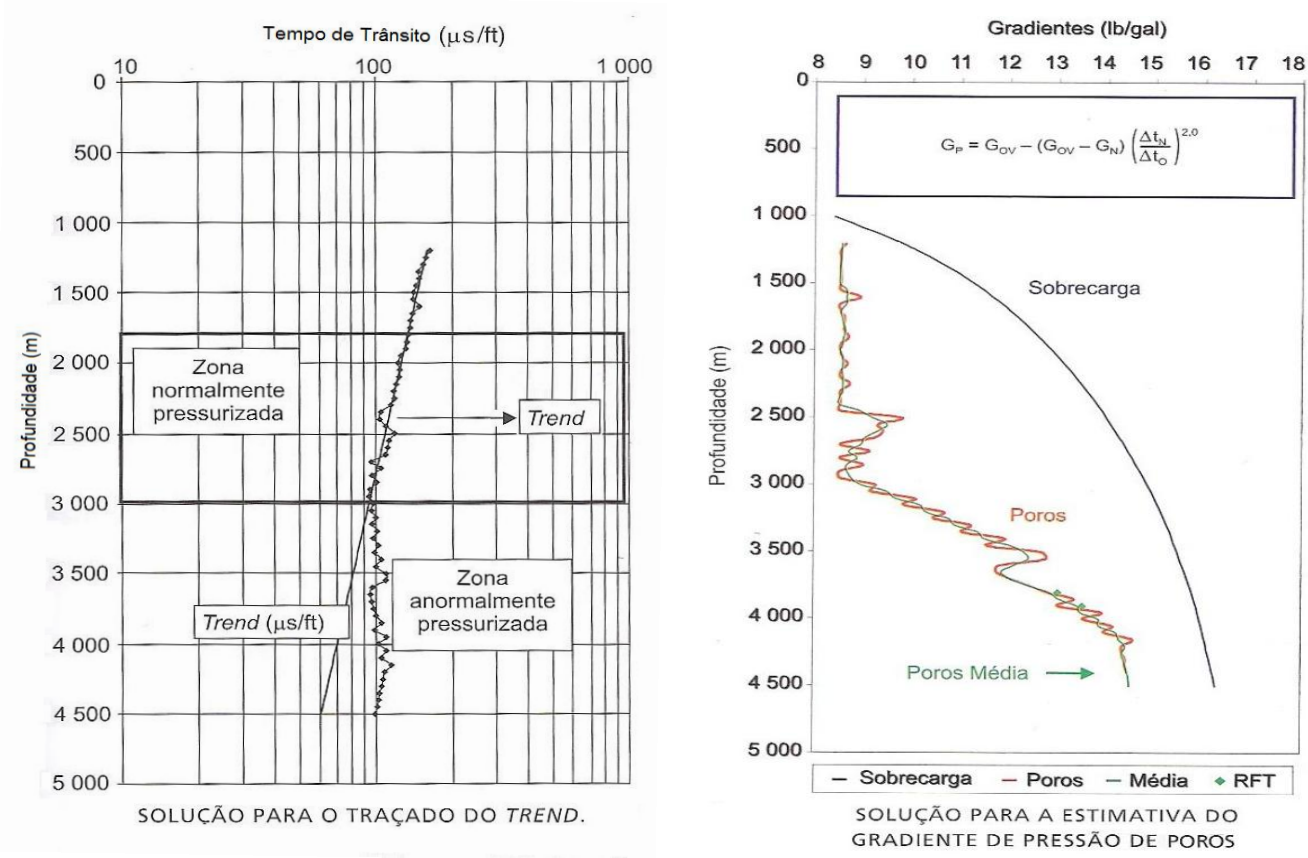

Figura 3.10 - Método de Eaton para estimar a Pressão de Poros. (Tomada de Rocha \& Azevedo, 2007). 
De posse o perfil de tempo de trânsito, o método de Eaton é calculado conforme eq. (3.5):

$$
G_{p}=G_{S}-\left(G_{S}-G_{N}\right)\left(\frac{D T C_{\text {normal }}}{D T C_{o b s}}\right)^{\text {exp }}
$$

Onde:

$G_{p}=$ Gradiente de pressão de poros (lb/gal).

$G_{s}=$ Gradiente de sobrecarga (lb/gal).

$G_{N}=$ Gradiente normal de pressão de poros na área (lb/gal).

$D T C_{\text {normal }}=$ Tempo de transito da onda compressional para o linha de tendência de compactação normal ( $\mu$ s/pé).

$D T C_{o b s}=$ Tempo de transito da onda compressional observado ( $\mu$ s/pé).

$\exp =$ Expoente de Eaton.

O módulo de propriedades mecânicas opta por utilizar correlações a partir de perfis elétricos e acústicos para determinar as propriedades mecânicas das rochas ao invés dos resultados de ensaios de laboratório sob as amostras da testemunhagem, devido a que, os perfis fornecem informações contínuas do comportamento geomecânico das rochas perfuradas em todo o intervalo perfilado do poço em relação aos resultados dos ensaios, que mesmo sejam mais representativos, não deixam de ser informações pontuais.

Considerando-se a rocha um meio homogêneo e isotrópico os parâmetros elásticos são obtidos em função tanto das velocidades das ondas compressional $(\mathrm{Vp})$ e cisalhante (Vs) quanto do tempo de trânsito das ondas compressional $(d t c=1 / V p)$ e cisalhante $(d t s=1 / V s)$ e da densidade da rocha $(\rho b)$ segundo as equações da teoria da elasticidade.

Estes parâmetros são o coeficiente de Poisson $(v)$, o módulo de Young (E), o módulo de cisalhamento $(G)$ e o módulo de compressibilidade dos grãos $(K)$ conforme as eq. (3.6), eq. (3.7), eq. (3.8), e eq. (3.9) respectivamente

$$
v=0,5\left(\frac{(d t s / d t c)^{2}-2}{(d t s / d t c)^{2}-1}\right)
$$

Onde $d t c$ e $d t s$ são tempo de trânsito da onda compressional e cisalhante respectivamente (em $\mu \mathrm{s} / \mathrm{pé})$. 


$$
\begin{gathered}
\mathrm{E}=2 G(1+v) \\
G=1,34 x 10^{10} x\left(\rho_{f} / d t s^{2}\right) \\
K_{S}=1,34 \cdot 10^{10} \rho_{f}\left(\frac{1}{d t m c^{2}}-\frac{4}{3 d t m s^{2}}\right)
\end{gathered}
$$

Onde:

$G=$ Módulo de cisalhamento (em psi).

$d t m c=$ Tempo de trânsito da onda compressional ( $\mu$ s/pé).

$d t m s=$ Tempo de trânsito da onda cisalhante ( $\mu \mathrm{s} /$ pé) .

Conforme Soares (1992), devido a estreitamentos existentes no espaço intergranular (por efeito da cimentação ou forma dos grãos) a pressão de poros não possui eficiência total na sua oposição à tensão total aplicada.

Deste modo, Biot propôs o fator de correção a para o efeito da pressão de poros (Economides, 1988) conforme a eq. (3.10):

$$
\sigma^{\prime}=\sigma-\alpha P_{P}
$$

Onde $\alpha$ varia entre 0 e 1 e seu valor depende da geometria do poro e das propriedades físicas dos constituintes sólidos da rocha. Após simplificações (Economides, 1988), o valor de a pode ser expresso conforme as eq. (3.11) e a eq. (3.12):

$$
\alpha=1
$$

$$
\alpha=1-\frac{K_{b}}{K_{S}}
$$

Onde:

$$
K_{b}=1,34 \cdot 10^{10} \rho_{f}\left(\frac{1}{d t c^{2}}-\frac{4}{3 d t s^{2}}\right)
$$

$K_{b}=$ Módulo de deformação volumétrica (psi).

$K_{s}=$ Módulo de compressibilidade dos grãos. 
Soares (1992) cita do trabalho de Coates e Denoo (1981) que utilizando dados de rochas sedimentares da literatura os autores propuseram uma relação para estimar a resistência à compressão uniaxial $\mathrm{C}_{0}$ a partir do volume de argila $\mathrm{V} c \mathrm{l}$ e do módulo de Young $\mathrm{E}$ da formação. A eq. (3.14) se aplica para as litologias mostradas na Figura 3.11.

$$
C_{o}=\left[0,0045\left(1-V_{c l}\right)+0,008 V_{c l}\right] E
$$

Os mesmos autores após vários estudos do comportamento das rochas propuseram a seguinte correlação empírica para estimar a coesão, conforme a eq. (3.15):

$$
C=0,025 \frac{\left[0,0045\left(1-V_{c l}\right)+0,008 V_{c l}\right] E}{10^{6} \cdot C_{b}}
$$

Onde $C_{b}$ é a compressibilidade em (1/psi), eq. (3.16):

$$
C_{b}=\frac{1}{K_{b}}
$$

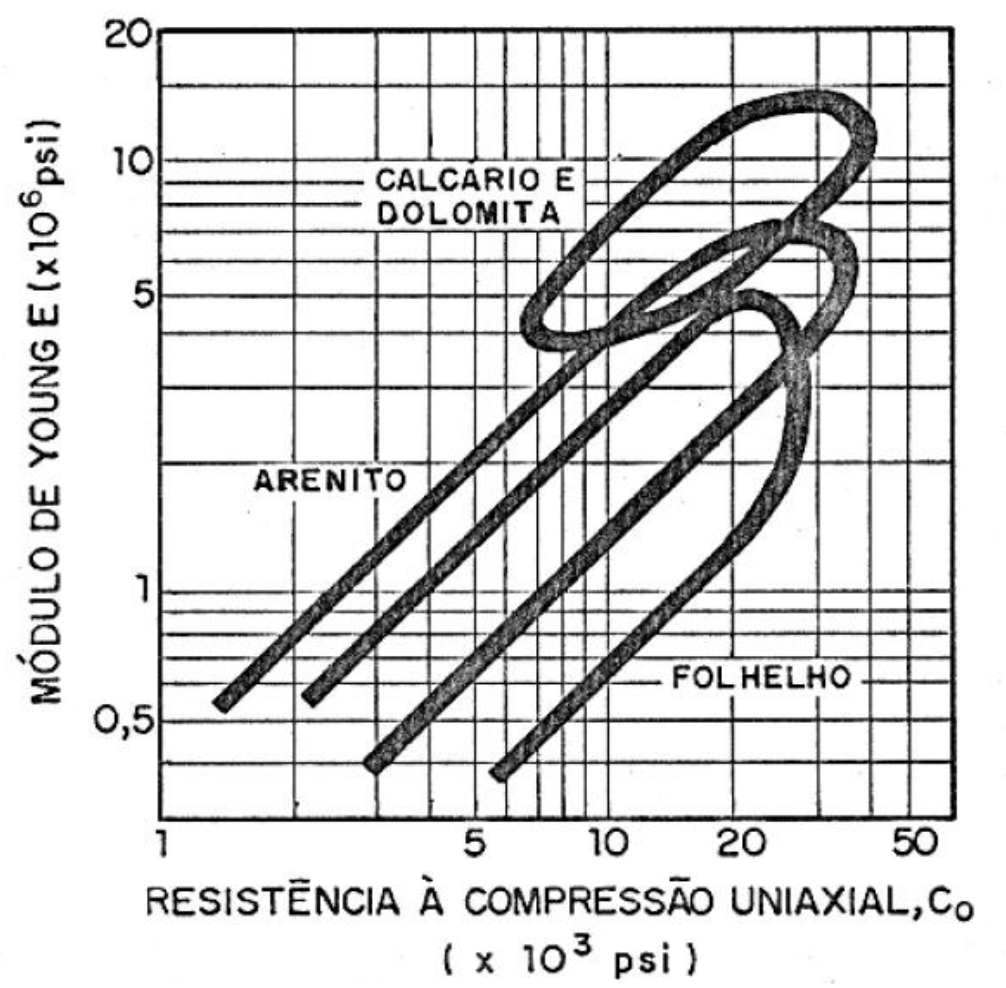

Figura 3.11 - Relação entre E e Co para diversas litologias. (Tomada de Soares, 1992). 
O valor para o ângulo de atrito pode ser adotado para todas as rochas igual a $\phi=30^{\circ}$ ou pode ser usada alguma das correlações da Tabela 3.3 apresentadas por Chang et al., (2006) para o calculo do ângulo de atrito interno $(\phi)$ conforme as eq. (3.17), eq. (3.18) e eq. (3.19) respetivamente.

Tabela 3.3 - Relações empíricas entre o angulo de fricção interna $(\Phi)$ e perfis. (Modificada de Chang et al., 2006).

\begin{tabular}{|c|c|c|c|}
\hline$\emptyset$ (graus) & $\begin{array}{l}\text { Comentários } \\
\text { Gerais }\end{array}$ & Referência & $\begin{array}{l}\text { Eq } \\
\text { No. }\end{array}$ \\
\hline $\sin ^{-1}((V p-1000) /(V p+1000))$ & Folhelho & Lal (1999) & $(3.17)$ \\
\hline $57,8-105 \emptyset$ & Arenito & $\begin{array}{c}\text { Weingarte } \\
\text { n e } \\
\text { Perkins } \\
\text { (1995) }\end{array}$ & $(3.18)$ \\
\hline $\tan ^{-1}\left(\frac{\left(G R-G R_{\text {arenito }}\right) \mu_{\text {folhelho }}+\left(G R_{\text {folhelho-GR }}\right) \mu_{\text {arenito }}}{G R_{\text {folhelho- }} G R_{\text {arenito }}}\right)$ & $\begin{array}{c}\text { Folhelho } \\
\text { Rocas } \\
\text { sedimentares }\end{array}$ & & $(3.19)$ \\
\hline
\end{tabular}

Já a resistência à compressão simples (UCS) conforme a eq. (3.20), é calculada em função da combinação de um par de parâmetros de resistência enquanto o terceiro parâmetro é calculado em função desses dois parâmetros escolhidos.

$$
U C S=2 . C \cdot \operatorname{Tan}\left(\frac{\pi}{4}+\frac{\phi}{2}\right)
$$

Chang et al., (2006) apresentaram algumas correlações para determinar a resistência a compressão simples (UCS) a partir do ângulo de atrito $(\phi)$ ou do tempo de trânsito $(\Delta \mathrm{t})$, assim como apresentado na Tabela 3.4 conforme as eq. (3.21), eq. (3.22), eq. (3.23), eq. (3.24), eq. (3.25), eq. (3.26), eq. (3.27), eq. (3.28), eq. (3.29), eq. (3.30), respectivamente. 
Tabela 3.4 - Relações empíricas entre a resistência à compressão não-confinada (UCS) e outras propriedades físicas em folhelhos. (Modificada de Chang et al., 2006).

\begin{tabular}{|c|c|c|c|c|}
\hline UCS (MPa) & $\begin{array}{c}\text { Região de } \\
\text { desenvolvimento }\end{array}$ & Comentários gerais & Referencias & $\begin{array}{l}\text { Eq } \\
\text { No. }\end{array}$ \\
\hline $0,77(304,8 / \Delta t)^{2,93}$ & Mar do Norte & $\begin{array}{c}\text { Geralmente folhelhos } \\
\text { com alta porosidade } \\
\text { da idade Terciaria }\end{array}$ & $\begin{array}{l}\text { Horsrud } \\
(2001)\end{array}$ & $(3.21)$ \\
\hline $0,43(304,8 / \Delta t)^{3,2}$ & Golfo do México & $\begin{array}{c}\text { Folhelhos jovens e do } \\
\text { Plioceno }\end{array}$ & & (3.22) \\
\hline $1,35(304,8 / \Delta t)^{2,6}$ & Globalmente & - & & (3.23) \\
\hline $0,5(304,8 / \Delta t)^{3}$ & Golfo do México & - & & $(3.24)$ \\
\hline $10(304,8 / \Delta t-1)$ & Mar do Norte & $\begin{array}{c}\text { Geralmente folhelhos } \\
\text { com alta porosidade } \\
\text { da idade Terciaria }\end{array}$ & Lal (1999) & $(3.25)$ \\
\hline $7,97 \mathrm{E}^{0,91}$ & Mar do Norte & $\begin{array}{c}\text { Geralmente folhelhos } \\
\text { com alta porosidade } \\
\text { da idade Terciaria }\end{array}$ & $\begin{array}{l}\text { Horsrud } \\
(2001)\end{array}$ & $(3.26)$ \\
\hline $7,22 \mathrm{E}^{0,712}$ & - & $\begin{array}{c}\text { Folhelhos fortes e } \\
\text { compactados }\end{array}$ & & (3.27) \\
\hline $1,001 \emptyset^{-1,143}$ & - & $\begin{array}{c}\text { Folhelhos com baixa } \\
\text { porosidade }(\phi<0,1) \text { e } \\
\text { alta resistência } \\
(\sim 79 \mathrm{MPa})\end{array}$ & $\begin{array}{c}\text { Lashkaripour } \\
\text { e Dusseault } \\
\text { (1993) }\end{array}$ & (3.28) \\
\hline $2,922 \emptyset^{-0,96}$ & Mar do Norte & $\begin{array}{l}\text { Geralmente folhelhos } \\
\text { da idade Terciaria } \\
\text { com alta porosidade } \\
\qquad(\phi<0,27)\end{array}$ & & (3.29) \\
\hline $0,286 \emptyset^{-1,762}$ & - & $\begin{array}{c}\text { Folhelhos com alta } \\
\text { porosidade }(\phi<0,27)\end{array}$ & & $(3.30)$ \\
\hline
\end{tabular}

Toda análise de estabilidade de poços requer a determinação das tensões in-situ, da pressão de poros e de um critério de falha das rochas perfuradas.

No entanto, a magnitude das tensões in-situ é provavelmente um dos parâmetros de entrada mais importantes e insuficientemente conhecidos.

No SEST ${ }^{\odot}$, as tensões in-situ podem ser determinadas no módulo de tensões in-situ.

As tensões in-situ estão compostas pelas tensões vertical $\left(\sigma_{\mathrm{v}}\right)$ e pelas tensões horizontal máxima $\left(\sigma_{\mathrm{H}}\right)$ e mínima $\left(\sigma_{\mathrm{h}}\right)$ como resposta a um 
estado de tensão que experimenta um elemento de rocha a certa profundidade, como resultado do carregamento das rochas sobrejacentes.

Cabe ressaltar que das tensões in-situ, a tensão vertical já foi obtida no módulo de sobrecarga.

No cálculo das tensões horizontais é considerada, a partir da teoria de elasticidade, a bacia como relaxada, ou seja, de parede lateral rígida, sem influência de movimentos tectônicos, a grandes profundidades, evitando que a formação tenda a se deformar lateralmente nas direções horizontais e assumindo o cálculo delas em função do coeficiente de Poisson que estabelece a relação entre as tensões principais como resultado do confinamento na direção vertical, resultante da atuação da tensão de sobrecarga.

O cálculo da tensão horizontal efetiva pela teoria da elasticidade considera que a presença da pressão de poros ajuda a suportar uma grande parcela da tensão total aplicada. Desta forma, a tensão efetiva atuante sobre a matriz rochosa é igual à tensão total menos a pressão de poros, conforme a eq. (3.31) de Terzaghi.

$$
\sigma^{\prime}=\sigma-P_{P}
$$

Onde:

$\sigma=$ Tensão vertical

$\sigma^{\prime}=$ Tensão vertical efetiva

$P_{p}=$ Pressão de poros

As tensões horizontais, por sua vez, são uma resposta ao carregamento vertical, e para efeitos desta análise, assumindo a condição de bacia com deformação lateral nula, pode-se escrever conforme a eq. (3.32) que:

$$
\sigma_{h}^{\prime}=\sigma_{H}^{\prime}=\left(\frac{v}{1-v}\right) \sigma_{v}^{\prime}
$$

Onde:

$\sigma^{\prime}{ }_{h}=$ Tensão horizontal mínima efetiva

$\sigma^{\prime}=$ Tensão horizontal máxima efetiva

$\mathrm{K}=$ razão entre a tensão efetiva horizontal e a tensão vertical

Sendo que o K a sua vez, é calculado em termos do coeficiente de Poisson $(v)$, conforme a eq. (3.33).

$$
K=\left(\frac{v}{1-v}\right)
$$


Por outra parte, as tensões horizontais em termos de direções e magnitude também podem ser estimadas a partir de medições diretas (como o teste de LOT para determinar a $\sigma_{h}$ ) ou através de cálculos baseados em modelos teóricos ou empíricos (Método das Tensões tangenciais, Método da Tensão Mínima ou de Correlações Especificas) correlacionados quando disponíveis, de estudos em perfis de imagem elétricos e/ou acústicos.

Tipicamente os tipos de falhas que ocorrem em torno do poço são breakouts e fraturas induzidas, pois esses são tipos de falhas que geralmente resultam de uma condição desfavorável de tensões ao redor do poço quando ele é perfurado.

Esses tipos de falhas podem ser detectados em um perfil de imagem através das marcas nas paredes do poço, pois as direções destas são governadas pelas direções das tensões principais.

O breakout é uma falha por cisalhamento que ocorre na direção da tensão horizontal mínima nos lados opostos do poço, mudando a seção reta do poço de circular para eliptica. Desta forma, possibilita a estimativa da direção das tensões horizontais pois podem ser identificados, por exemplo, em um perfil de imagem através das zonas de desmoronamento.

Já as fraturas tendem a se propagar na direção perpendicular à menor tensão horizontal in-situ. No caso em que a maior tensão é a tensão vertical, a fratura se propagará na direção da tensão horizontal máxima, sendo assim possivel estimar a orientação dessa tensão.

No caso de um poço vertical, as fraturas naturais no perfil de imagem podem ser detectadas facilmente devido a sua forma senoidal e precisamente esta característica é a que a diferencia das fraturas induzidas, pois estas últimas apresentam um traço linear vertical ao longo do perfil de imagem. Já no caso de um poço direcional, a forma como aparecem às fraturas também depende da inclinação do poço.

Na Figura 3.12 é possível identificar tanto fraturas naturais, responsáveis pela geração de cavings, quanto uma zona de desmoronamento. 

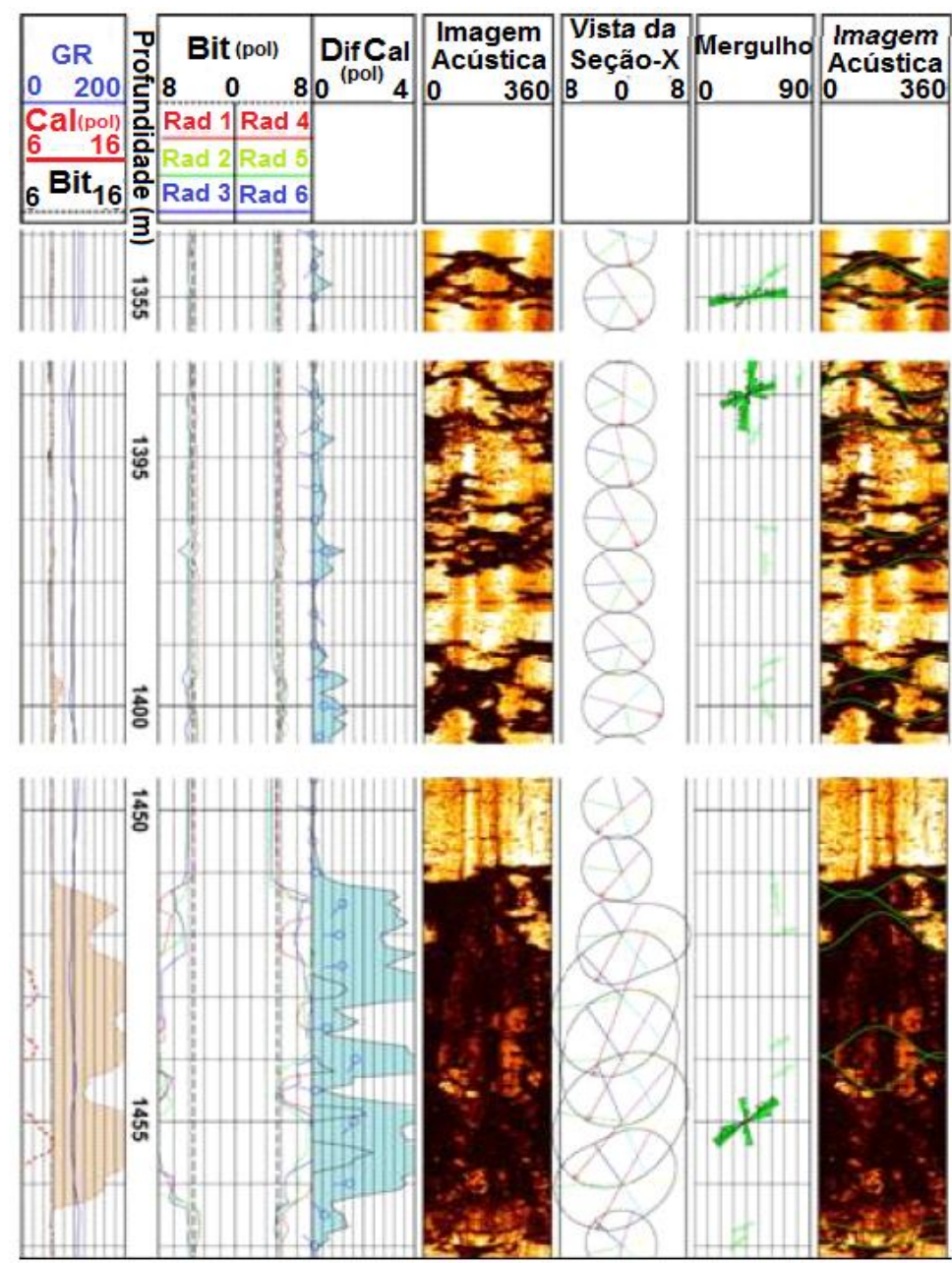

Figura 3.12 - Desmoronamentos e fraturas naturais no perfil de imagem. (Modificada de Fontana et al., 2009).

Do perfil de imagem acústico da formação de folhelho Aike Palermo, apresenta-se um crescente alargamento do poço com a profundidade, indicando deste modo, a probabilidade do aumento da intensidade da fratura com a profundidade.

A Figura 3.13 da Bacia de Neuquén (Argentina), traz um exemplo de um breakout incipiente encontrado no perfil de imagem assim como de uma fratura induzida. 


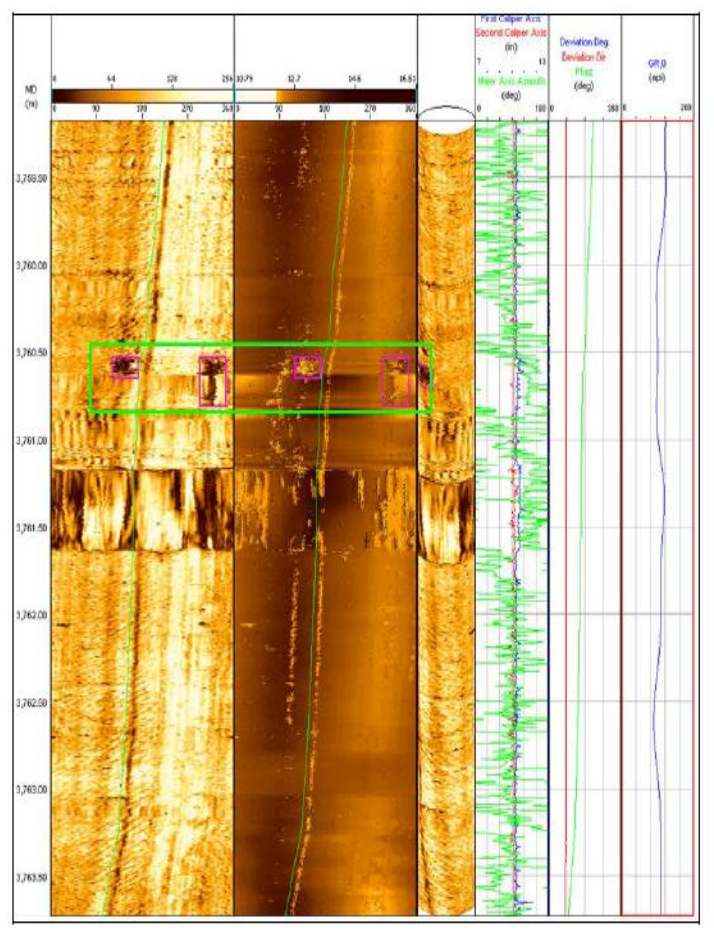

Figura 3.13 - Breakouts e fraturas naturais e induzidas no perfil de imagem. (Modificada de Araujo et al., 2009).

Por último, no módulo de gradientes, é definida a janela operacional tal como apresentada na Figura 3.14, que determina o intervalo permissível da variação de um peso de fluido de perfuração dentro dos limites demarcados pelos gradientes de pressões de poros, colapso e fratura atuantes na formação, de forma a manter a integridade do poço.

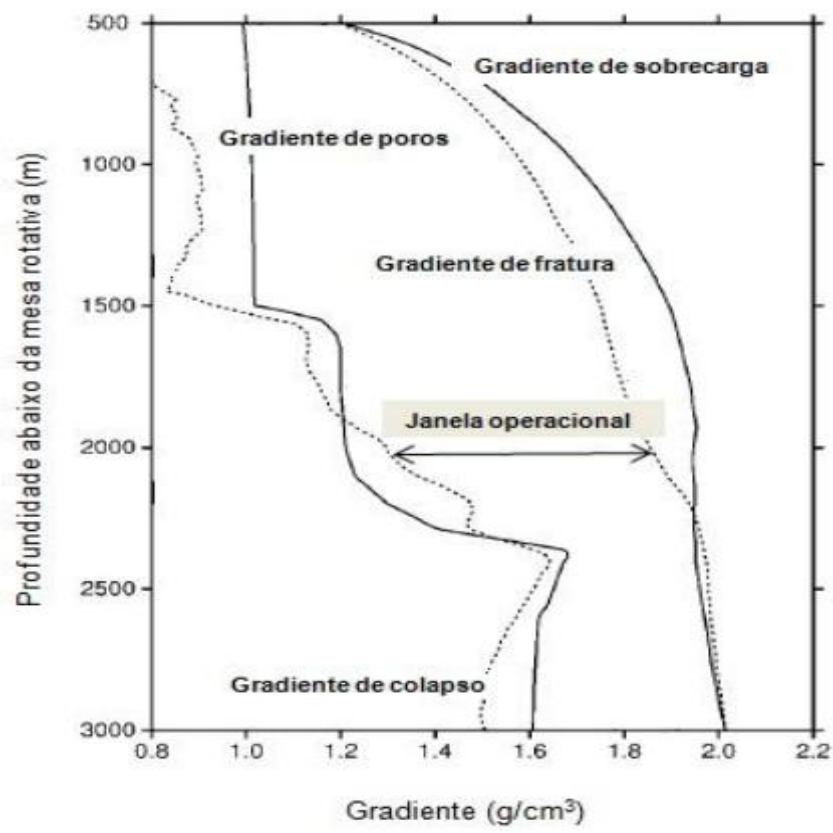

Figura 3.14 - Exemplo típico de janela operacional de um poço. (Modificada de Fjaer, 2008). 
Segundo Rocha e Azevedo (2007), o gradiente de colapso geralmente determina o limite inferior da janela operacional, ou seja, é o limite inferior do peso do fluido de perfuração que pode ser utilizado sem que haja colapso da formação.

Por outro lado, o gradiente de fratura pode ser determinado usando métodos diretos ou métodos indiretos. Os métodos diretos, tais como o teste de absorção clássico (LOT) e o teste de microfraturamento, embora ofereçam informações mais reais e confiáveis terminam não sendo efetuados, pois são geralmente testes caros e que consomem tempo de sonda. Por essa razão, os métodos indiretos são mais usados, pois permitem a estimativa do gradiente de fratura ao longo do todo o poço.

Os mesmos autores afirmam que o gradiente de fratura pode ser estimado em poços verticais utilizando o método da tensão mínima, pois é o método que é mais representativo das tensões atuantes nas regiões mais distantes do poço.

Neste método, as principais hipóteses são que a rocha não possui resistência à tração e que a fratura ocorre quando a pressão dentro do poço atinge a tensão in situ mínima, ou seja, $\sigma_{\mathrm{h}}$, para que a propagação da fratura ocorra.

$\mathrm{Na}$ eq. (3.34) a $\mathrm{P}_{\mathrm{w}}$ é a pressão dentro do poço, devido ao fluido de perfuração, que leva à fratura da formação.

$$
P_{w}=\sigma_{h}
$$

Define-se a $\sigma_{h}$ a partir da eq. (3.35):

$$
\sigma_{h}=P_{p}+\left(\sigma_{h}-P_{p}\right)
$$

Usando a correlação entre as tensões efetivas horizontal mínima e vertical, definida por K, a eq. (3.35) resulta na eq. (3.36):

$$
K=\frac{\left(\sigma_{h}-P_{p}\right)}{\left(\sigma_{v}-P_{p}\right)}
$$


Combinando as eq.(3.34), eq. (3.35) e a eq. (3.36), e assumindo que a tensão vertical é igual à tensão de sobrecarga, a $P_{w}$ pode ser expressa conforme a eq. (3.37):

$$
P_{w}=P_{p}+\left(\sigma_{o v}-P_{p}\right)
$$

Em termos de gradientes como a eq. (3.38):

$$
G_{f}=G_{p}+\left(\sigma_{o v}-G_{p}\right)
$$

Onde $G_{f}=$ gradiente de sobrecarga

No entanto, caso não haja dados de tensão mínima, utiliza-se a pressão de absorção (resultados de LOT) como uma aproximação para o cálculo do gradiente de fratura, pois esse teste estima o gradiente máximo de pressão a que o poço pode ser submetido sem que ocorra perda de circulação, eq. (3.39):

$$
P_{w}=\sigma_{h}=\text { LOT }
$$

Substituindo a eq. (3.39) na eq. (3.36), obtém-se a eq. (3.40):

$$
K=\frac{\left(L O T-P_{p}\right)}{\left(\sigma_{v}-P_{p}\right)}
$$

Na previsão do gradiente de fratura, além de utilizar os resultados de LOT dos poços de correlação, pode-se estimar um coeficiente $\mathrm{K}$ para toda uma área com o fim de prever uma curva de gradiente de fratura ao longo de todo o poço.

Este coeficiente representa a razão entre tensão efetiva horizontal mínima e tensão efetiva vertical. Pode-se estabelecer correlações de $\mathrm{K}$ versus profundidade de sedimentos, para se obter uma melhor estimativa do gradiente de fratura nos diferentes tipos de formações.

Outra consideração importante no que se refere à obtenção da janela operacional é a determinação do fluido de perfuração como penetrante ou não penetrante, pois a partir da definição da tensão efetiva, sabe-se que o efeito das tensões ao redor do poço e das tensões in-situ é reduzido pela pressão de poros. Por essa razão, faz-se necessária a distribuição da pressão de poros a partir do centro do poço. 
No caso do fluido não penetrante, não há fluxo entre o poço e a formação. Nesse caso, a pressão de poros na parede do poço é igual à pressão de poros da formação distante do poço $\left(\mathrm{P}_{\mathrm{e}}\right)$.

A Figura 3.15 (esquerda), representa o caso de um poço com diferencial de pressão positivo $\left(P_{w}>P_{e}\right)$ e, a Figura 3.15 (direita), o caso de um poço com diferencial de pressão negativo.
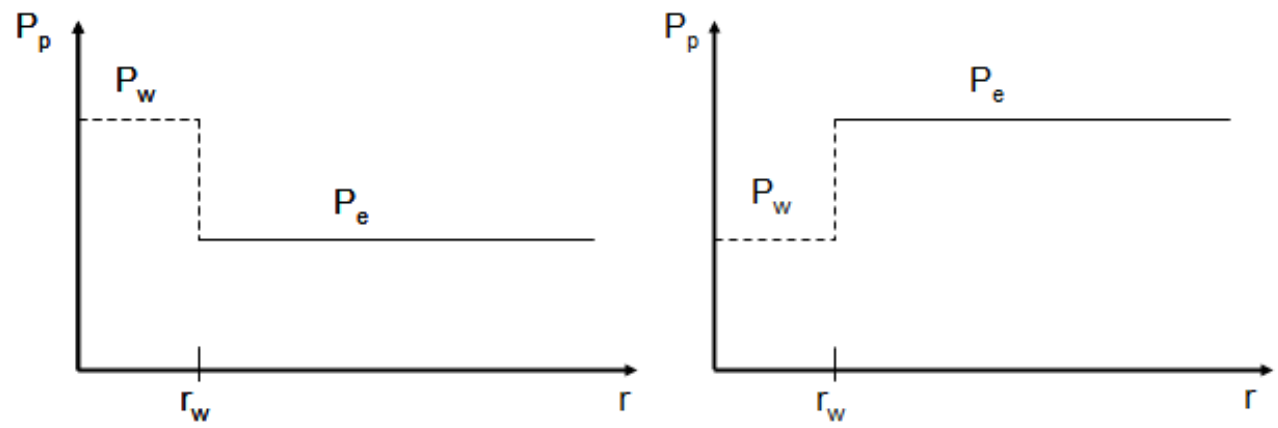

Figura 3.15 - Distribuição da pressão de poros a partir do centro do poço caso o fluido seja não penetrante com descontinuidade na parede do poço $\left(r=r_{w}\right)$. (Tomada de Rocha \& Azevedo, 2007).

Um fluido é chamado penetrante quando há fluxo entre o poço e a formação. Nessa hipótese, a pressão de poros na parede do poço deve ser igual à pressão dentro do poço, como apresentado na Figura 3.16.

Nesta situação a distribuição é contínua e, desta forma no caso a esquerda como a direita o diferencial de pressão na parede do poço é nulo.
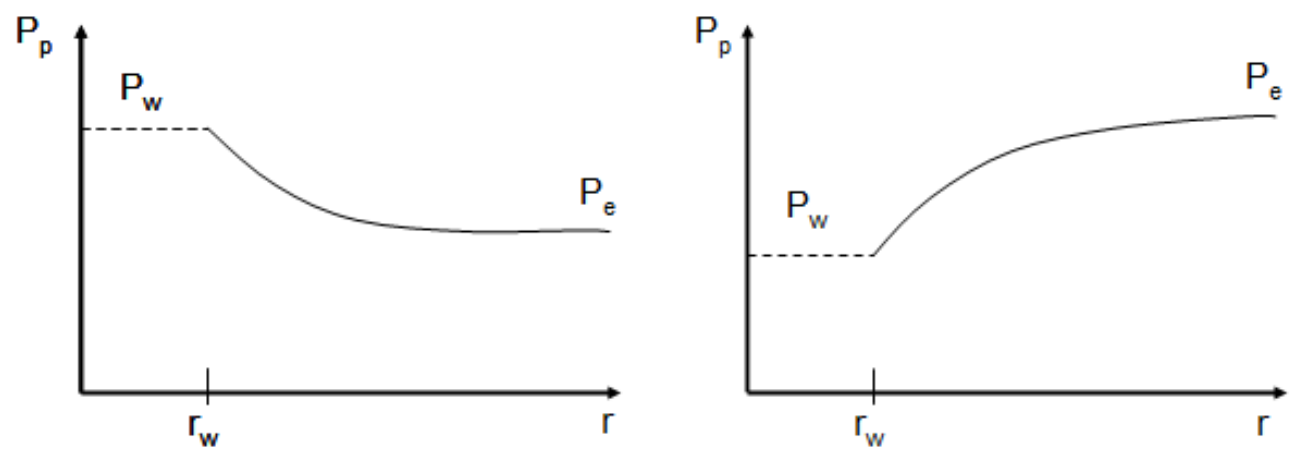

Figura 3.16 - Distribuição da pressão de poros a partir do centro do poço caso o fluido seja penetrante. (Tomada de Rocha \& Azevedo, 2007). 


\subsection{4. Modelagem tridimensional dos eventos de perfuração.}

A modelagem tridimensional gera os insumos chave que proporcionam uma visão mais realista do comportamento e das condições físicas do poço, permitindo, deste modo, que as interpretações gerais do campo sejam de melhor qualidade, esclarecendo as possíveis causas e mecanismos de instabilidade que os ocasionaram, podendo ser incorporadas nas futuras operações de perfuração e no planejamento de novos poços, através da revisão contínua do modelo geomecânico e da avaliação de riscos operacionais.

Nesta etapa, continua-se o procedimento para a construção do MEM aplicado para a estabilidade de poços, através da representação tridimensional dos problemas e eventos de perfuração identificados nas etapas anteriores em conjunto com as informações relevantes dos poços perfurados, ou seja, geologia estrutural do campo, perfis dos poços, $\operatorname{BDP}(\mathrm{s})$, dados de sismica, entre outros. Tudo com o fim de otimizar o processo de perfuração eliminando o TNP relacionado com os problemas de instabilidade.

Segundo McIntyre et al., (2009), a população e visualização dos eventos que evidenciam a ocorrência de problemas de perfuração em um ambiente tridimensional permite que estes sejam correlacionados, validados e sintetizados com informações geológicas, geofísicas e estruturais.

Neste sentido, um conhecimento geral do campo pode ser obtido uma vez que é possível identificar em um modelo estrutural, por meio da delimitação dos horizontes litológicos (topos da formação), as denominadas "zonas de instabilidade" que destacam onde, quando, e por que eses problemas de instabilidade na formação tendem a ocorrer.

Do mesmo modo, define-se o grid geométrico 3D segundo o grau de detalhamento que se deseje ter no final do modelo, pois nesta distribuição espacial, serão integrados e consolidados esses dados.

$\mathrm{Na}$ Figura 3.17 é apresentado o esquema geral para a construção tridimensional do MEM combinando os perfis de poços com os horizontes geológicos e sísmicos. 


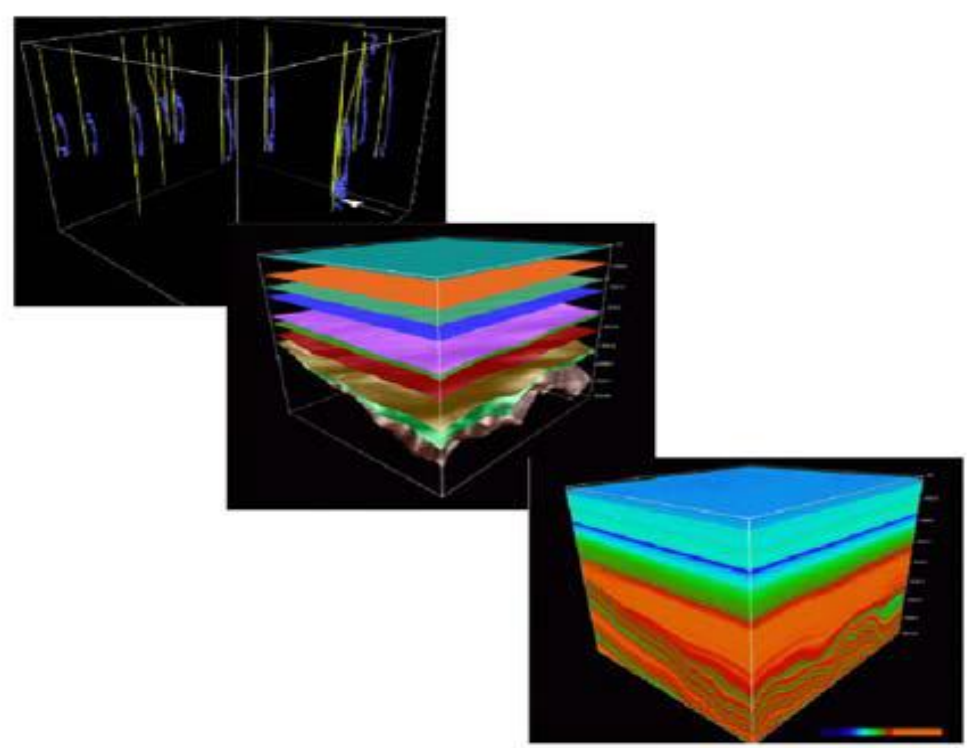

Figura 3.17 - Etapas da construção do modelo 3D (Tomada de Sayers et al., 2006).

\subsubsection{1.}

\section{Estrutura do tratamento dos dados na modelagem geomecânica.}

A estrutura dos dados de entrada para o modelador $\operatorname{PETREL}^{\odot}$, foi dividida em três etapas: preparação dos dados brutos, lançamento dos dados para efetuar a análise bi e tridimensional da modelagem e, a análise da modelagem em função da sísmica do campo.

A metodologia adotada para a preparação dos dados brutos, constituídos pelos eventos de perfuração extraídos dos $\operatorname{BDP}(s)$, consistiu na elaboração de planilhas segundo o formato de importação do modelador $\operatorname{PETREL}^{\odot}$, por exemplo, perfis, pontos, etc.

As planilhas elaboradas foram lançadas no modelador com o fim de serem analisadas em conjunto com as informações que compõem o MEM como parte final da fase de retroanálise em ambientes bi e tridimensionais para a estimativa da estabilidade dos poços na formação de interesse como os folhelhos

Para o lançamento dos dados brutos, foram usados dois tipos de formatos de importação: para o caso de perfis foi usado o formato well logs, enquanto que, para a informação pontual foi usado o formato point well data format. Ambos os formatos foram utilizados tanto para os dados discriminados em contínuos e discretos.

Neste sentido, cabe-se ressaltar que os dados discretos e contínuos foram definidos como aqueles dados que representaram qualitativa e quantitativamente as informações dos poços. Neste trabalho se teve disponibilidade de ambos os dados. 
Para exemplificar o procedimento descrito acima, os repasses vieram a ser tratados como dados discretos importados com formato profile, (pois foram identificados por trechos em função da profundidade no BDP), os quais uma vez importados no $\operatorname{PETREL~}^{\odot}$, são mais bem representados ao longo dos poços por meio de barras onde a ocorrência foi observada, tal como pode ser observada (em vermelho) na Figura 3.18.

Do mesmo modo, os peixes e as topadas no poço foram tratados como dados discretos, no entanto, foram importados segundo o formato point já que o problema só foi registrado pontualmente.

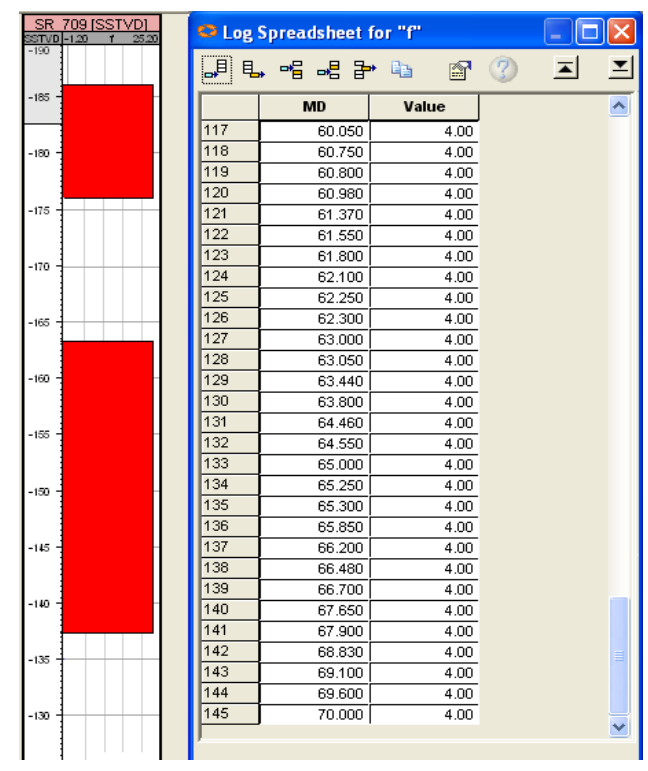

Figura 3.18 - Formato de apresentação dos dados discretos. (Modificada de Marchesi, 2008).

Os arrastes na descida e na retirada da coluna de perfuração foram tratados como dados contínuos, sendo que estes também ocorrem ao longo de trechos de profundidade.

A intensidade do atrito gerado entre a coluna de perfuração com as paredes do poço é quantificada proporcionalmente em função da força do arraste, isto é, quanto maior ou menor este seja maior ou menor será o valor do atrito.

Adicionalmente, foi usada a ferramenta upscale para definir a variação da intensidade ocorrência em uma escala de cores, assim como é apresentada na Figura 3.19, estabelecida entre os limites mínimo e máximo. 


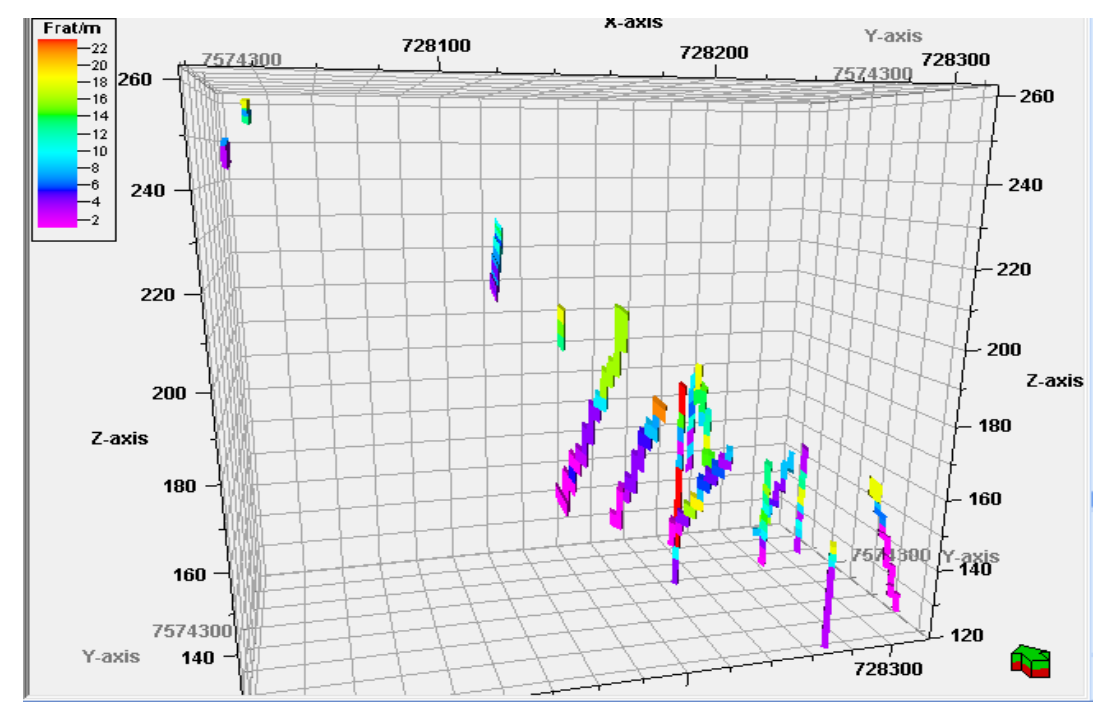

Figura 3.19 - formato de apresentação dos dados contínuos. (Modificada de Marchesi, 2008).

Seguindo a mesma metodologia usada para a identificação dos eventos, os parâmetros de perfuração, tais como torque, vazão, pressão da injeção, taxa de penetração, revoluções por minuto foram levantados das descrições do BDP que reportaram os problemas de estabilidade analisados acima.

Esta estruturação dos dados favoreceu a comparação entre os perfis dos poços estabelecendo comportamentos padrões em função, ou não, da ocorrência de eventos, o que facilitou a identificação das possíveis zonas de instabilidade.

Uma vez realizado esse primeiro contato dos eventos ou problemas de instabilidade e dos parâmetros de perfuração com os perfis dos poços em um ambiente bidimensional, optou-se por delimitar a área da modelagem tridimensional em função de dois horizontes estratigráficos até o momento conhecidos, tais como: o fundo do mar e a cota de fundo do poço.

Deste modo, pretendeu-se ter uma boa cobertura das informações através de uma modelagem espacial que abranja representativamente, o entorno do campo, como um passo essencial de uma previsão de estabilidade dos poços.

Contemplando a possibilidade da interconexão dos eventos de instabilidade, e de posse os limites estratigráficos mencionados acima, foram traçados horizontes intermediários em função da litoestratigrafia, que compreende o uso da continuidade lateral das rochas ou o conjunto delas para definir automaticamente seções geológicas entre eles, que possam de alguma forma contribuir com as interpretações a serem feitas nos ambientes bi e tridimensionais a seguir. 
$\mathrm{Na}$ Figura 3.20, esse procedimento permite o traço completo dos horizontes litológicos, que contribui grandemente para as análises tridimensionais.

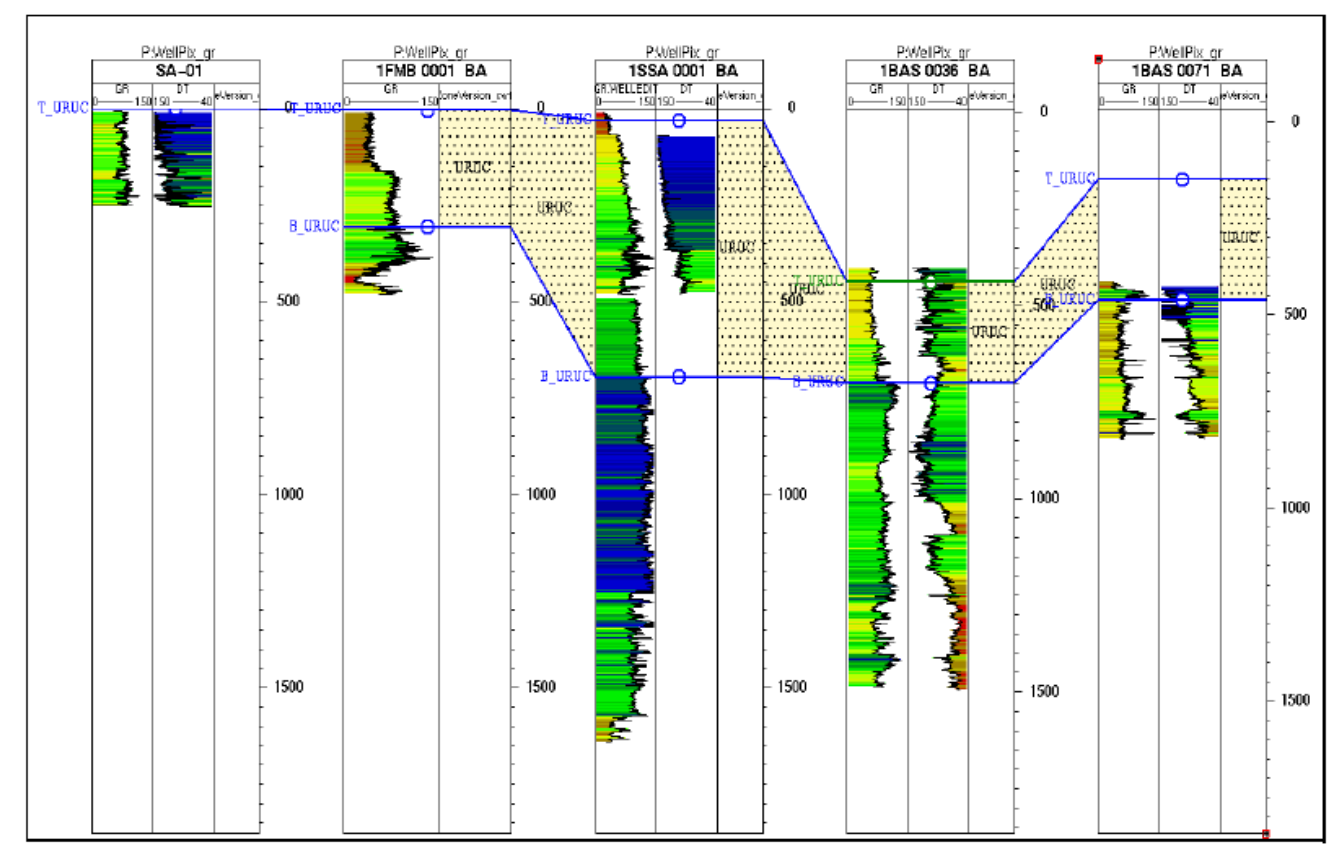

Figura 3.20 - correlação dos horizontes litológicos nos poços analisados na janela bidimensional. (Modificada de Pereira de Lima, 2005).

Delimitou-se o grid tridimensional do modelo, definindo as superfícies de fundo do mar e fundo do poço como o limite geométrico superior e inferior do modelo, onde os poços e os problemas de perfuração foram demarcados.

Uma vez limitado o grid tridimensional por estas superfícies, os horizontes litológicos (well tops), criados na etapa anterior, são tomados como dados de entrada na modelagem através da ferramenta make horizon.

Implicitamente esta ferramenta, contém uma serie de opções que permitem visualizar o volume tridimensional do modelo composto pelas zonas compreendidas entre os horizontes, podendo também ser representadas as interseções entre os vetores $i$ e $j$, segundo a necessidade. 


\section{4.}

\section{Resultados e Análise}

A metodologia proposta foi aplicada no estudo de caso composto de quatro poços perfurados.

$\mathrm{Na}$ Tabela 4.1 se apresenta a lista dos poços estudados de acordo com a ordem cronológica das perfurações e, na Figura 4.1, apresenta-se a localização dos mesmos.

Tabela 4.1 - Poços analisados.

\begin{tabular}{|c|c|c|c|c|}
\hline Nome & Tipo de poço & $\begin{array}{c}\text { Mesa } \\
\text { Rotativa } \\
(\mathrm{m})\end{array}$ & $\begin{array}{c}\text { Lâmina } \\
\text { da água } \\
(\mathrm{m})\end{array}$ & $\begin{array}{c}\text { Prof. } \\
\text { Medida } \\
(\mathrm{m})\end{array}$ \\
\hline P-001 & Vertical & 25 & 1208 & 3327 \\
\hline P-002 & Vertical & 25 & 1180 & 3500 \\
\hline P-003 & Vertical & 25 & 1420 & 3450 \\
\hline P-004 & Direcional & 25 & 1046 & 3325 \\
\hline
\end{tabular}

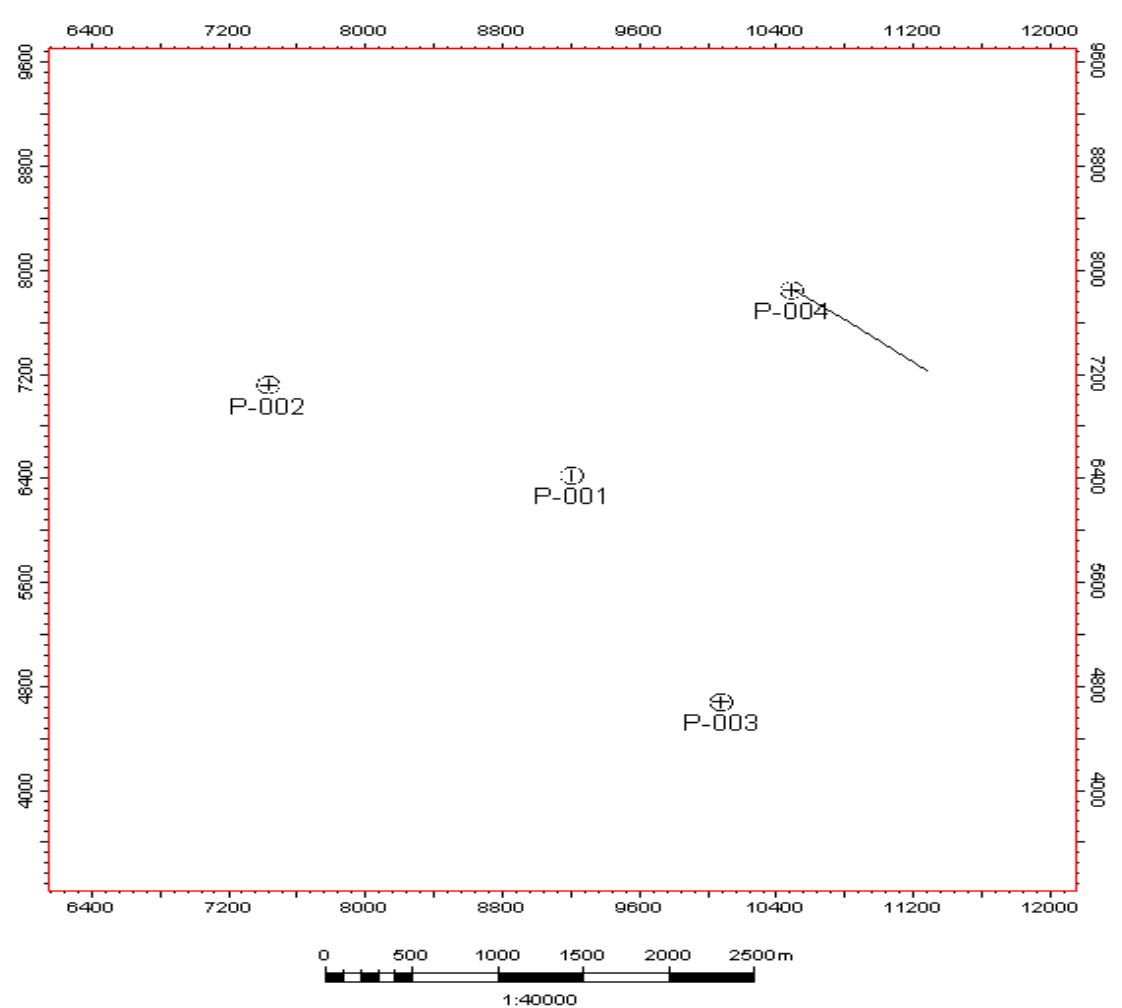

Figura 4.1 - Localização dos poços do estudo de caso. 
A seguir são apresentados os resultados obtidos em cada etapa da aplicação da metodologia.

\section{1.}

\section{Aquisição e Organização dos Dados}

De forma análoga às metodologias existentes na literatura, na metodologia proposta, foram identificados e analisados principalmente, os problemas de perfuração associados às condições de instabilidade de poços, tais como, fechamento do poço, arrombamentos, repasses, arrastes (na descida como na retirada da coluna durante a perfuração), peixe no poço e topadas.

Dado que o procedimento de levantamento de dados seria aplicado de igual forma em todos os poços analisados, optou-se por apresentar a aplicação da metodologia proposta ao poço direcional P-004, os demais resultados serão apresentados no apêndice deste trabalho.

\section{2. \\ Análises dos Dados}

A análise dos dados de perfuração foi subdividida em quatro etapas: Estudo dos BDP(s) dos poços disponíveis para a identificação dos problemas e eventos de instabilidade com o fim de realizar as análises Post-Mortem; levantamento do TNP gerado pelos problemas e eventos de instabilidade previamente identificados, análises de estabilidade no $\mathrm{SEST}^{\odot} \mathrm{e}$, por último, a modelagem tridimensional do campo.

\subsection{1. Identificação dos eventos de instabilidade e construção das curvas de acompanhamento dos poços}

Inicialmente, foi realizado nos $\operatorname{BDP}(\mathrm{s})$ o levantamento dos problemas e eventos de instabilidade cuja ocorrência, segundo a literatura consultada, pode estar relacionada à instabilidade dos folhelhos.

Neles, um controle de qualidade dos dados foi realizado, pois geralmente, os $\mathrm{BDP}(\mathrm{s})$ são elaborados por diversos técnicos que podem registrar um mesmo evento de perfuração de varias formas distintas.

Uma vez revisados os $\operatorname{BDP}(s)$, consideraram-se tanto problemas de instabilidade, os repasses por fechamento do poço e peixes no poço, quanto como possíveis eventos de sinais de instabilidade geomecânica, os repasses por 
condicionamento do poço, arrastes na descida e retirada das colunas durante a perfuração, e topadas das colunas de perfuração.

Para cada poço analisado, realizou-se o gráfico de profundidade versus tempo com o fim de reconstruir o histórico da perfuração que permita resaltar a influência da ocorrência dos problemas e dos eventos de instabilidade sob o desempenho da curva de avanço do poço.

Uma vez gerado esse gráfico, foi possível correlacionar esses eventos e problemas de instabilidade com as fases de perfuração, litologia, e profundidade onde esses ocorreram.

Em continuação se apresenta as análises realizadas ao poço P-004 como modelo de referencia para a construção do $M E M$, pois esse é um poço direcional no qual foram observadas à maioria das ocorrências dos eventos de instabilidade tal como o apresentado na Figura 4.2. Os gráficos obtidos para os demais poços serão apresentados no apêndice deste trabalho

Já na Figura 4.3, apresenta-se a correlação dos problemas e eventos de instabilidade com a litologia, o perfil caliper e com a trajetória do poço.

Na mesma figura, confirma-se a condição da instabilidade das paredes do poço na fase 12 1/4" devido aos constantes arrombamentos experimentados durante a perfuração Além disso, ressalta-se que a coluna litológica do trecho analisado esta composta basicamente por folhelhos.

A ocorrência destes arrombamentos evidencia uma condição de instabilidade das paredes do poço, a qual inevitavelmente está relacionada à trajetória direcional do poço, pois são gerados pela ação mecânica do contato da coluna de perfuração com a formação.

Segundo os registros no BDP, varias operações de repasse tiveram que ser realizadas para o condicionamento das paredes do poço devido à ocorrência desses arrombamentos, com o fim de evitar um possível risco de prisão das ferramentas de perfuração.

No entanto, devido à contínua manifestação da instabilidade no poço por meio da ocorrência dos arrombamentos, uma prisão da coluna durante a perfuração gerou um peixe no poço. 


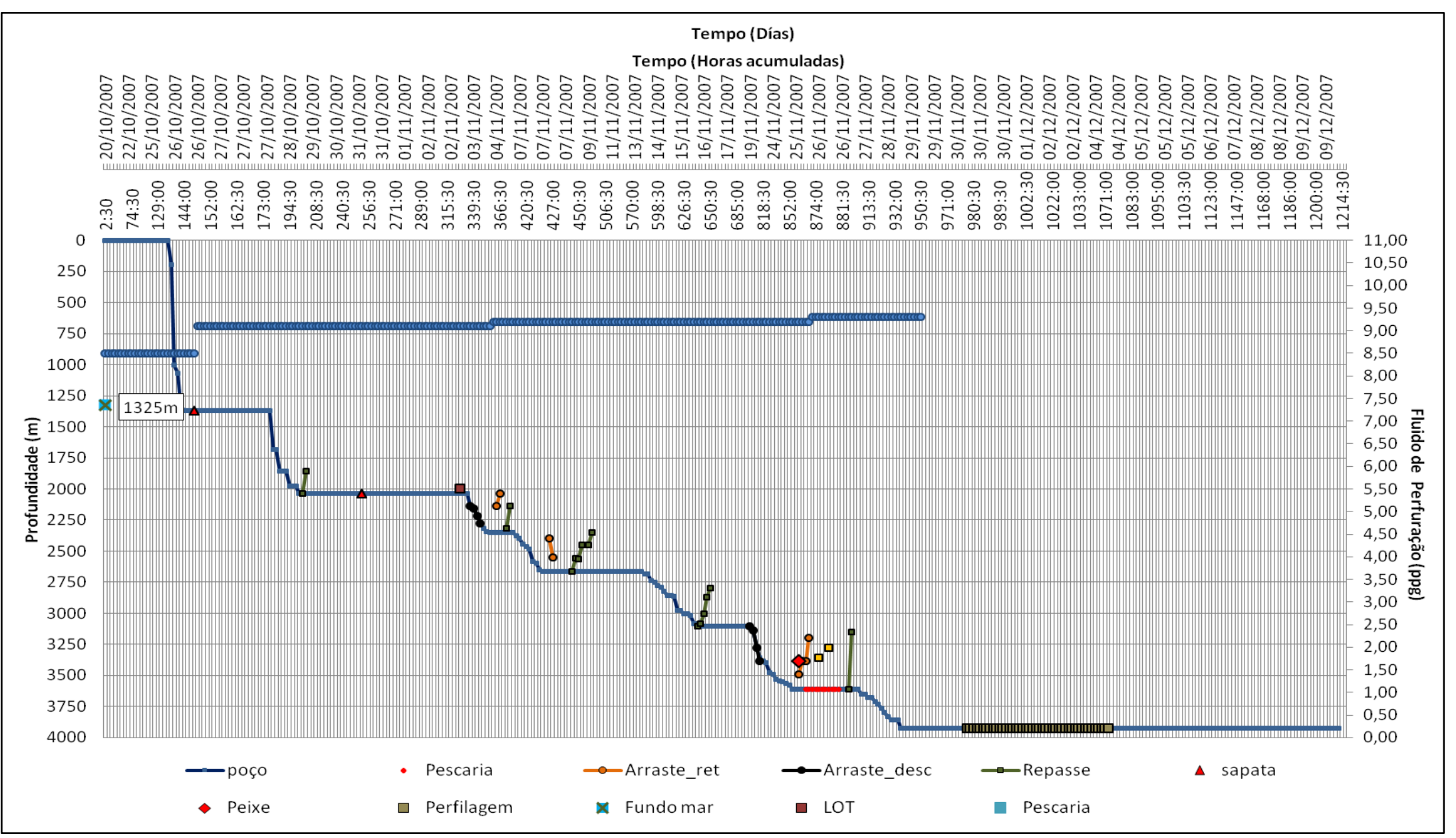

Figura 4.2 - Gráfico de Perfuração versus Tempo do poço direcional P-004. 


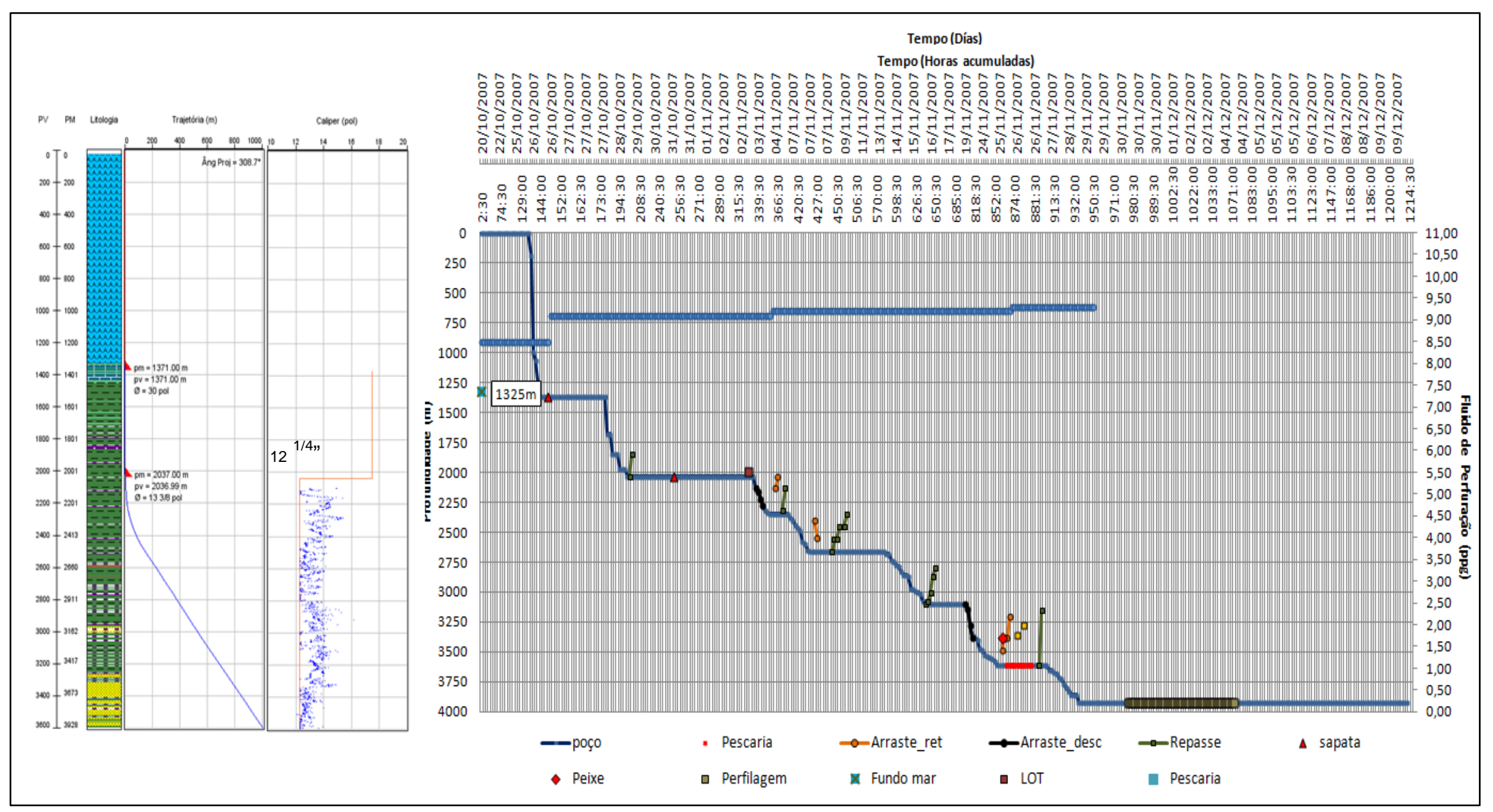

Figura 4.3 - Correlação da litologia, Trajetória, Perfil caliper e Gráfico de Profundidade versus Tempo do poço P-004. 
Uma análise complementar, para corroborar a influência de ganho de ângulo do poço na ocorrência dos problemas de instabilidade do poço P-004, é através do mapeamento desses ao longo da trajetória do poço.

Foi construído esse gráfico tal como o apresentado na Figura 4.4, observando que, a superposição dos problemas ao longo da trajetória do poço permite ter uma ideia das possíveis zonas de instabilidade em função da trajetória do poço P-004.

Nota-se na Figura 4.4 que, as operações de repasse foram realizadas ao longo de todo o poço, correspondendo principalmente às operações de condicionamento dos trechos onde ocorreram arrombamentos na medida que 0 poço se torna direcional.

Da Figura 4.4, também se pode concluir que a ocorrência do peixe no poço, consequência da prisão e quebra de uns dos componentes da coluna e perfuração, ocorreu durante um arraste retirando a coluna de perfuração, provocando que maiores esforços de arraste foram experimentados em várias tentativas com diferentes configurações de ferramentas de pescaria para retirar 0 peixe do poço.

Já no caso do arraste descendo a coluna de perfuração, esses aparecem à medida que o poço começa a ganhar ângulo em torno de $2037 \mathrm{~m}$.

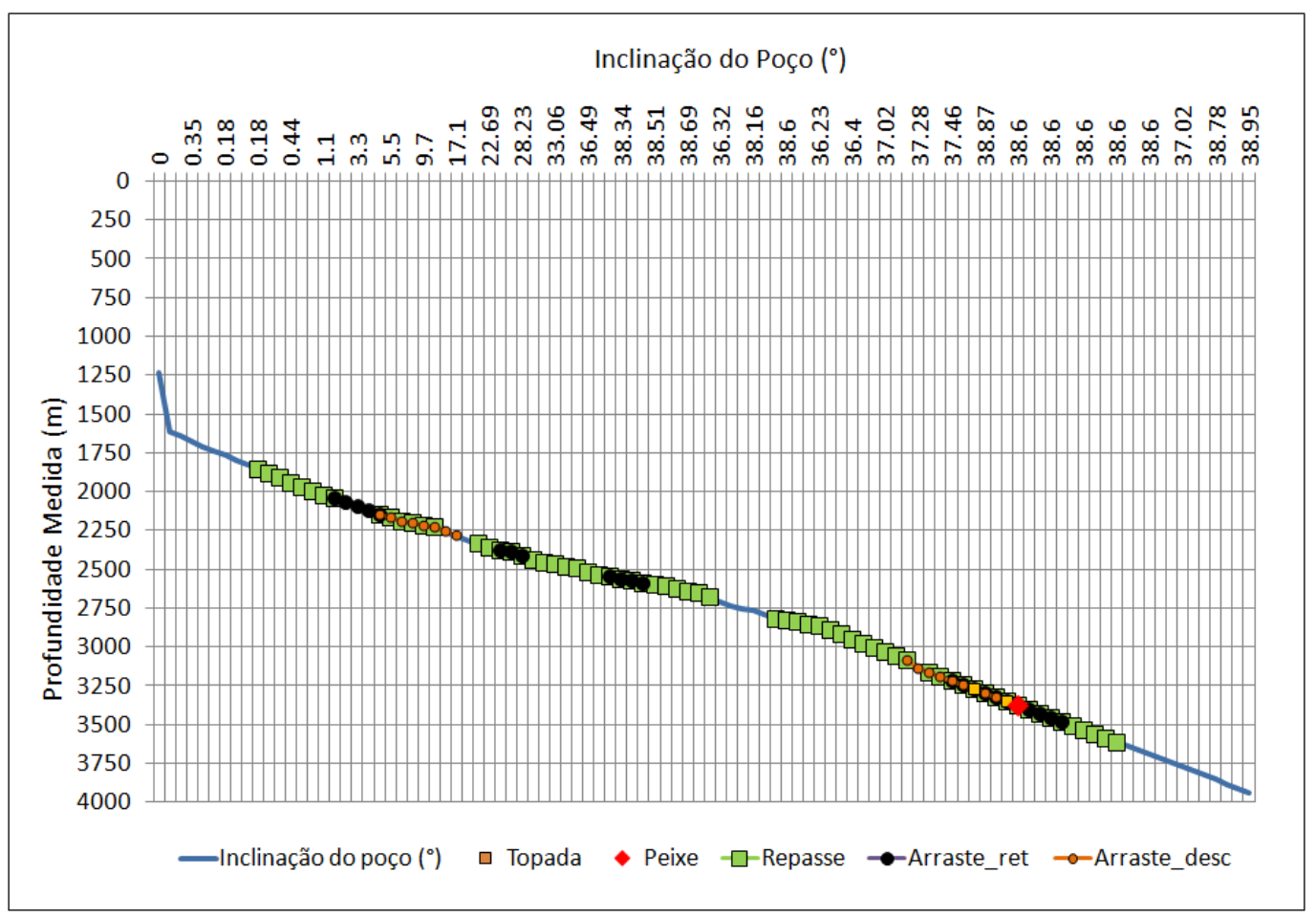

Figura 4.4 - Problemas de instabilidade ao longo da trajetória do poço P-004. 
Findas as análises dos eventos e dos problemas de instabilidade nos gráficos descritos acima, continuam-se as análises em função do TNP gerado por eles.

No entanto, considerou-se para a análise do TNP, apenas o tempo gasto pelos eventos e problemas de instabilidade pre-classificados acima, razão pela qual não se inclue o tempo gasto nas operações de avanço o manobra das colunas de perfuração.

Em função da pre-classificação dos problemas e eventos mencionados acima, foram construídos três gráficos de pizza.

Na Figura 4.5, no gráfico de pizza se discrimina a duração total em termos de horas acumuladas das atividades mais representativas durante a perfuração. Cada uma delas inclui um variado número de tarefas que contribuem com sua execução.

\section{Tempo de Perfuração Total do Poço P-004}

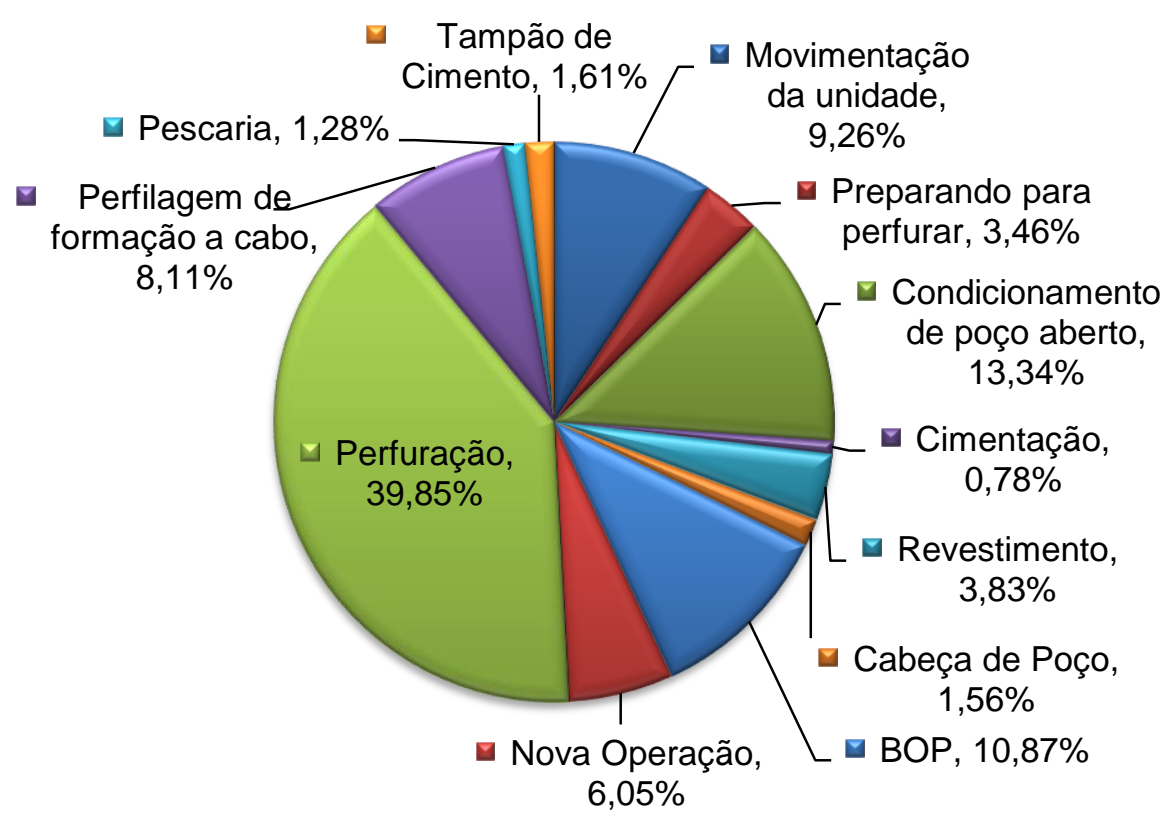

Figura 4.5 - Atividades principais do poço P-004.

No entanto, dado que o gráfico da Figura 4.6 engloba implicitamente tanto os tempos efetivamente operacionais (TO) quanto os TNP causados pelos problemas e eventos instabilidade geomecânica, é construído um segundo gráfico, para discriminar efetivamente em termos de horas acumuladas, esses tempos que fazem parte da perfuração, tal como apresentado Figura 4.6. 
TO (h) e TNP(h) do poço P-004

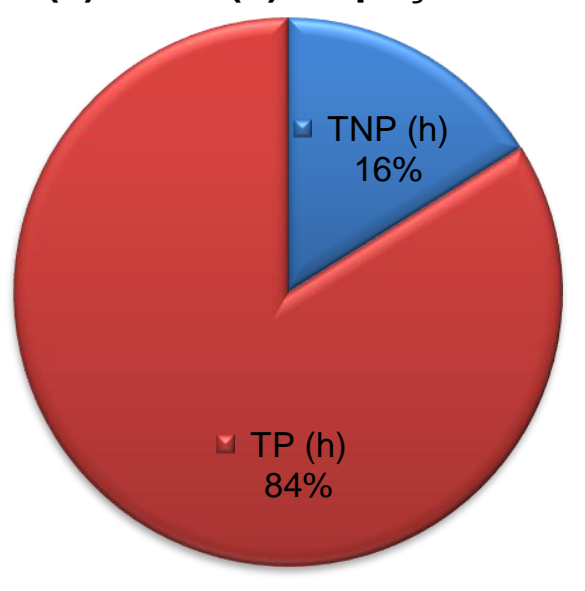

Figura 4.6 - Discriminação do Tempo efetivo operacional e do TNP do poço.

No entanto, devido a que nem sempre os problemas e eventos de instabilidade geomecânicos ocorrem em uma única fase da perfuração, o TNP causado por eles, deve ser representado em um terceiro gráfico de pizza que discrimine em detalhe a contribuição de cada um deles na geração do TNP total do poço. Na Figura 4.7 apresenta-se esse gráfico.

\section{TNP (h) nas atividades do poço P-004}

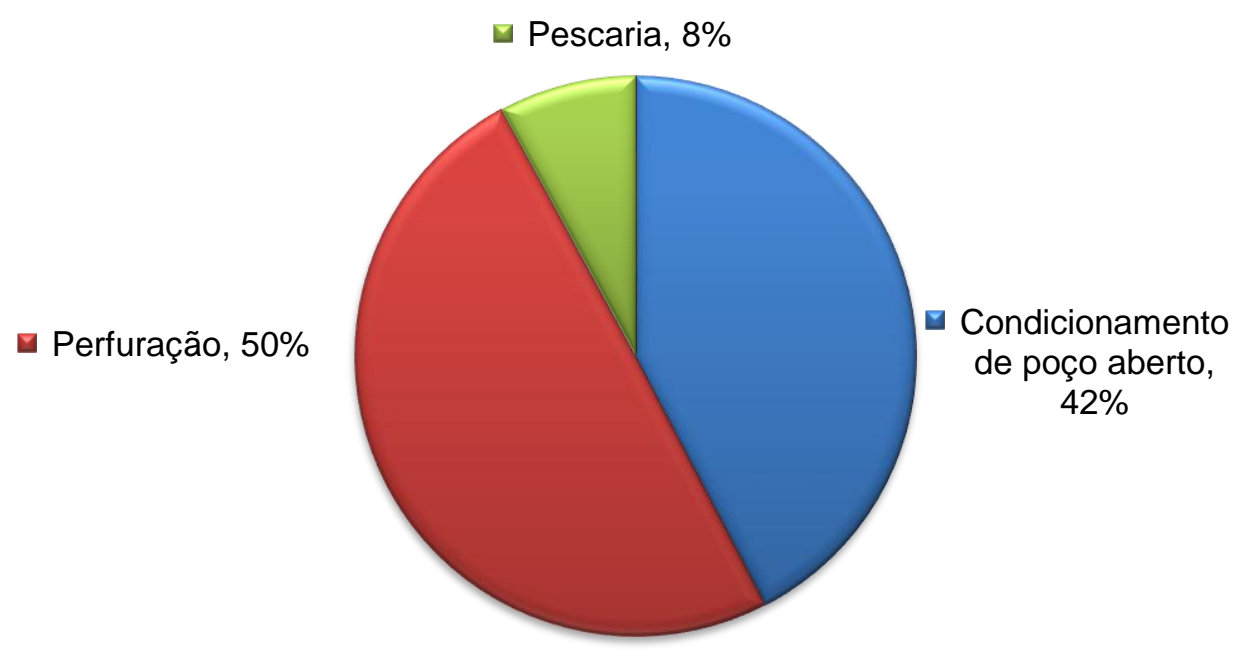

Figura 4.7 - Detalhe dos eventos de instabilidade que contribuem no TNP.

Uma última análise da informação contida nos BDP(s) foi realizada em un gráfico de Pareto para representar a frequência da ocorrencia de todos os eventos de instabilidade levantados dos $\operatorname{BDP}(\mathrm{s})$. 
Na Figura 4.8, apresenta-se os eventos de instabilidade que ocorreram no poço P-004. Cabe resaltar que foram contabilizadas as frequências das ocorrências dos repasses e arrastes por trecho e as topadas e o peixe no poço de forma pontual.

Da Figura 4.8 é possível identificar que os repasses são as operações mais frequentes no poço, como uma alternativa para o condicionamento do poço frente a uma condição de instabilidade geomecânica durante a perfuração do poço P-004.

Percebeu-se também que, no gráfico da Figura 4.8, é possível obter informações bastante úteis que permitem priorizar e tratar aqueles eventos considerados mais críticos, contribuído assim na melhora do desempenho das operações naquelas áreas identificadas como mais deficientes.

Frequência de problemas de perfuração no poço P-004

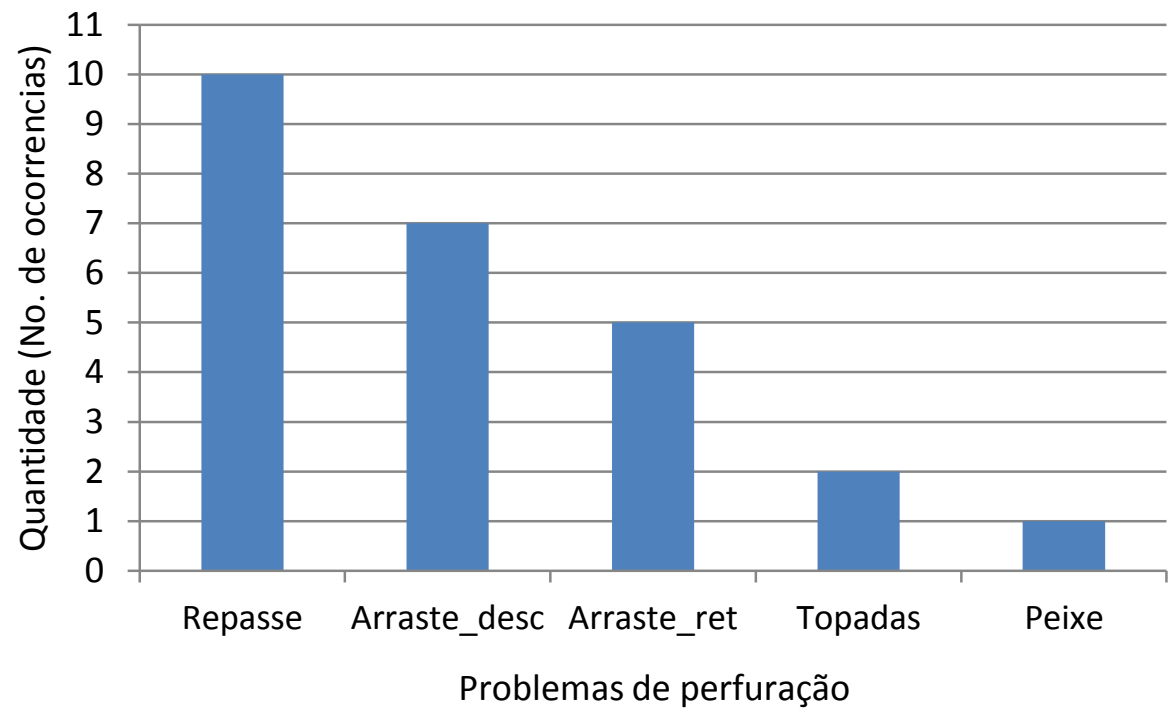

Figura 4.8 - Gráfico de Pareto poço P-004.

Esse gráfico de Pareto pode ser ainda mais representativo, quando analisado coletivamente segundo a ordem cronológica de perfuração dos poços, pois da comparação de resultados, podem-se identificar um comportamento padrão entre as ocorrências, verificando a aplicação o não de uma curva de aprendizado do campo. 
$\mathrm{Na}$ Figura 4.9 se apresentam os problemas de perfuração segundo a ordem cronológica dos poços analisados, com o fim de avaliar se houve o não a aplicação da curva do aprendizado do campo.

Frequência dos problemas de perfuração dos poços analisados

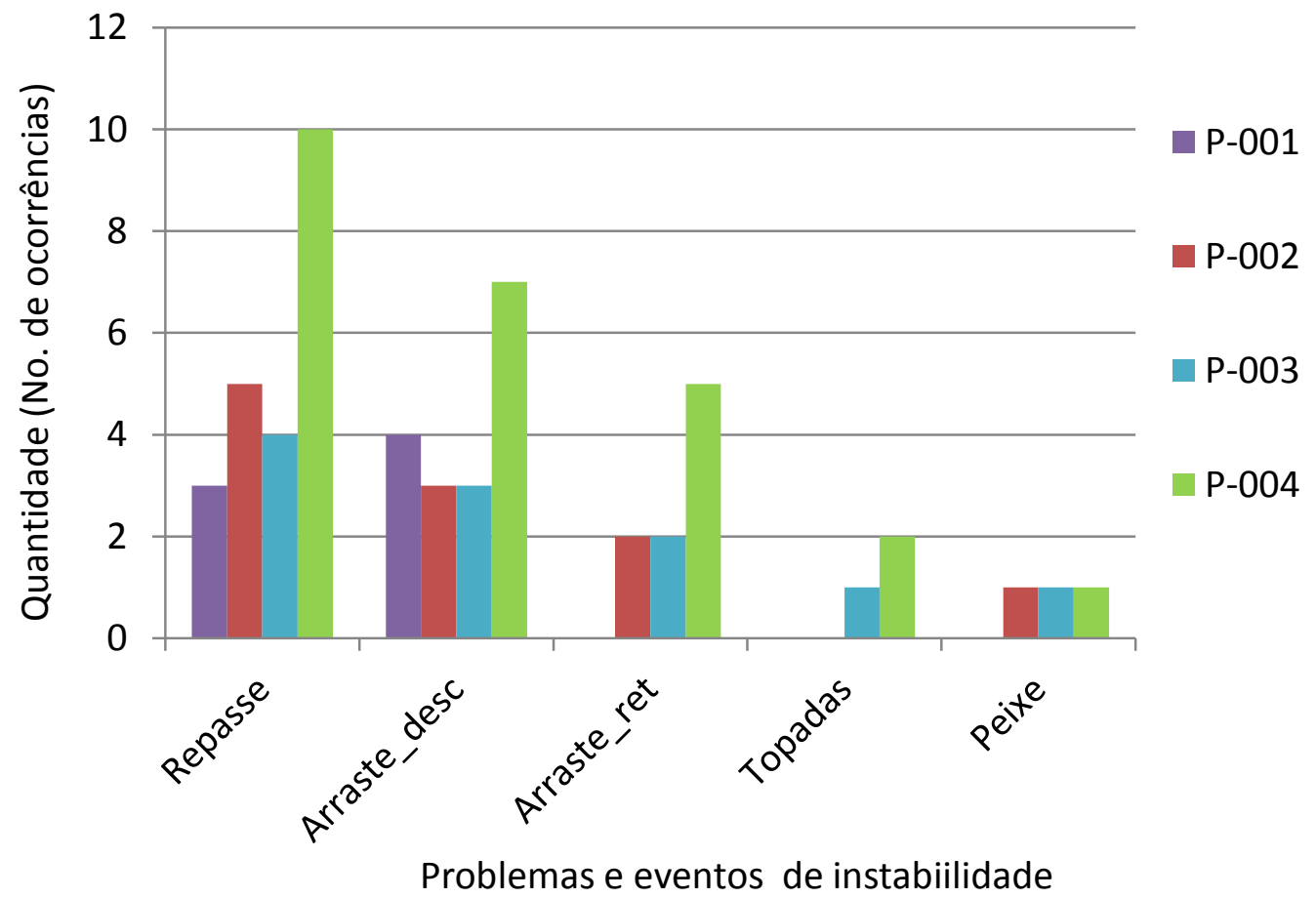

Figura 4.9 - Gráfico de Pareto dos poços analisados.

Nota-se na Figura 4.9, que os repasses e os arrastes descendo a coluna de perfuração são as operações mais frequentes. Como era esperado, no poço direcional, ocorreram mais operações de repasse em comparação com os poços verticais, dado que as condições do poço se tornam mais criticas em função da inclinação do poço.

Segundo os registros dos BDP(s), após experimentados arrastes descendo a coluna de perfuração foram realizadas operações de repasses, condição que é verificada no gráfico na Figura 4.9, pois tanto os arrastes descendo a coluna quanto os repasses apresentam quase a mesma frequência em termos de número de ocorrências. 
Findas as análises dos dados contidos nos BDP(s), realizou-se a análise das condições da estabilidade dos poços do estudo de caso, particularmente nas formações de folhelhos, considerando perfis sintéticos e aquelas correlações da literatura mais adequadas para os folhelhos.

A análise de estabilidade dos poços foi determinada seguindo a sequência de cálculo dos módulos estabelecidos na estrutura do software SEST ${ }^{\odot}$ em função dos perfis dos poços disponíveis, isto é, perfil Raios Gamma, perfis caliper, Perfil do Tempo de Transito, Perfil de Densidade da Formação, a partir dos quais, foram estimadas correlações para determinar os parâmetros necessários para gerar a janela operacional.

$\mathrm{Na}$ Figura 4.10, apresenta-se a janela de cálculos do módulo de perfis, na qual, da esquerda para direita está composta pela profundidade do poço, tanto vertical como medida, a coluna litológica, a trajetória, e os perfis sintéticos de tempo de trânsito, de Raios Gamma e caliper. Nota-se que o perfil de resistividade não foi criado, o que significa que para o cálculo do cálculo do gradiente de pressão de poros será usado o perfil de tempo de trânsito.

Nota-se na Figura 4.10, que os perfis mencionados começam a partir da sapata a $2037 \mathrm{~m}$ (cor azul), no entanto, foi realizado um ajuste de curva para obter a tendência do perfil desde o fundo do mar (cor vermelha).

$\mathrm{Na}$ mesma Figura 4.10, nota-se o comportamento suave e continuo do perfil Raios Gamma nas formações argilosas e o contraste com o comportamento perturbado na zona reservatório.

Nesta Figura 4.10, também é possivel correlacionar a coluna litológica, a trajetória e o perfil caliper para verificar uma vez mais que a trajetória influi na geração dos arrombamentos e que a maioria deles ocorreram em formações de folhelho evidenciando uma possivel condição de instabilidade.

$\mathrm{Na}$ Figura 4.12, apresenta-se os perfis sintéticos calculados a partir dos perfis de entrada. Oberva-se nessa figura que, efetivamente, o perfil de densidade aumenta ao longo da profundidade como produto da sobreposição das camadas subjacentes.

Já no perfil de densidade dos grãos, observa-se que a coluna litológica em sua maioria é composta por folhelho pois obteve-se um perfil quase constante em $2,75 \mathrm{~g} / \mathrm{cm}^{3}$, que corresponde aos folhelhos. Os valores menores da densidade dos grãos correspondem às outras litologias como marga, argilito e arenito principalmente.

Obteve-se um perfil quase constante do volume de argila nas formações impermeáveis como folhelho, marga e argilito em comparação com o trecho de 
reservatorio que diminui considerávelmente dado que a formação é básicamente permeável.

Nota-se também no perfil de porosidade, sua diminuição ao longo da profundidade o que é característico de um processo de compactação normal. 


$$
\text { F }
$$




$$
\text { I }
$$


Na Figura 4.12, dá-se inicio ao cálculo da sobrecarga no módulo de sobrecarga do SEST ${ }^{\odot}$.

Aqui a partir do perfil sintético do tempo de trânsito e usando a correlação de Gardner, foi estimado o perfil sintético de densidade a partir do qual foi calculado o gradiente de sobrecarga.

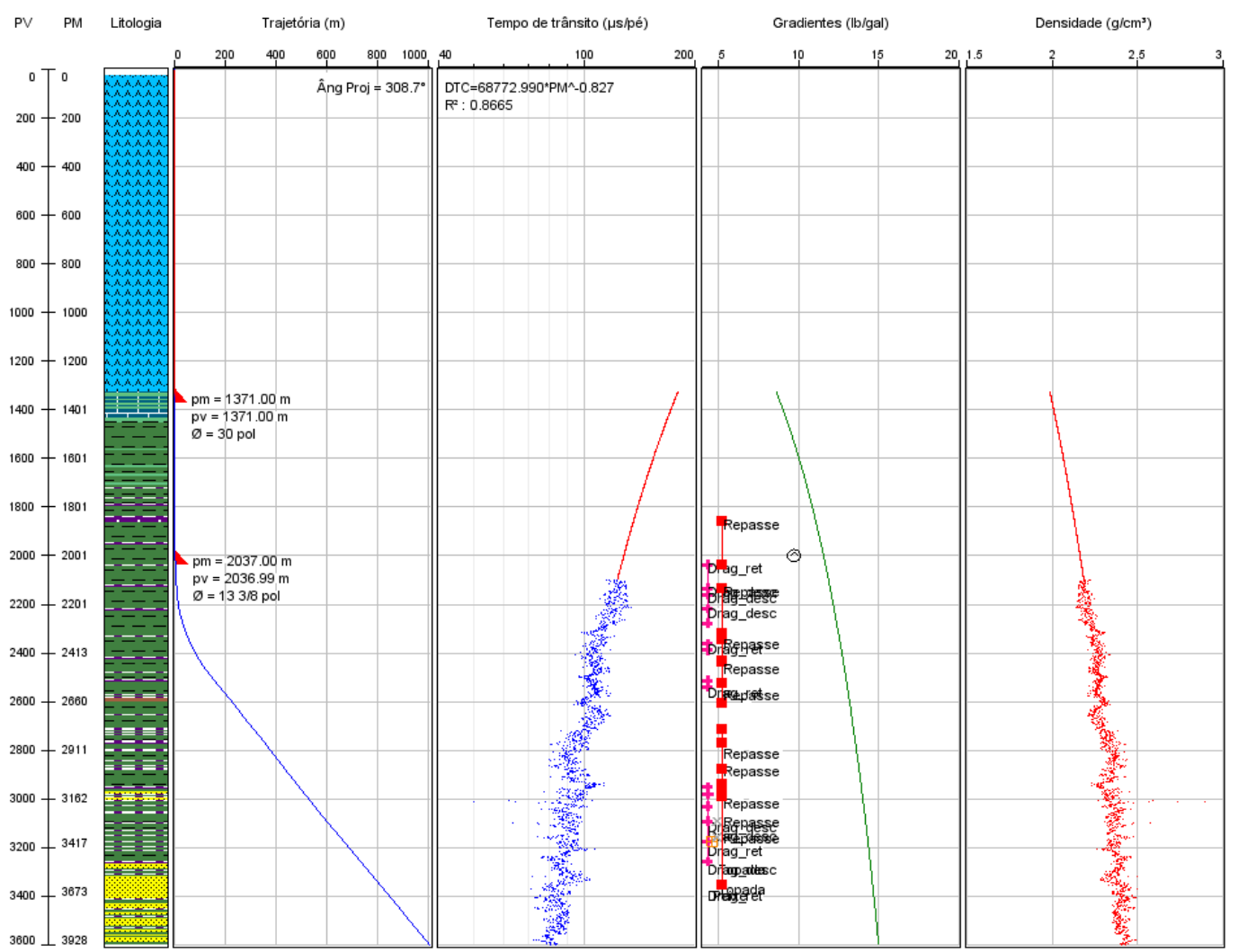

Figura 4.12 - Módulo de sobrecarga - Gradiente de sobrecarga do poço P-004.

Na Figura 4.13, calculou-se o gradiente de pressão de poros usando o método de Eaton em função do perfil de tempo de trânsito.

Note-se que foi criada uma réplica do perfil do tempo de trânsito chamada de tempo de trânsito-FLH com o fim de traçar sob este perfil, a linha de compactação normal para identificar uma possivel zona de subcompactação.

A linha de tendência de compactação traçada sob o perfil do tempo de trânsito nesse grafico semilogaritmico, tem um comportamento linear ao longo da profundidade, o que indica que a medida em que a profundidade aumenta diminui a porosidade, ou seja, há um comportamento de compactação normal no poço P-004. 


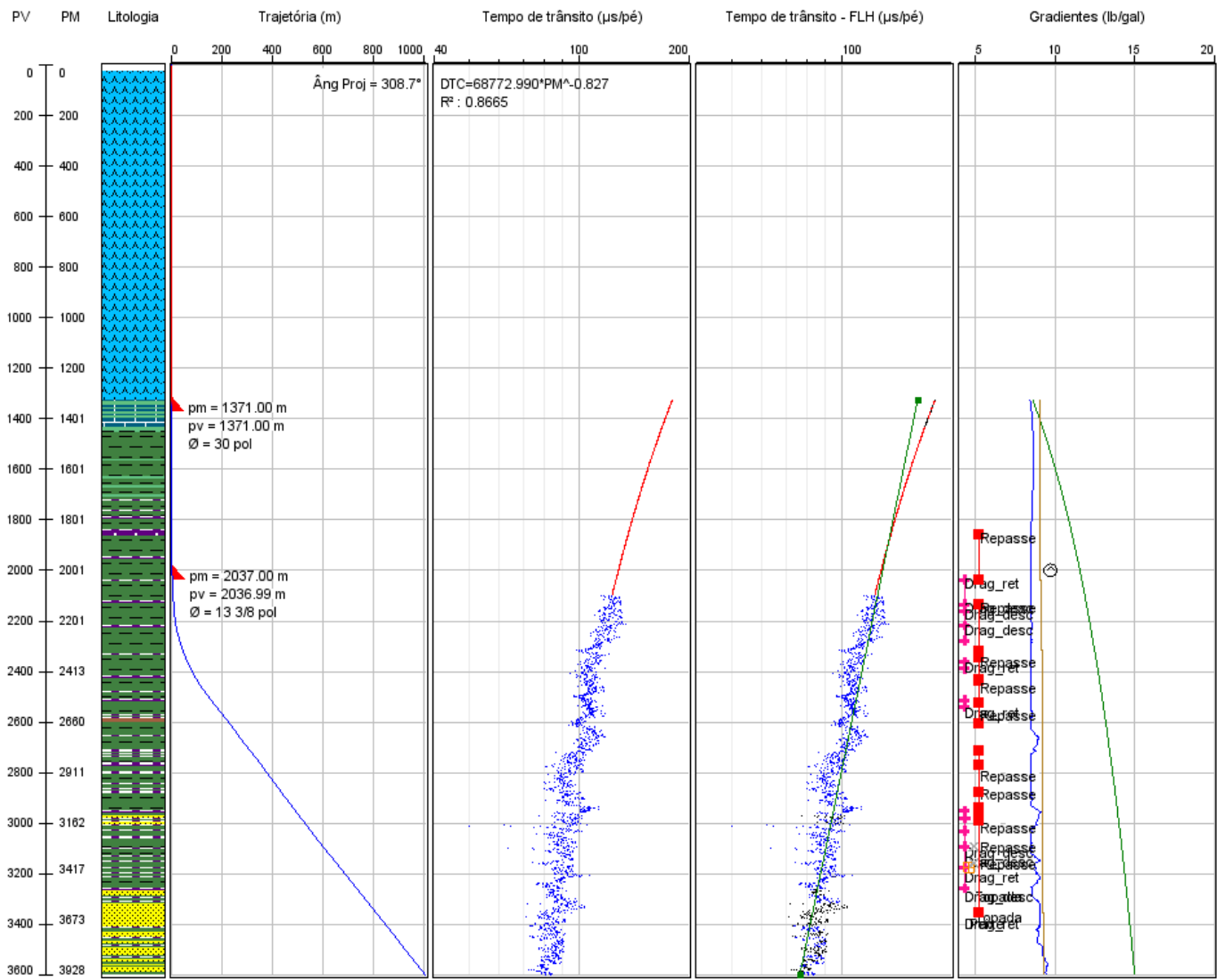

Figura 4.13 - Módulo de pressão de poros - Gradiente de pressão de poros poço P-004.

Nas figuras Figura 4.14, Figura 4.15 e Figura 4.16, apresentam-se os perfis das propriedades mecânicas das rochas perfuradas.

Como dado de entrada para os cálculos desses perfis, foi considerado um ângulo de atrito fixo de $30^{\circ}$ para todas as rochas perfuradas e um coeficiente de Biot igual a um, considerando a teoria da elasticidade. 


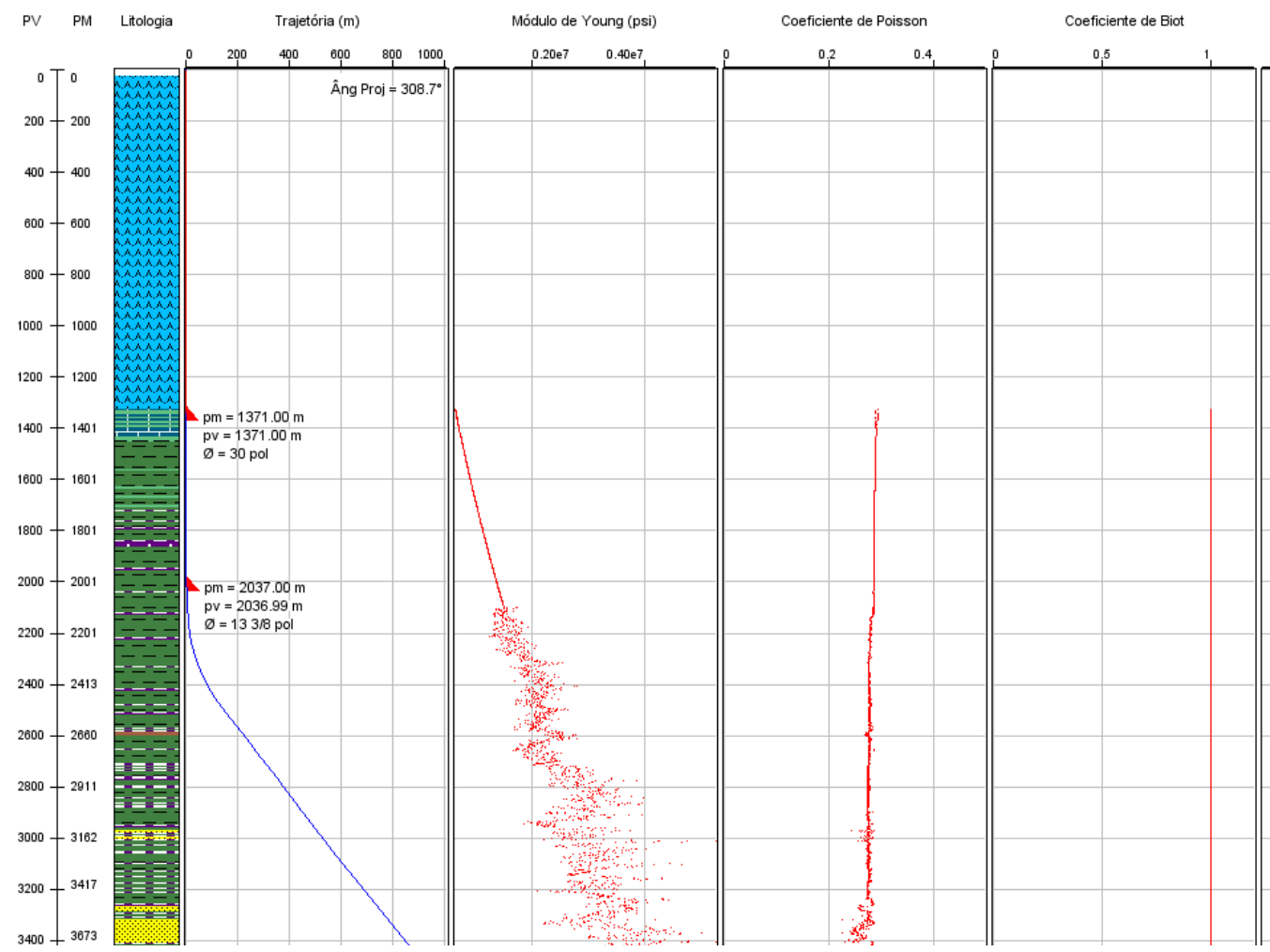

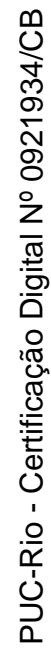

Figura 4.14 - Módulo de pressão de propriedades mecânicas - Propriedades mecânicas do poço P-004.

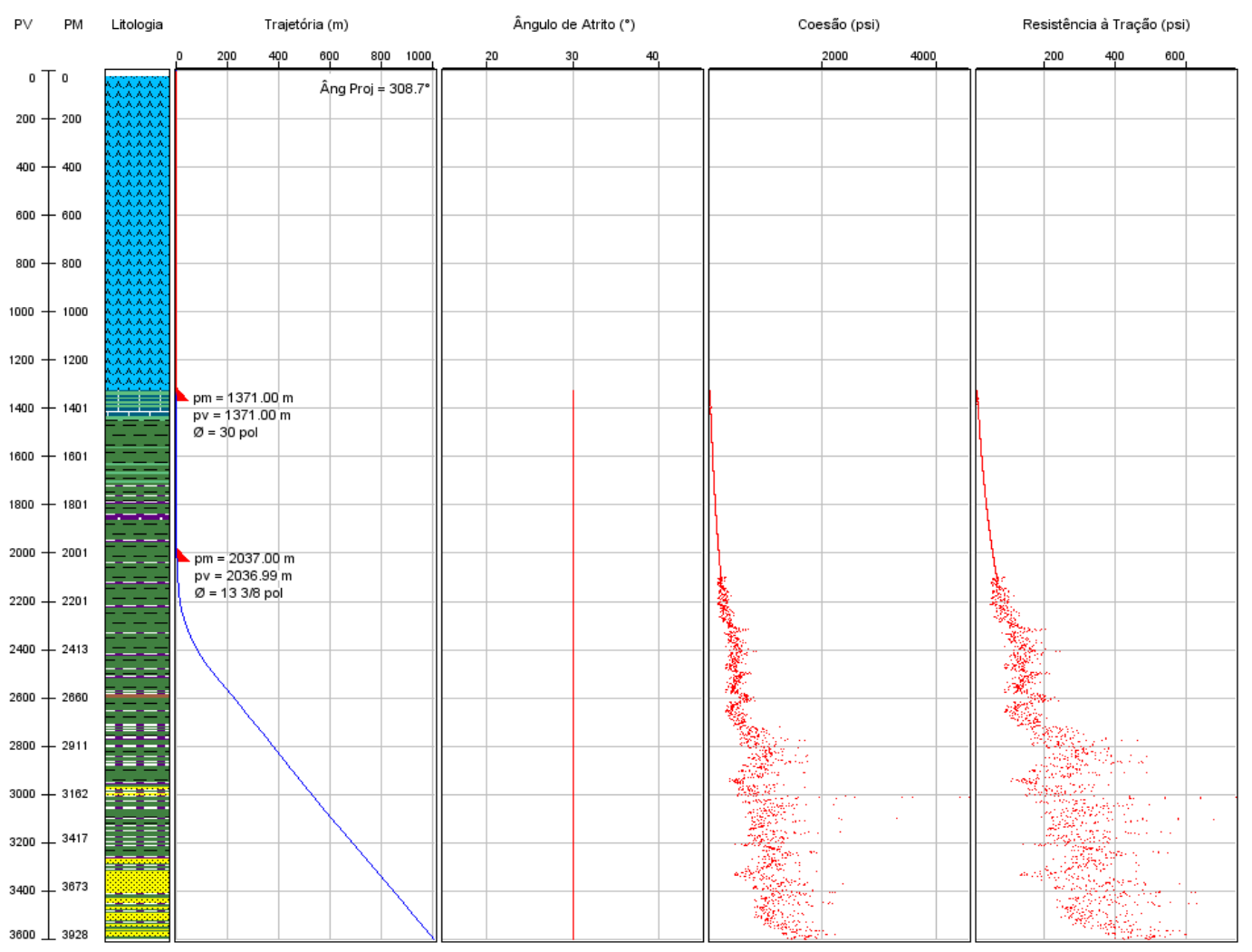

Figura 4.15 - Continuação Módulo de pressão de propriedades mecânicas - Propriedades mecânicas do poço P-004. 


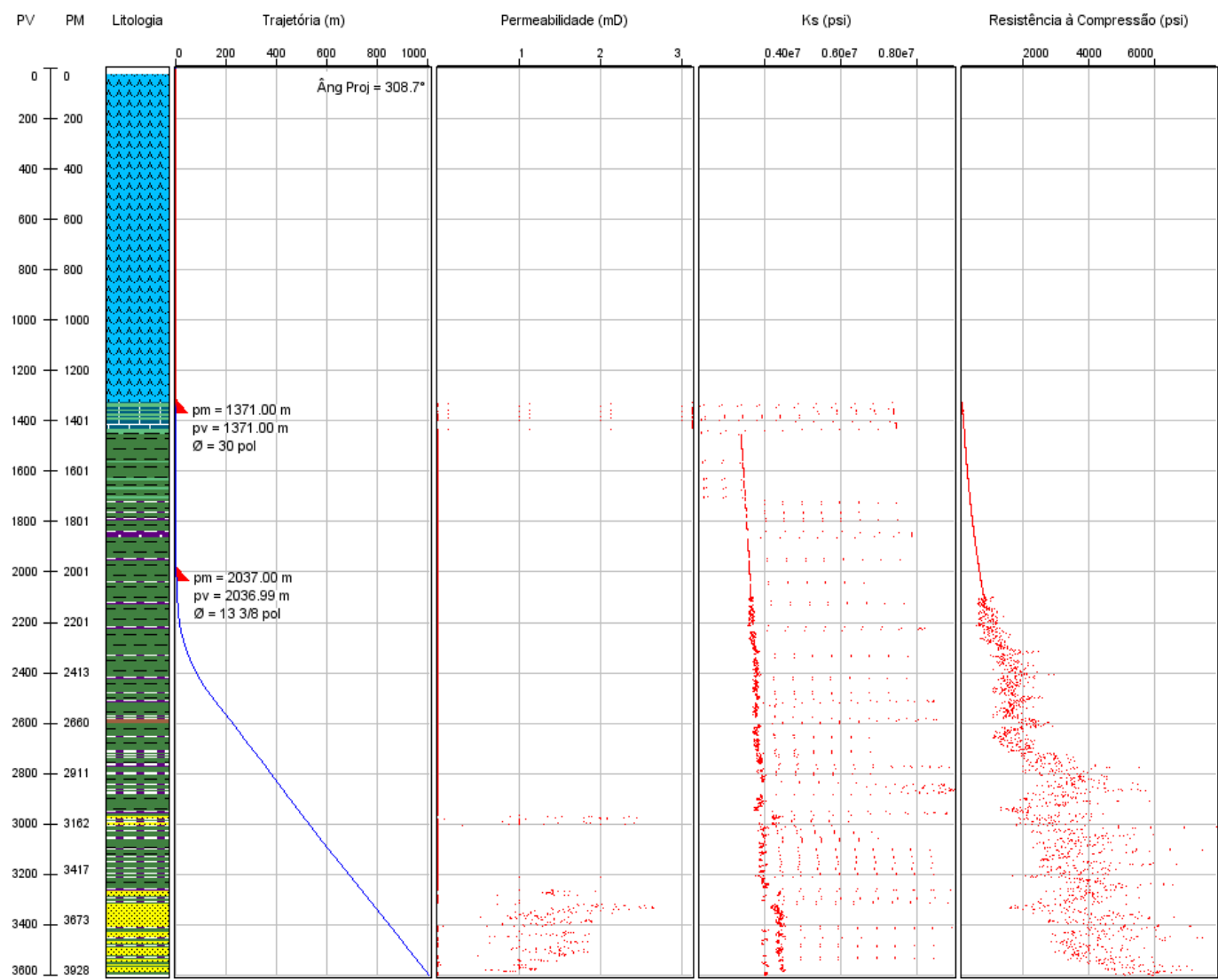

Figura 4.16 - Continuação Módulo de pressão de propriedades mecânicas - Propriedades mecânicas do poço P-004.

No módulo de tensões in-situ, obteve-se a estimativa das tensões horizontais in-situ considerando, a partir da teoria de elasticidade, a bacia como relaxada. O cálculo delas foi realizado em função do coeficiente de Poisson que estabelece a relação entre as tensões principais como resultado do confinamento na direção vertical, resultante da atuação da tensão de sobrecarga.

Foi levantado das informações do BDP do poço P-004, o dado de um LOT com absorção à profundidade de $2037 \mathrm{~m}$ o qual pode ser usado para a calibração da tensão horizontal mínima $\sigma_{h}^{\prime}$. No entanto, dado que o perfil da tensão horizontal mínima $\sigma_{h}^{\prime}$ passa justo pelo valor do LOT $=9,7$ ppg, evidencia uma boa estimativa desse perfil em função do coeficiente de Poisson e dado que o LOT foi com absorção, adota-se o perfil da tensão horizontal mínima ${\sigma^{\prime}}_{h}$ como o limite superior da janela operacional. 


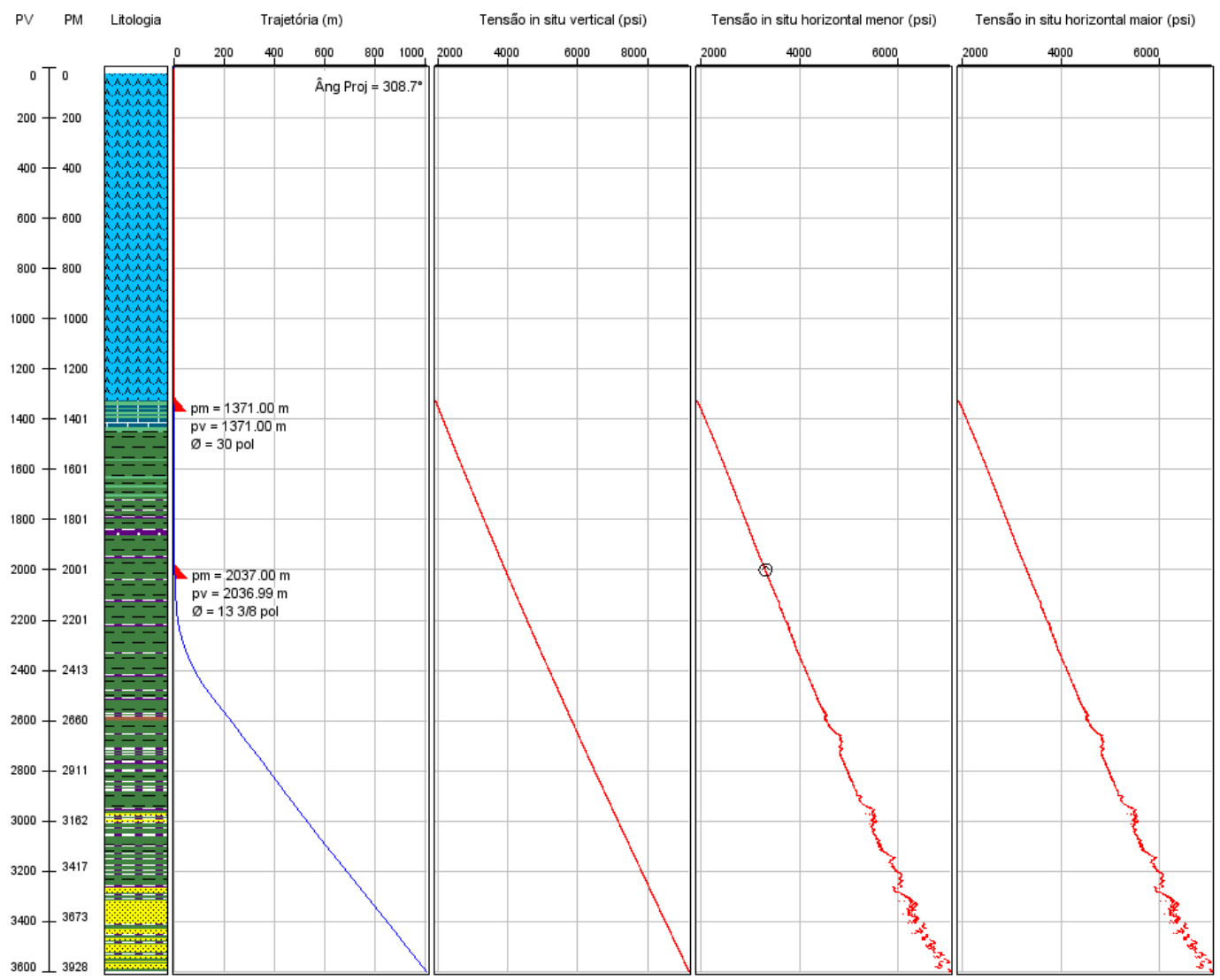

Figura 4.17 - Módulo de Tensões in-situ - Tensões in-situ do poço P-004.

Por último, no módulo de gradientes, obteve-se a determinação dos gradientes de colapso inferior, colapso superior, fratura os quais em conjunto com os gradientes de sobrecarga, pressão de poros e as tensões in-situ determinadas os módulos anteriores mais o peso do fluido de perfuração usado no poço P-004 geraram a janela operacional da Figura 4.18.

Plotaram-se também na Figura 4.18 todos os problemas e eventos de instabilidade levantados do BDP do poço P-004, os quais, correlacionados com o perfil caliper, trajetória e a litologia do poço confirmam uma vez mais a condição da instabilidade do poço P-004.

A retroanálise do poço $\mathrm{P}-004$ permitiu concluir que a janela operacional do poço usando um fluido de perfuração não penetrante, é delimitada entre o gradiente de colapso inferior e a tensão horizontal mínima $\sigma_{h}^{\prime}$ era mesmo muito estreita e que a densidade do fluido de perfuração era menor de que o gradiente de colapso inferior, o qual confirma a geração dos arrombamentos no poço e consequentemente dos problemas subsequentes, em sua maioria, de repasses e arrastes elevados da coluna de perfuração. 


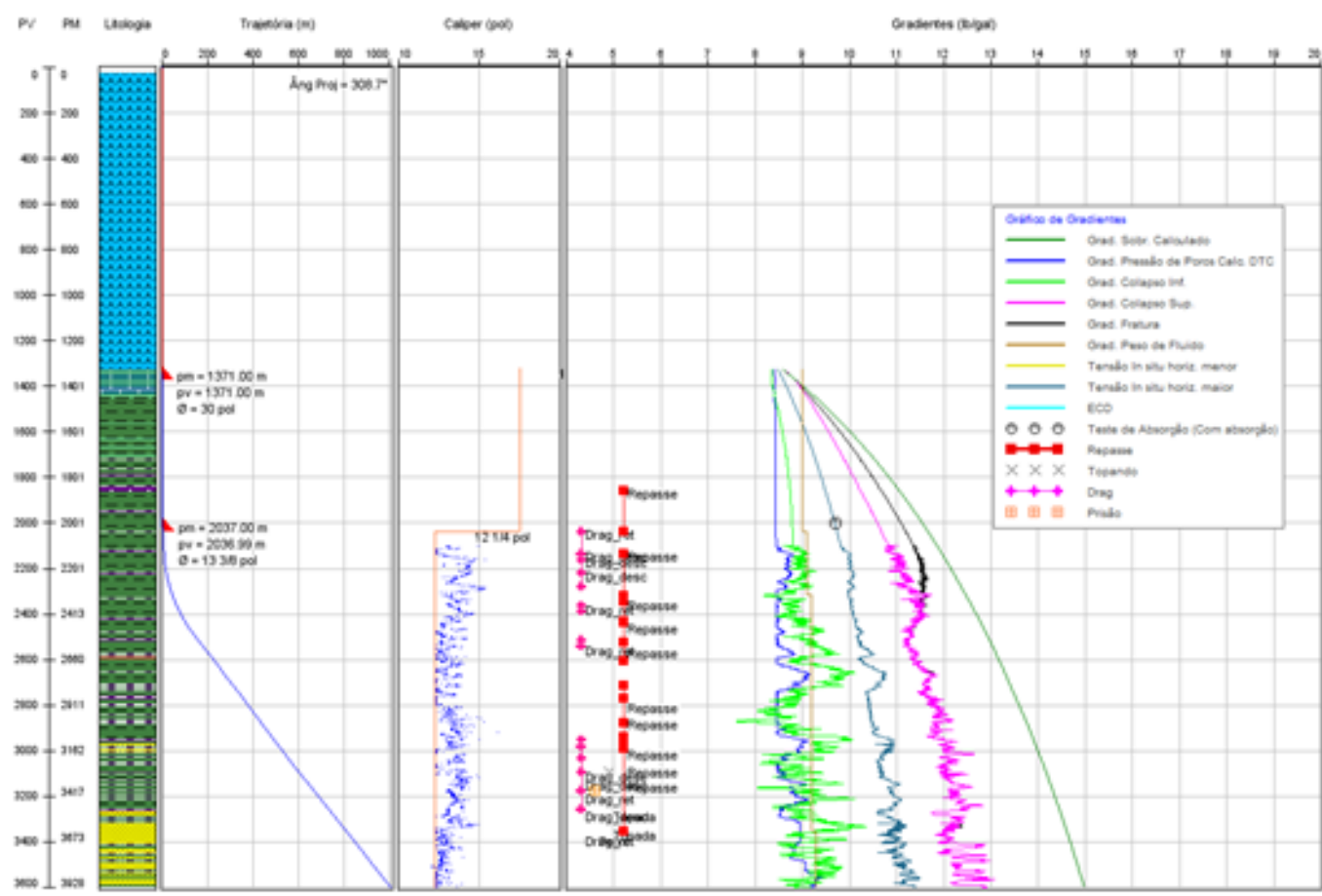

Figura 4.18 - Módulo de Gradientes - Janela Operacional do poço P-004.

A estrutura dos dados de entrada para o modelador PETREL ${ }^{\odot}$, foi dividida em três etapas: preparação dos dados brutos, lançamento dos dados para efetuar a análise bi e tridimensional da modelagem respetivamente.

Para o lançamento dos dados brutos, foram usados dois tipos de formatos de planilhas para a importação dos dados; para o caso de perfis foi usado o formato well logs, enquanto que, para a informação pontual foi usado o formato point well data format. Ambos os formatos foram utilizados tanto para os dados discriminados em contínuos e discretos.

Na Figura 4.19, apresenta-se o arquivo para a importação dos repasses do poço P-004 como dados discretos. Os valores atribuídos a cada repasse correspondem à contagem correspondente a cada dia da perfuração do poço começando no 20/10/2007 até o 10/12/2007 para um total de 52 dias.

Já na Figura 4.20, apresenta-se o arquivo para a importação dos arrastes descendo a coluna de perfuração do poço P-004 como dado contínuo. Neste arquivo, a cada trecho com arraste foi atribuído o valor da magnitude da força do arraste gerado pelo atrito entre a coluna de perfuração com as paredes do poço. 


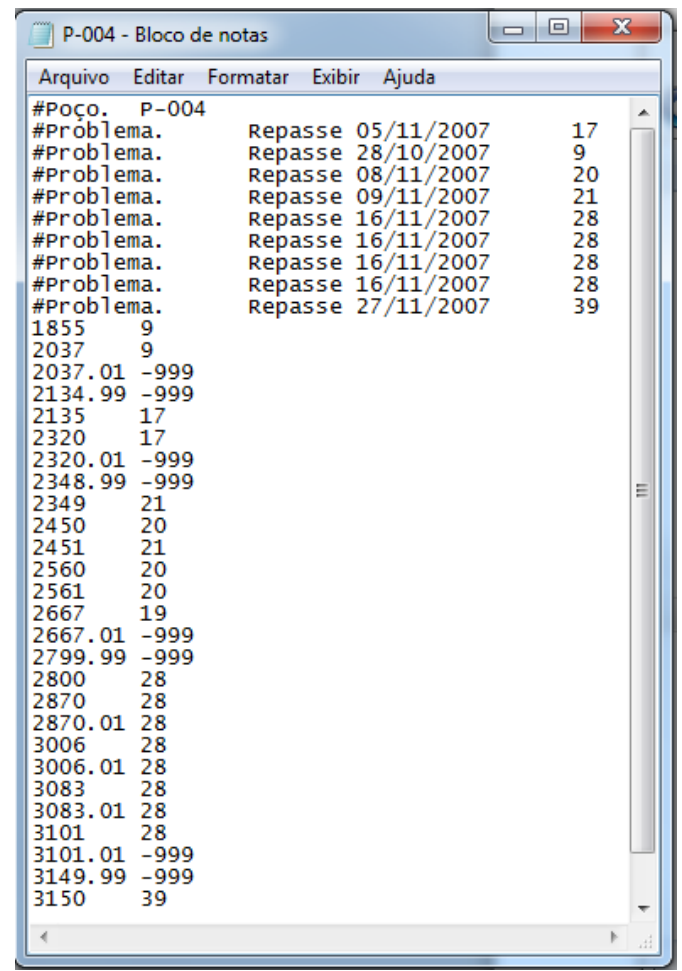

Figura 4.19 - Arquivo de importação dos repasses do poço P-004 como dado discreto.

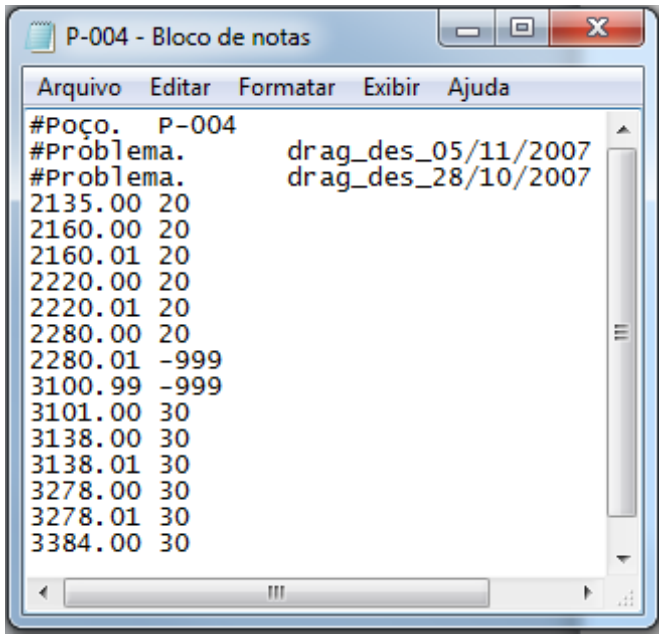

Figura 4.20 - Arquivo de importação dos arrastes descendo a coluna de perfuração do poço P-004 como dado contínuo.

Uma vez concluída a etapa de preparação dos dados brutos segundo o formato de importação do $\operatorname{PETREL}^{\odot}$, foi realizada a análise bidimensional.

$\mathrm{Na}$ Figura 4.21, em um ambiente bidimensional, optou-se por delimitar a área da modelagem tridimensional em função de dois horizontes estratigráficos até o momento conhecidos tais como: o horizonte do fundo do mar e o horizonte do fundo do poço, de forma a abranger representativamente o entorno do campo, com o fim de garantir uma boa cobertura das informações através de 
uma modelagem espacial como passo essencial de uma previsão de estabilidade dos poços.

Contemplando a possibilidade da interconexão dos eventos de instabilidade, e de posse os limites estratigráficos mencionados acima, foram traçados horizontes intermediários em função da litoestratigrafia dos poços, que compreende o uso da continuidade lateral das rochas ou o conjunto delas para definir automaticamente seções geológicas entre eles, que possam de alguma forma contribuir com as interpretações a serem feitas nos ambientes bi e tridimensionais a seguir.

Nesse contexto, foram identificadas quatro zonas geológicas bem diferenciadas a certas profundidades, definidas como: zona inicial de intercalações de calcarenito e argilito, zona de folhelhos, zona de intercalações entre folhelho marga e siltito e, por último, a zona de rochas reservatório como arenitos.

Uma vez identificadas as principais zonas geológicas em comum dos poços, traçaram-se horizontes litológicos usando a ferramenta well tops, para correlacionar a ocorrência dos problemas e eventos de instabilidade com a litologia dos poços, com o fim de identificar sua possível ocorrência em trechos de folhelho.

Na Figura 4.21, apresentam-se a correlação entre os arrombamentos e a litologia dos poços em função dos horizontes estratigráficos.

Correspondentemente, na Figura 4.22 apresentam-se a correlação entre os repasses e os arrastes tanto na descida quanto na retirada da coluna de perfuração com a litologia dos poços em função dos horizontes estratigráficos. 


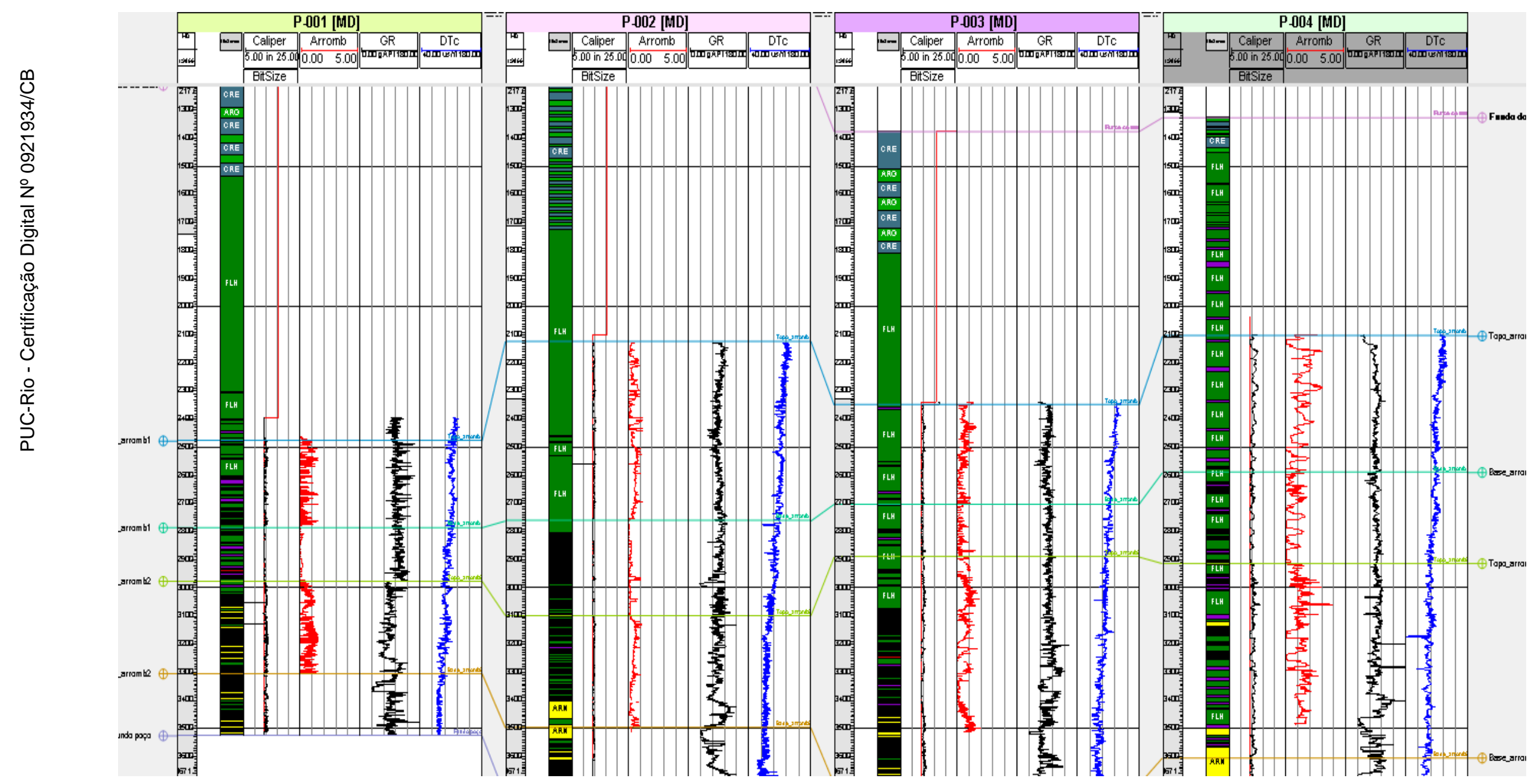

Figura 4.21 - Correlação entre os arrombamentos e a coluna litológica nos poços do estudo de caso a partir dos horizontes estratigráficos. 


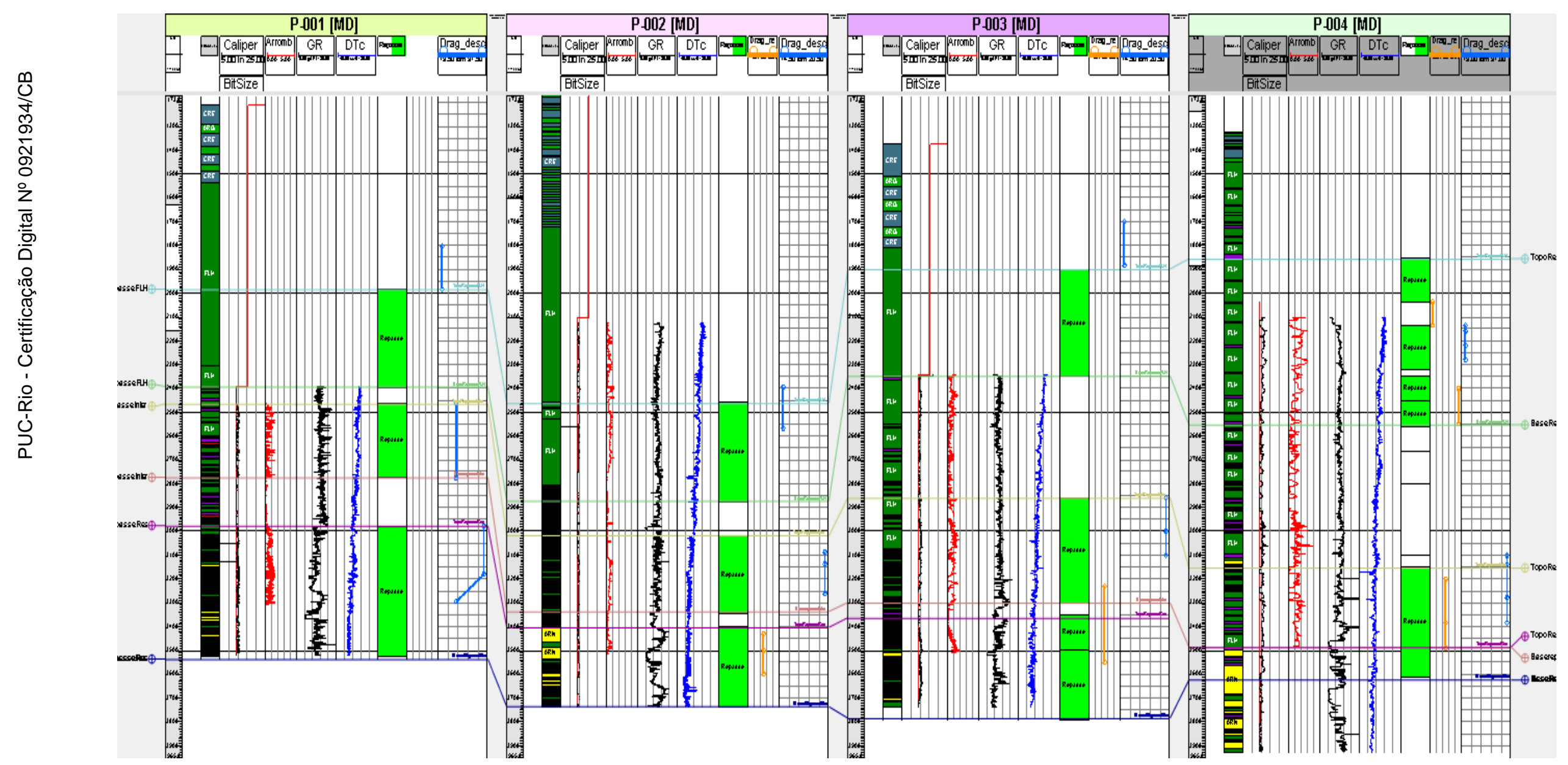

Figura 4.22 - Correlação entre os repasses e arrastes na descida e retirada da coluna de perfuração com a coluna litológica nos poços do estudo de caso a partir dos horizontes estratigráficos. 
Já na modelagem tridimensional foram definidos como o limite geométrico superior e o inferior do modelo as superfícies de fundo do mar e fundo do poço.

$\mathrm{Na}$ Figura 4.23 se apresenta a ocorrência dos arrombamentos ao longo dos poços.

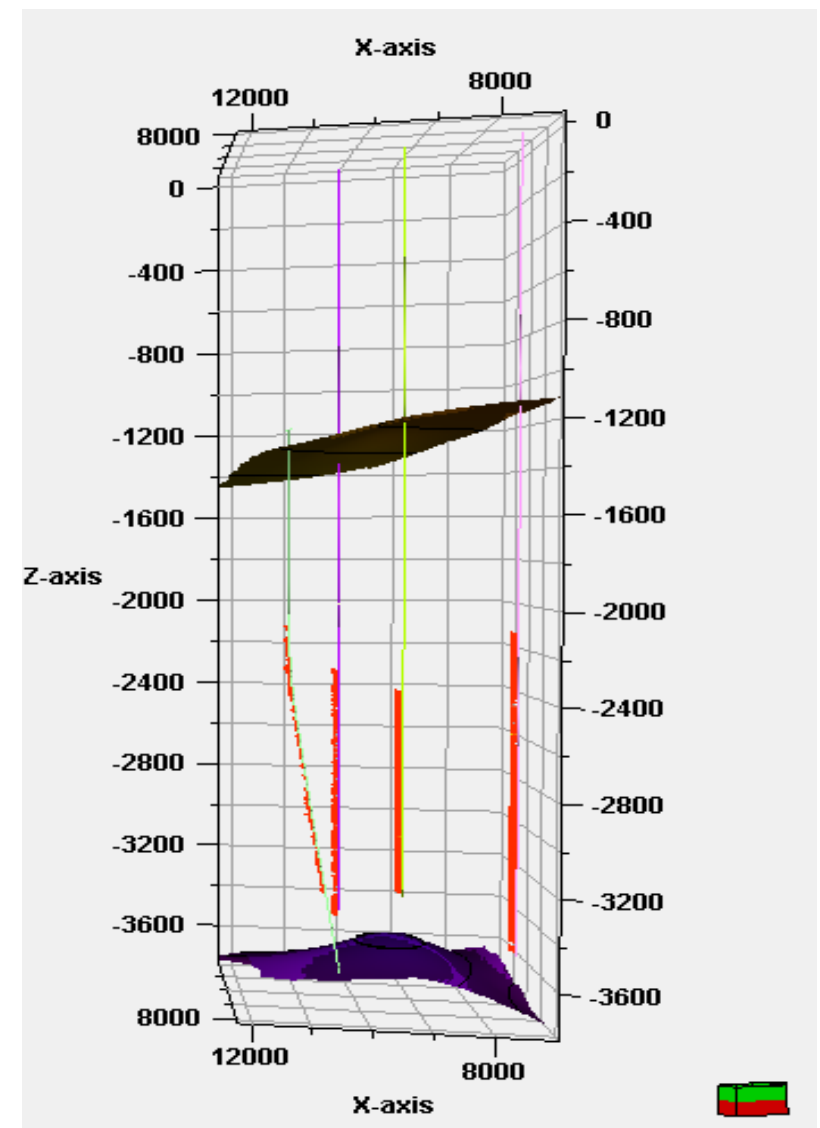

Figura 4.23 - Representação tridimensional dos arrombamentos nos poços do estudo de caso.

Já na Figura 4.24 se apresenta a representação tridimensional dos horizontes estratigráficos definidos na Figura 4.21 em função dos arrombamentos do poço.

Por último, na Figura 4.25 apresentam-se as zonas de instabilidade em função dos arrombamentos. 


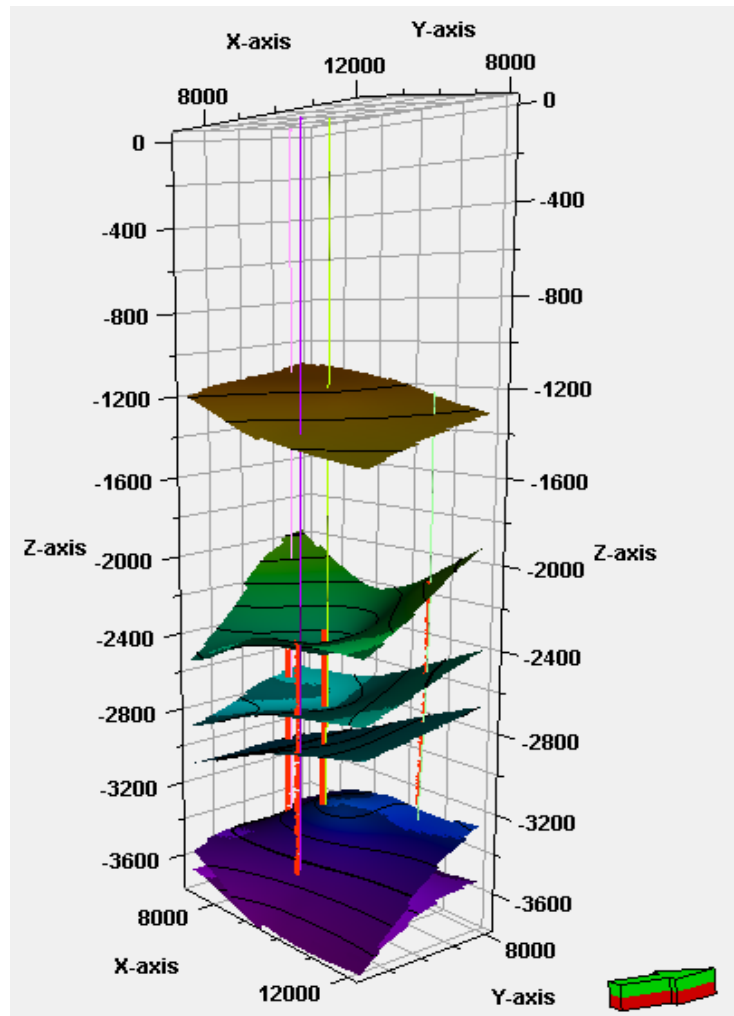

Figura 4.24 - Modelagem tridimensional dos horizontes litoestratigráficos em função dos arrombamentos nos poços do estudo de caso.

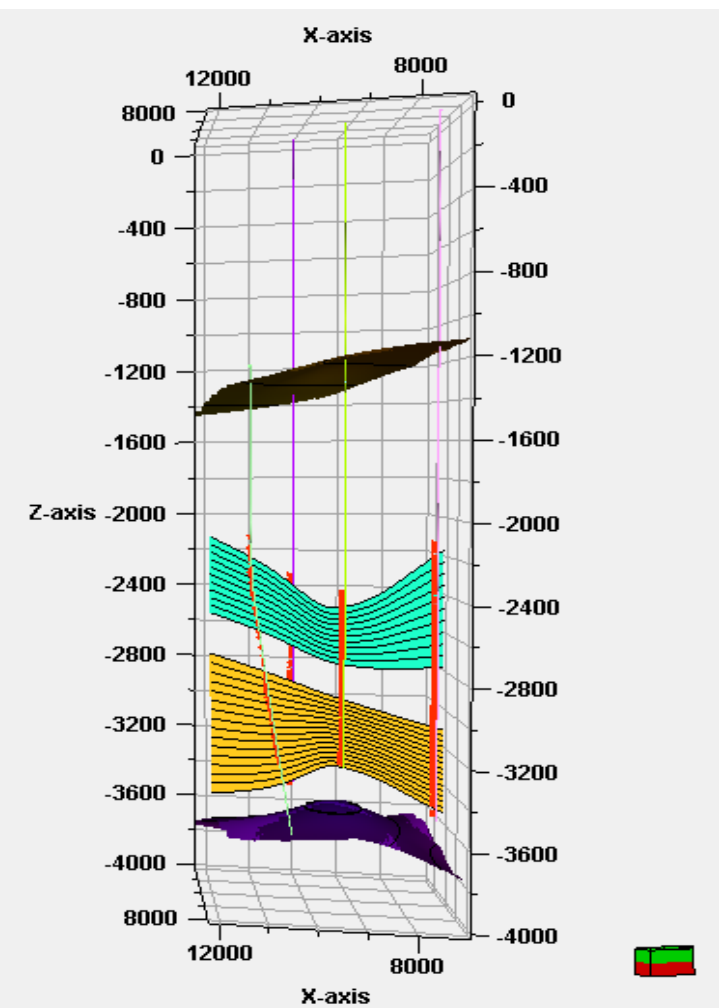

Figura 4.25 - Zonas de instabilidade em função dos arrombamentos dos poços do estudo de caso. 
A análise realizada para o tratamento dos arrombamentos foi realizada para o tratamento dos repasses no poço. Na Figura 4.26, apresenta-se a distribuição tridimensional da ocorrência dos repasses ao longo da trajetória dos poços do estudo de caso.

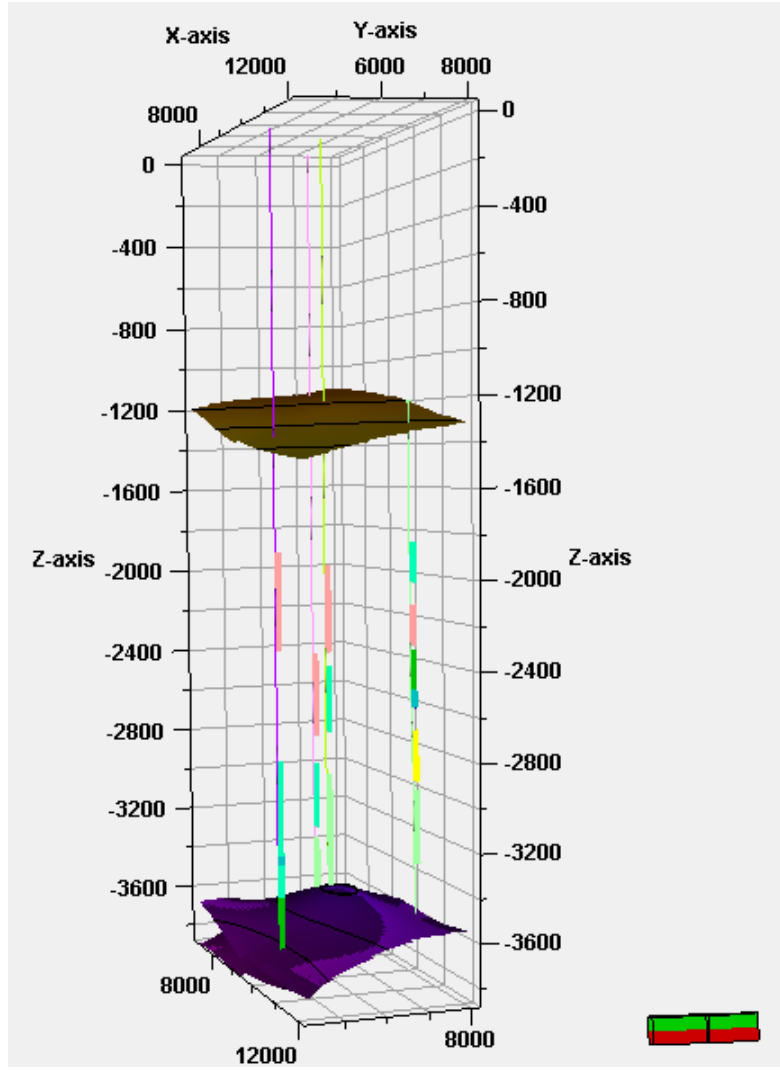

Figura 4.26 - Zonas de maior instabilidade em função dos repasses nos poços do estudo de caso.

Na Figura 4.27 se apresenta a representação tridimensional dos horizontes estratigráficos definidos na Figura 4.22 em função dos repasses do poço.

Por último, na Figura 4.28, são apresentadas as zonas de instabilidade em função desses repasses. 


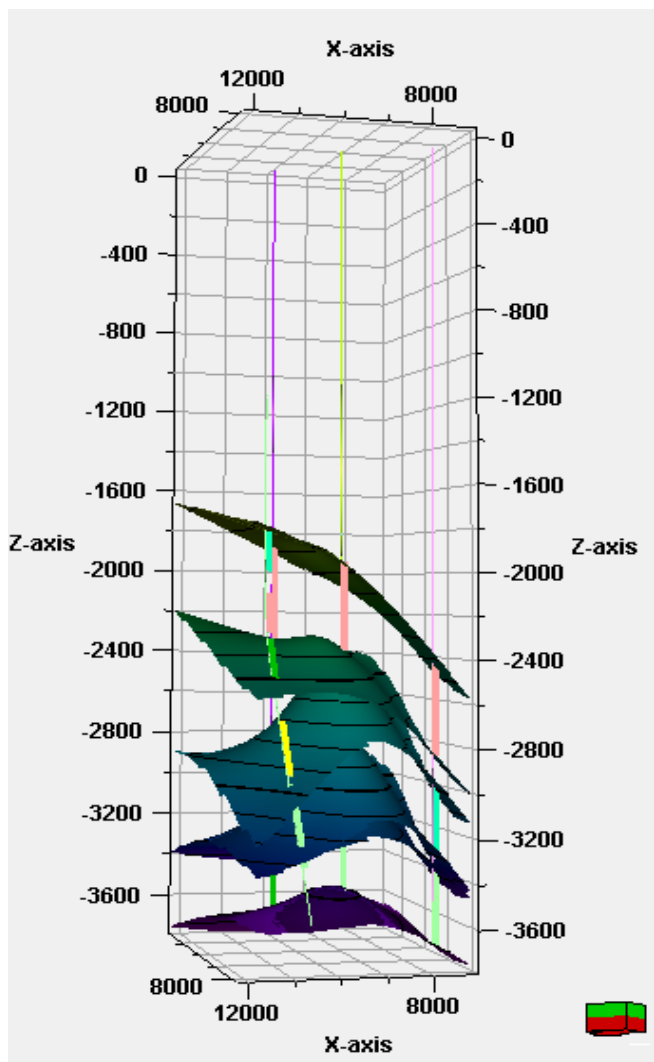

Figura 4.27 - Modelagem tridimensional dos horizontes litoestratigráficos em função dos repasses nos poços do estudo de caso.

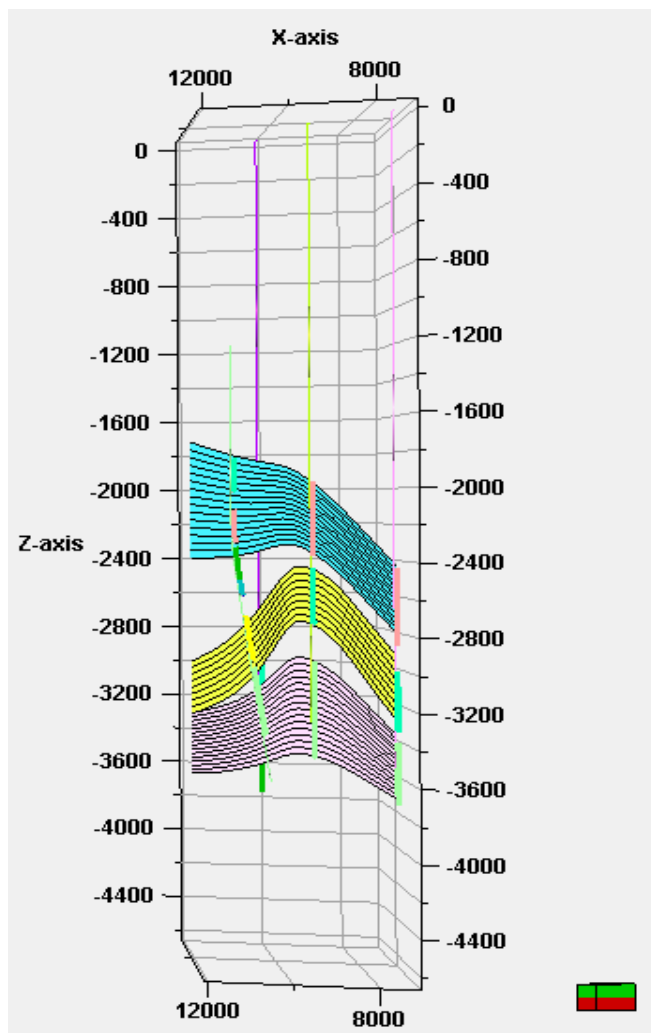

Figura 4.28 - Zonas de instabilidade em função dos repasses dos poços do estudo de caso.. 


\section{5. \\ Conclusões e sugestões.}

Inicialmente, diversos trabalhos consultados evidenciaram a relevância da análise dos dados de perfuração como fonte de conhecimento e aprendizado para elaboração de novos projetos.

Também foi possível confirmar através da revisão bibliográfica que, dependendo do nível de severidade dos problemas de instabilidade nos poços perfurados, nem sempre estes podem ser solucionados através de uma análise convencional de estabilidade, devido à falta do conhecimento geomecânico do campo. Assim, o MEM têm se convertido em uma ferramenta versátil para estimar a estabilidade dos poços e ajudar na redução dos riscos de perfuração.

Neste trabalho, a construção do MEM para estimar a estabilidade dos poços, particularmente nas formações de folhelhos, em função dos problemas e eventos de instabilidade identificados dos $\operatorname{BDP}(\mathrm{s})$, foi representativa o suficiente para avaliar as condições da estabilidade do campo de estudo em termos da possível ocorrência do fechamento do poço e de prisões da coluna de perfuração em função dos repasses arraste, topadas e peixe no poço devido a que podem evidenciar a ocorrência deles.

A reconstrução do histórico de perfuração individual dos poços por meio do gráfico da profundidade versus tempo em conjunto com os eventos e problemas de instabilidade, gerou informações vitais para análises de estabilidade de poços para identificar, onde, quando, em que profundidades, atividades de perfuração e litologias esses tendem a ocorrer.

O mesmo gráfico pode ser ainda aprimorado, quando combinado com o perfil caliper, pois permite ter uma ideia clara das condições da estabilidade paredes dos poços, o qual auxilia na compreensão das causas e consequências da ocorrência destes eventos de instabilidade com relação aos folhelhos.

No gráfico de Profundidade versus Inclinação verificou-se o efeito do ganho de ângulo como possível fator de instabilidade (poço direcional).

O gráfico de Pizza para as análises do TNP apresentou-se bastante satisfatório uma vez que permitiu discriminar de forma total e detalhada a fração correspondente ao TNP causado pelos eventos e problemas de instabilidade em termos de horas acumuladas. 
O gráfico de Pareto permitiu estimar quantitativamente a frequência dos eventos e problemas de instabilidade, identificando a execução dos repasses como as principais operações para o condicionamento dos poços devido a uma evidente condição de instabilidade geomecânica durante a perfuração dos mesmos.

Do mesmo modo, do gráfico de Pareto é possível obter informações úteis para priorizar o tratamento de aqueles eventos considerados mais críticos, contribuindo assim, para a melhora do desempenho das operações naquelas áreas identificadas como mais deficientes.

Esse gráfico de Pareto pode ser ainda mais representativo, quando construído em função da frequência de todos os eventos e problemas de instabilidade segundo a ordem cronológica dos poços em estudo, pois, comparando a frequência das ocorrências, permite identificar um comportamento padrão entre elas, verificando a aplicação ou não de uma curva de aprendizado do campo.

A análise de estabilidade no $\mathrm{SEST}^{\odot}$ aplicada aos poços de correlação permitiu identificar que os problemas de perfuração observados estão relacionados às falhas por cisalhamento, devido à perfuração realizada em condições próximas ao limite da estabilidade, ou seja, perto do Gradiente de Colapso Inferior.

O estudo dos eventos e problemas de instabilidade dentro de um ambiente tridimensional auxiliou na caracterização do campo a partir da identificação das seções críticas de instabilidade delimitadas entre os horizontes litoestratigráficos.

Com base nas análises apresentadas, concluiu-se que uma das maiores contribuições às análises de estabilidade convencionais é a modelagem tridimensional do campo de estudo, pois permite que os eventos de instabilidade sejam correlacionados, validados e sintetizados com informações geológicas, geofísicas e estruturais através de uma distribuição espacial, destacando onde, quando, e por que eses problemas de instabilidade na formação tendem a ocorrer.

Por último, do procedimento até aqui executado, é estabelecido que uma colaboração mais estreita entre as experiências e os conhecimentos geomecânicos obtidos da modelagem geomecânica, permite avaliar a instabilidade do poço e adquirir o conhecimento geomecânico do campo, incorporados às lições aprendidas, às operações futuras de novos projetos de perfuração enquanto se mitigam os riscos operacionais garantindo a redução do TNP e, consequentemente, dos custos extras não projetados. 
Como sugestões para trabalhos futuros:

- Sugere-se à indústria, dentro do possível, que não se poupem esforços para compilar as informações geomecânicas de um campo em estudo por certo período de tempo, pois estas podem ser usadas na construção de um MEM.

- No possível, sugere-se a disponibilidade de perfis de imagens, pois estes fornecem informações muito importantes no que se refere ao entendimento e diagnóstico da origem da instabilidade dos poços, auxiliando na determinação das orientações das tensões principais.

- Aplicar técnicas que agilizem a busca das informações dos BDP(s) com o fim de transformar os dados gerados em informações que permitam caracterizar melhor os problemas no campo.

- Aplicar a metodologia proposta nesta dissertação a um poço de projeto, com o fim de validar as predições de estabilidade geradas pelo MEM, pois este deve ser capaz de reproduzir as falhas nos poços nos locais onde foram observadas nas experiências de perfuração passadas.

- Utilizar a modelagem geomecânica tridimensional de forma a aproveitar o potencial do modelo gerado. 


\section{6. Referências Bibliográficas}

AARRESTAD, T. V. Torque and Drag - Two Factors in Extended-Reach Drilling. Journal of Petroleum Technology, SPE 27491, 1994.

ADAMS, A.; GIBSON, C.; SMITH, R. G. Probabilistic Well-Time Estimation Revisited. SPE Drilling \& Completion, v. 25, n. 4, p. 472-499, 2010.

AL-WARDY, W. M.; PORTILLO, O. E. Geomechanical Modeling for Wellbore Stability during Drilling Nahr Umr Shales in a field in Petroleum Development Oman. International Petroleum Exhibition and Conference, 2010, Abu Dhabi. Proceedings... Abu Dhabi, UAE: Society of Petroleum Engineers, SPE 138214, 2010.

AMANI, M.; RAZMGIR, S. M.; KARIMI, H.; YOUSEFI, S. Using Drilling and Logging Data for Developing 1D Mechanical Earth Model for a Mature Oil Field to Predict and Mitigate Wellbore Stability Challenges. International Oil and Gas Conference and Exhibition in China, 2010, Beijing, China. Proceedings... Beijing, China: Society of Petroleum Engineers, SPE 132187, 2010.

ARAUJO, E. M. P.; CASALIS, D.; WARD, C. D.; SHERIDAN, J. Geomechanical Modeling Helps Designing the Wells in the Neuquen Basin, Argentina. Annual Technical Conference and Exhibition, 2009, New Orleans, Louisiana Proceedings... New Orleans, Louisiana: Society of Petroleum Engineers, SPE 124982, 2009.

ARAUJO, E. M. P.; WARD, C. D.; BRUDY, M.; ARAUJO, E. M. P.; SHERIDAN, J.; FERNANDEZ-IBANEZ, F.; MATEUS, D.; ALVARELLOS, J.; ALCALDE, R.; ORDONEZ, L. Y.; CARDONA, F. Drilling Optimization Using 3D Geomechanical Modeling in the Llanos Orientales Basin, Colombia. Latin American and Caribbean Petroleum Engineering Conference, 2010, Lima, Peru. Proceedings... Lima, Peru: Society of Petroleum Engineers, SPE 138752, 2010.

ARÉSTEGUI, V. M. M. Avaliação experimental dos parâmetros de transporte em folhelhos. Dissertação de Mestrado. Departamento de Engenharia Civil, Pontificia Universidade Católica do Rio de Janeiro, Rio de Janeiro, 1999, p. 2543.

AZEVEDO, M. S. Análise geomecânica aplicada à análise de estabilidade de poços. Projeto de Graduação. Curso de Engenharia de Petróleo, Universidade Federal do Rio de Janeiro, Rio de Janeiro, 2011.

BELASKIE, J. P.; MCCANN, D. P.; LESHIKAR, J. F. A Practical Method To Minimize Stuck Pipe Integrating Surface and MWD Measurements. Drilling Conference, 1994, Dallas, Texas. Proceedings... Dallas, Texas: Society of Petroleum Engineers, SPE/IADC 27494, 1994. 
BRADLEY, W. B. Failure of inclined boreholes. Journal of Energy Resources Technology, p. 232-239; Trans., ASME, 101; 1979a.

BRADLEY, W. B. Predicting borehole failure near salt domes. The Oil and Gas Journal, p. 125-130; 1979b.

BELLOTTI, P.; GIACCA, D. Pressure evaluation improves drilling programs. The Oil and Gas Journal, 1978.

CAICEDO, H. U.; PRIBADI, M. A.; BAHUGUNA, S.; WIJNANDS, F. M.; SETIAWAN, N. B. Geomechanics, ECD Management and RSS to Manage Drilling Challenges in a Mature Field. In: OIL AND GAS INDIA CONFERENCE AND EXHIBITION, 2010, Mumbai, India. Proceendings... Mumbai, India: Society of Petroleum Engineers, 2010. SPE 129158

CARDOSO JUNIOR, J. V. L. Diagnóstico de problemas em poços direcionais durante as manobras. Dissertação de Mestrado. Departamento de Engenharia de Petróleo, Universidade Estadual de Campinas, São Paulo, 1992.

CERQUEIRA, J. P.: A metodologia de análise e solução de problemas. Equipe Grifo. 2ª . ed. Editora Afiliada. 1997, São Paulo/Brasil.

COATES, G.R.; DENOO, S. A. Mechanical properties program using borehole analysis and Mohr's circle. Society of Petrophysicists \& Well Log Analysts-SPWLA, 1981.

CHANG, C.; ZOBACK, M. D.; KHAKSAR, A. Empirical relations between rock strength and physical properties in sedimentary rocks. Journal of Petroleum Science and Engineering, v. 51, n. 3-4, p. 223-237, 2006.

CHEATHAM JR., J. B. Wellbore Stability. SPE Journal of Petroleum Technology, v. 36, n. 6, p. 889-896,1984.

CHEN, G. A study of wellbore stability in shales including poroelastic, chemical, and thermal effects. Doctor's Dissertation. Faculty of the Graduate School of the University of Texas at Austin, Texas, 2001, p.1-15.

CHIPINDU, N. S. CH. Pós-análise em problemas de perfuração de poços marítimos de desenvolvimento. Dissertação de Mestrado. Faculdade de Engenharia Mecânica e Instituto de Geociências, Universidade Estadual de Campinas, São Paulo, 2010, 113p.

DODSON, J. K. Gulf of Mexico 'trouble time' creates major drilling expenses. Offshore Magazine, v. 64, n.1, 2004.

DUPRIEST, F. E.; JR., W. C. E.; OTTESEN, S.; PASTUSEK, P. E.; ZOOK, J. R.; APHALE, C. Borehole-Quality Design and Practices To Maximize Drill-Rate Performance. SPE Drilling \& Completion, n. 06, 2011.

ECONOMIDES, M. J; NOLTE, K.G. Reservoir stimulation. Prentice-Hall, 1988.

FJÆR E., HOLT R. M., NES O., SØNSTEB $\varnothing$ E. F.; Mud Chemistry Effects on Time-Delayed Borehole Stability Problems in Shales; SPE/ISRM Rock Mechanics Conference, 2002, Irving, Texas. Proceendings... Irving, Texas: Society of Petroleum Engineers, SPE 78163-MS; 2002. 
FONTANA, H.; PARIS, J. M.; ONG, S. Borehole Stability (Geomechanics) Modeling and Drilling Optimization Practices Improve Drilling Curves in Naturally Fractured Shaleâ€"A South Argentina Experience. Middle East Drilling and Technology Conference, 2007, Cairo, Egypt. Proceedings... Cairo, Egypt: Society of Petroleum Engineers, SPE/IADC 107474, 2007.

GAGGIOTTI, K. V. B. Caracterização de folhelhos baseada em amostras de calha, testemunhos e interpretação de perfis. Dissertação de Mestrado. Departamento de Engenharia Civil, Pontificia Universidade Católica do Rio de Janeiro, Rio de Janeiro, 1999, 121p.

GALLANT, C.; ZHANG, J.; WOLFE, C. A.; FREEMAN, J.; AL-BAZALI, T. M.; REESE, M. Wellbore Stability Considerations for Drilling High-Angle Wells Through Finely Laminated Shale: A Case Study From Terra Nova. Annual Technical Conference and Exhibition, 2007, Anaheim, California. Proceedings... Anaheim, California: Society of Petroleum Engineers, SPE 110742, 2007.

GARCIA, O. C. C. Avaliação da influencia da interação rocha-fluido na estabilidade de poços. Dissertação de Mestrado. Departamento de Engenharia Civil, Pontificia Universidade Católica do Rio de Janeiro, Rio de Janeiro, 2003, p. 22-31.

GARDNER, G.; GARDNER, L.; GREGORY, A. Formation velocity and density: the diagnostic basis for stratigraphic traps. Geophysics, 1974, Tulsa, Okla. Proceedings... Tulsa, Okla, v.39, n.6, p. 770-780, 1974.

HORSRUD, P.; HOLT, R. M.; SONSTEBO, E. F.; SVANO, G.; BOSTROM, B. Time dependent borehole stability: Laboratory studies and numerical simulation of different mechanisms in shale. Rock Mechanics in Petroleum Engineering, 1994, Delft, Netherlands. Proceedings... Delft, Netherlands: Society of Petroleum Engineers, SPE 28060, 1994.

IDAGAWA, L. S. Estudo do diagnóstico de problemas na perfuração. Dissertação de Mestrado. Departamento de Engenharia de Petróleo, Universidade Estadual de Campinas, São Paulo, 1990, p. 11-41.

LAST, N.; PLUMB, R.; HARKNESS, R.; CHARLEZ, P.; ALSEN, J.; MCLEAN, M. An Integrated Approach to Evaluating and Managing Wellbore Instability in the Cusiana Field, Colombia, South America. Annual Technical Conference and Exhibition, 1995, Dallas, Texas. Proceedings... Dallas, Texas: Society of Petroleum Engineers, SPE 30464, 1995.

LEE, D.; CASSANELLI, J. P.; FRYDMAN, M.; PALACIO, J.; DELGADO, R.; COLLINS, B. Using a Dynamic Mechanical Earth Model and Integrated Drilling Team to Reduce Well Costs and Drilling Risks in San Martin Field. Annual Technical Conference and Exhibition, 2003, Denver, Colorado. Proceedings... Denver, Colorado: Society of Petroleum Engineers, SPE 84557, 2003.

MARCHESI, V. R. Modelagem geomecânica tridimensional de maciços rochosos para a análise bidimensional da estabilidade dos taludes de excavação da casa de força do AHE_Simplício. Dissertação de Mestrado. Departamento de Engenharia Civil, Pontificia Universidade Católica do Rio de Janeiro, Rio de Janeiro, 2008. p. 58-82. 
MCINTYRE, B.; DIXON, R.; MOHAMED, F.; BIRAN, V.; LIU, C.; ISLAM, S. A.; DONALD, J. A. Wellbore Instability in Forties: Diagnosis of Root Causes for Improved Drilling Performance Offshore Europe, 2009, Aberdeen, UK. . Proceedings... Aberdeen, UK: Society of Petroleum Engineers, SPE 124670, 2009.

MCINTYRE, B.; HIBBERT, E. D.; DIXON, R.; KEIR, D.; OROURKE, T.; MOHAMMED, F.; DONALD, J. A.; CHANG, L.; SYED, A.; BIRAN, V. Managing Drilling Risk in a Mature North Sea Field. Offshore Europe, 2009. Aberdeen, UK. Proceedings... Aberdeen, UK: Society of Petroleum Engineers, SPE 124666, 2009.

MENDOZA, J. A. Análise da estabilidade de poços verticais em formações rochosas. Dissertação de Mestrado. Departamento de Engenharia Civil, Pontificia Universidade Católica do Rio de Janeiro, Rio de Janeiro, 1987, p. 6-7.

MIURA, K. Método para aquisição e representação do conhecimento sobre procedimentos operacionais em serviços de completação de poços marítimos. Dissertação de Mestrado. Departamento de Engenharia de Petróleo. Universidade Estadual de Campinas, Campinas, 1991.

MIURA, K.; GUILHERME, I. R.; MOROOKA, C. K.; MENDES, J. R. P.: Processing Technical Daily Reports in Offshore Petroleum Engineering - An experience. Journal Advanced Computational Intelligence and Intelligent Informatics. v.7, n.2, 2003.

MIURA, K; MENDES, J. R. P.; MARTINS, L. F.: Gerenciamento do conhecimento de campo. Relatório Interno da Genesis do Brasil. Rio de Janeiro, 2009.

MOAZZENI, A. R.; NABAEI, M.; SHAHBAZI, K.; SHADRAVAN, A. Mechanical Earth Modelling Improves Drilling Efficiency and Reduces Non-Productive Time (NPT). SPE Deep Gas Conference and Exhibition, 2010, Manama, Bahrain. Proceedings... Manama, Bahrain: Society of Petroleum Engineers, SPE 131718, 2010.

O'BRIEN, D. E.; CHENEVERT, M. E. Stabilizing Sensitive Shales With Inhibited, Potassium-Based Drilling Fluids. SPE Journal of Petroleum Technology, v. 25, n. 9 , p. $1089-1100,1973$.

OORT, E. V. A novel technique for the investigation of drilling fluid induced borehole instability in shales. Rock Mechanics in Petroleum Engineering, 1994,. Delft, Netherlands. Proceedings... Delft, Netherlands: Society of Petroleum Engineers, SPE 28064, 1994.

PEREIRA DE LIMA, K. T. Utilização de métodos sísmicos, perfilagem e testemunhos de poços para caracterização dos turbiditos da formação Urucuruca na Bacia de Almada (BA). Dissertação de Doutorado. Centro de Ciência e Tecnologia, Universidade Estadual do Norte Fluminense. Macaé, 2005, 146p.

PETREL $^{\odot}$ versão 2011.1. Schlumberger, 2011.

PLUMB, R.; EDWARDS, S.; PIDCOCK, G.; LEE, D.; STACEY, B. The Mechanical Earth Model Concept and Its Application to High-Risk Well 
Construction Projects. IADC/SPE Drilling Conference, 2000, New Orleans, Louisiana. Proceedings... New Orleans, Louisiana: Society of Petroleum Engineers, IADC/SPE 59128, 2000.

QIU, K.; FELGUEROSO, J. G.; LALINDE, G.; COSTE, B. J.; NAAS, A.; FULLER, J. Geomechanics Enables the Success of Horizontal Well Drilling in Libya: A Case Study. Drilling Conference, 2008, Orlando, Florida. Proceedings... Orlando, Florida: Society of Petroleum Engineers, IADC/SPE132440 2008.

RABELO, C. A. C. Uma metodologia para análise de dados de perfuração de poços de desenvolvimento. Dissertação de Mestrado. Faculdade de Engenharia Mecânica e Instituto de Geociências, Universidade Estadual de Campinas, São Paulo, 2008, 100p.

RAZI, S.; SHADIZADEH, R. S.; SHAHRIAR, K.; KAZEMZADEH, E. Building a Precise Mechanical Earth Model and its Application in Drilling Operation Optimization: A Case Study of Asmari Formation in Mansuri Oil Field. International Oil and Gas Conference and Exhibition in China, 2010, Beijing, China. Proceedings... Beijing, China: Society of Petroleum Engineers, SPE 132204, 2010.

REID, D.; ROSENBERG, S.; MONTGOMERY, M.; SUTHERLAND, M.; YORK, P. Drilling-Hazard Mitigation-Reducing Nonproductive Time by Application of Common Sense and High-Value-Well Construction Techniques. Offshore Technology Conference, 2006, Houston, Texas Proceedings... Houston, Texas Society of Petroleum Engineers, SPE 18084-MS, 2006.

ROCHA, L. A. S., AZEVEDO, C. T. Projetos de Poços de Petróleo: Geopressões e Assentamentos de Colunas de Revestimentos, 2.ed. Rio de Janeiro: Ed. Interciência, Petrobras, 2007.

SANTOS, H.; REGO, L. F. B.; DA FONTOURA, S. A. B. Integrated Study of Shale Stability in Deepwater, Brazil. Latin American and Caribbean Petroleum Engineering Conference, 1997, Rio de Janeiro, Brazil. Proceedings... Rio de Janeiro, Brazil: Society of Petroleum Engineers, SPE 38961, 1997.

SAYERS, C. M.; BOER, L. D.; LEE, D. W.; HOOYMAN, P. J.; LAWRENCE, R. P. Predicting Reservoir Compaction and Casing Deformation in Deepwater Turbidites Using a 3D Mechanical Earth Model. First International Oil Conference and Exhibition in Mexico, 2006, Cancun, Mexico. Proceedings... Cancun, Mexico: Society of Petroleum Engineers, SPE 103926, 2006.

SEST ${ }^{\odot}$-Sistema de ESTabilidade, versão 5.72, GTEP/PUC-RIO e TEP/CENPES/PETROBRAS, 2012.

SOARES, J. A. Um estudo da estabilidade mecânica de poços a partir de perfis geofísicos em formações pouco consolidadas. Dissertação de Mestrado. Departamento de geofísica. Universidade Federal do Pará, Belém,1992, 114p.

TAVARES, R. M. Interpretação e análise de dados de perfuração em poços de petróleo. Dissertação de Mestrado. Departamento de Engenharia de Petróleo. Universidade Estadual de Campinas, São Paulo, 2006, 129p. 
TIBILETTI, M.; MOHAMED, O.; TOUBAR, E.-M. Reducing NPT (Non-Productive Time) in Deepwater Subsea High Rate Wells - A Field Case History. Offshore Technology Conference, 2004. Houston, Texas Proceedings... Houston, Texas. Society of Petroleum Engineers, SPE 16625-MS, 2004.

VARGAS, J. A. M. Análise de estabilidade de poços verticais em formações rochosas. Dissertação de Mestrado. Departamento de Engenharia de Petróleo. Universidade Estadual de Campinas, São Paulo, 1987, p.1-25.

VOS, B. E., REIBER F. The Benefits of Monitoring Torque \& Drag in Real Time. IADC/SPE Asia Pacific Drilling Technology, 2000, Kuala Lumpur, Malaysia. Proceedings... Kuala Lumpur, Malaysia: Society of Petroleum Engineers, SPE 62784-MS, 2000.

WARAGAI, T.; YAMAMOTO, K.; TOKUDA, N. Eliminating Additional Drilling Expense Due to Well Stability Problem in Laminated/Fractured Nahr Umr Shale Formation. Abu Dhabi International Petroleum Exhibition and Conference, 2006. Abu Dhabi, UAE. Proceedings... Abu Dhabi, UAE: Society of Petroleum Engineers, SPE 101383, 2006.

WEISS, W. J.; GRAVES, R. H.; HALL, W. L. 9. Shale Controlling Drilling Fluids. 5th World Petroleum Congress, 1959, New York, USA. Proceedings... New York, USA: Society of Petroleum Engineers, SPE 8108,1959.

WHITE, A.; MCINTYRE, B.; CASTILLO, D.; TROTTA, J.; MAGEE, M.; WARD, C.; O'SHEA, P. Updating the Geomechanical Model and Calibrating Pore Pressure from 3D Seismic Using Data from the Gnu-1 Well, Dampier Sub-basin, 2007, Australia. Proceedings... Australia: Society of Petroleum Engineers, SPE 110926-MS, 2007.

YAMAMOTO, K.; SHIOYA, Y.; MATSUNAGA, T.; KIKUCHI, S.; TANTAWI, I. A mechanical model of shale instability problems offshore Abu Dhabi. Abu Dhabi International Petroleum Exhibition and Conference, 2002. Abu Dhabi, UAE. Proceedings... Abu Dhabi, UAE: Society of Petroleum Engineers, SPE 78494, 2002.

YAMAMOTO, K.; WARAGAI, T.; KIKUCHI, S.; FADA'Q, A. S.; KOYAMA, T.; MATSUNAGA, T. Historical Review and Rock Mechanics Approach to Improve the Wellbore Stability in Nahr Umr Shale Formation. Abu Dhabi International Conference and Exhibition, 2004, Abu Dhabi, UAE. Proceedings... Abu Dhabi, UAE: Society of Petroleum Engineers, SPE 88782, 2004.

YARIM, G.; RITCHIE, G. M.; MAY, R. B. A Guide to Successful Backreaming: Real-Time Case Histories. SPE Drilling \& Completion, v. 25, n. 1, p. 27-38, 2010.

YORK, P. L.; PRICHARD, D. M.; DODSON, J. K.; DODSON, T.; ROSENBERG, S. M.; GALA, D.; UTAMA, B. Eliminating Non-Productive Time Associated with Drilling through Trouble Zones. Offshore Technology Conference 2009. Houston, Texas. Proceedings... Houston, Texas. Society of Petroleum Engineers, SPE 20220, 2009

Zhang, J. The impact of shale properties on wellbore stability. Doctor's Dissertation. Faculty of the Graduate School of the University of Texas at Austin, Texas, 2005, p. 1-50. 


\section{Apêndice A}

Gráficos de profundidade versus tempo

Neste capítulo serão apresentados os gráficos da profundidade versus tempo dos poços P-001, P-002 e do P-003 do estudo de caso. 


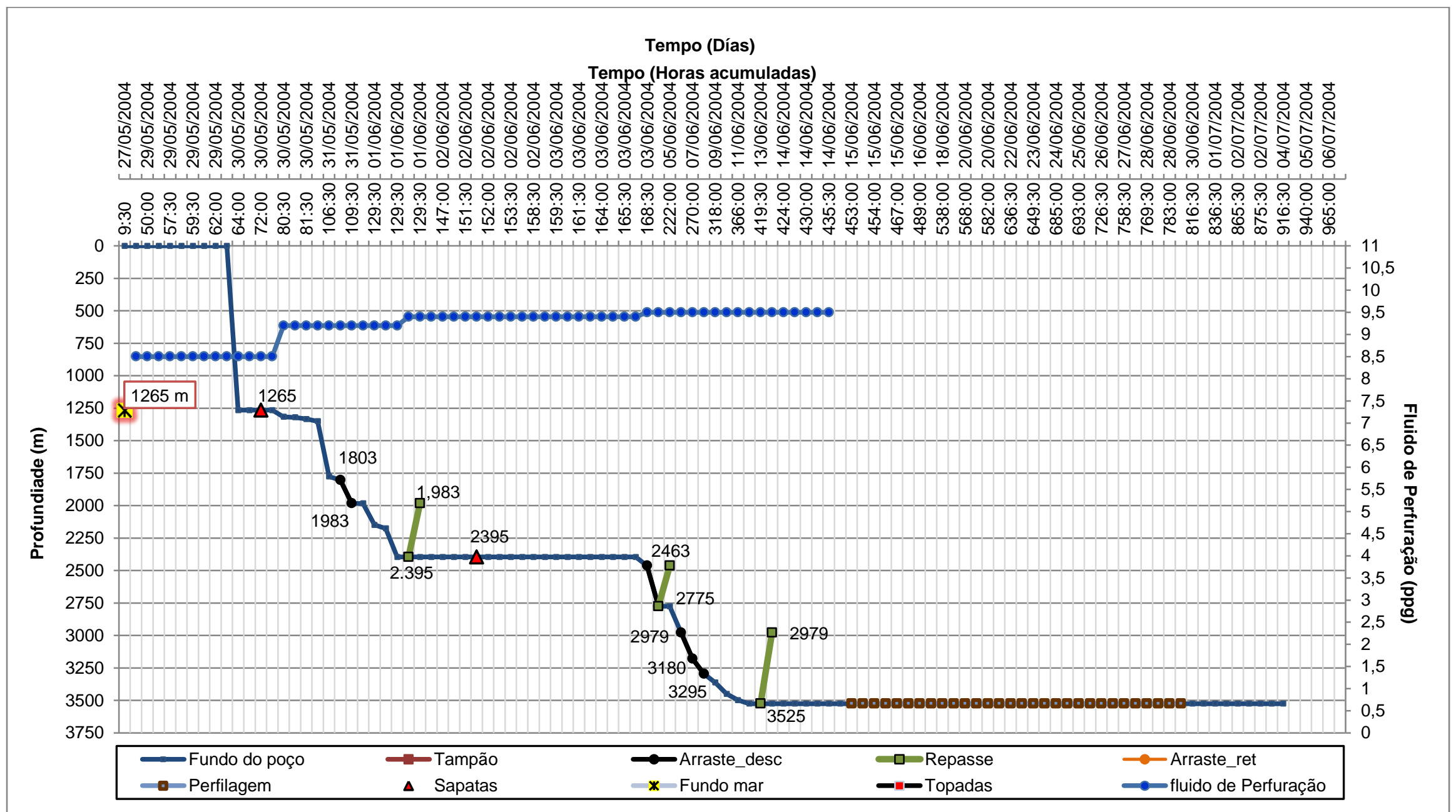

Apêndice A.1 - Gráfico de profundidade versus tempo do poço P-001. 


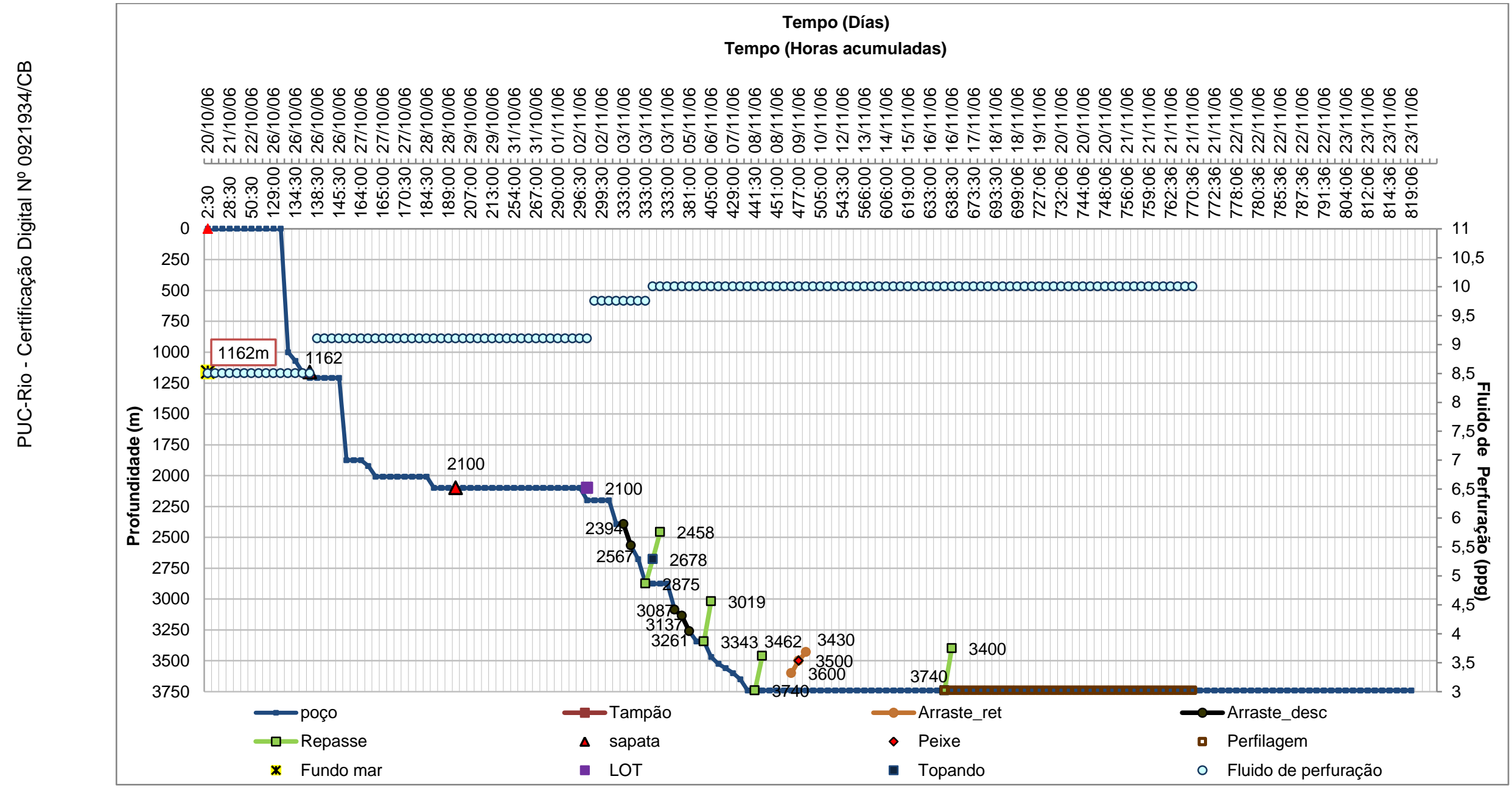

Apêndice A.2 - Gráfico de profundidade versus tempo do poço P-002. 


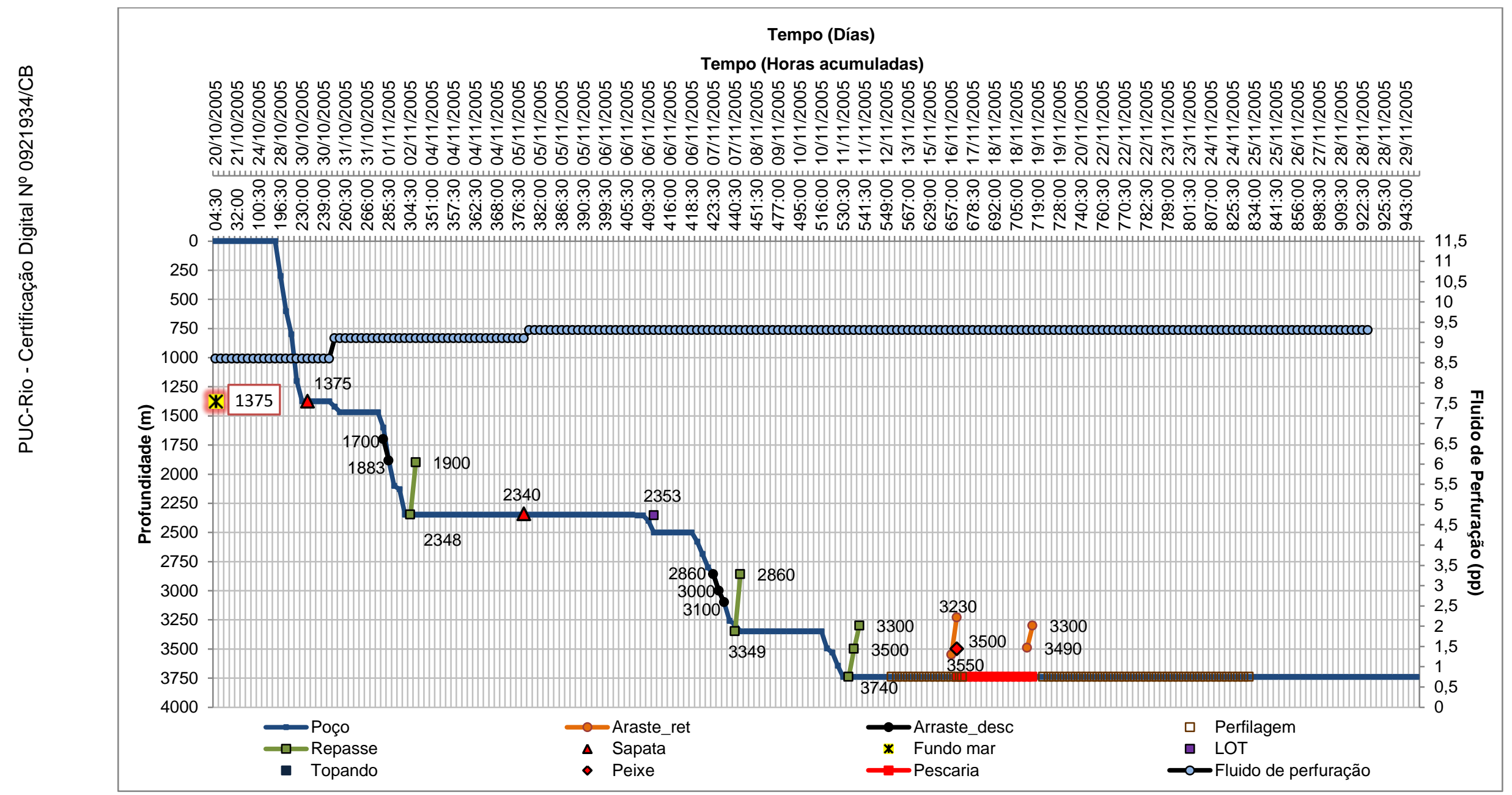

Apêndice A.3 - Gráfico de profundidade versus tempo do poço P-003. 


\section{Apêndice B \\ Gráficos para a análise do TNP}

Neste capítulo serão apresentados os gráficos de pizza para a análise do TNP dos poços P-001, P-002 e do P-003 do estudo de caso.

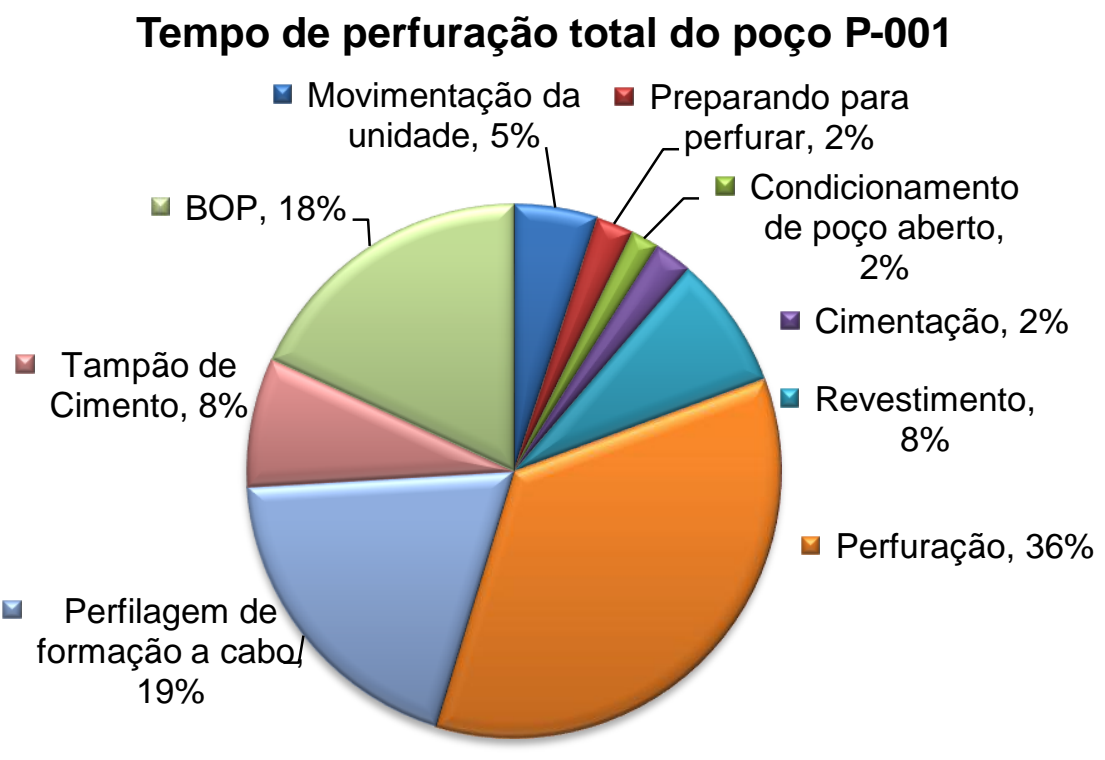

Apêndice B.1 - Gráfico do tempo de perfuração das atividades principais do poço P-001.

\section{TP (h) e TNP (h) do poço P-001}

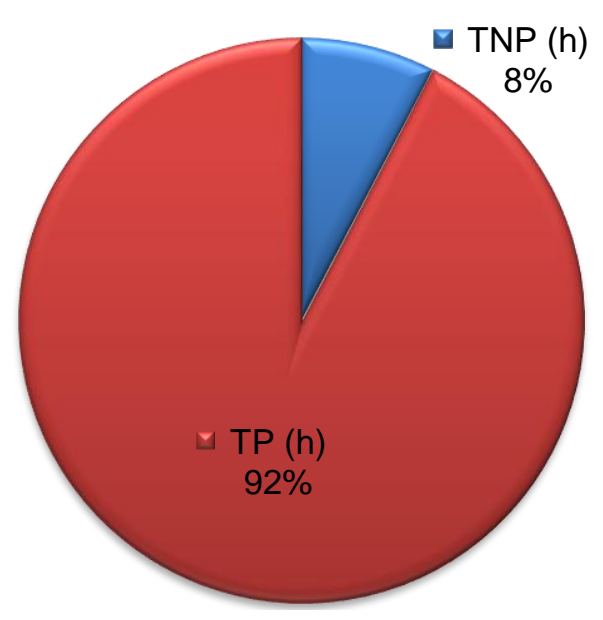

Apêndice B.2 - Gráfico do Tempo produtivo (TP) e do Tempo Não Produtivo (TNP) do poço P-001. 


\section{TNP (h) na perfuração do poço P-001}

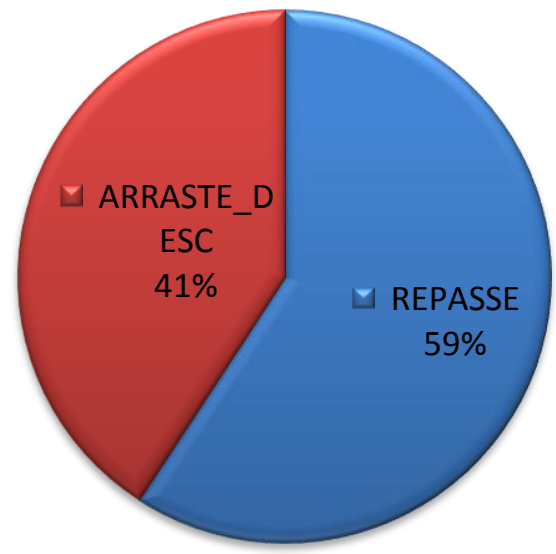

Apêndice B.3 - Gráfico dos problemas de instabilidade que geram o Tempo Não Produtivo (TNP) do poço P-001.

\section{Tempo de perfuração total do poço P-002}

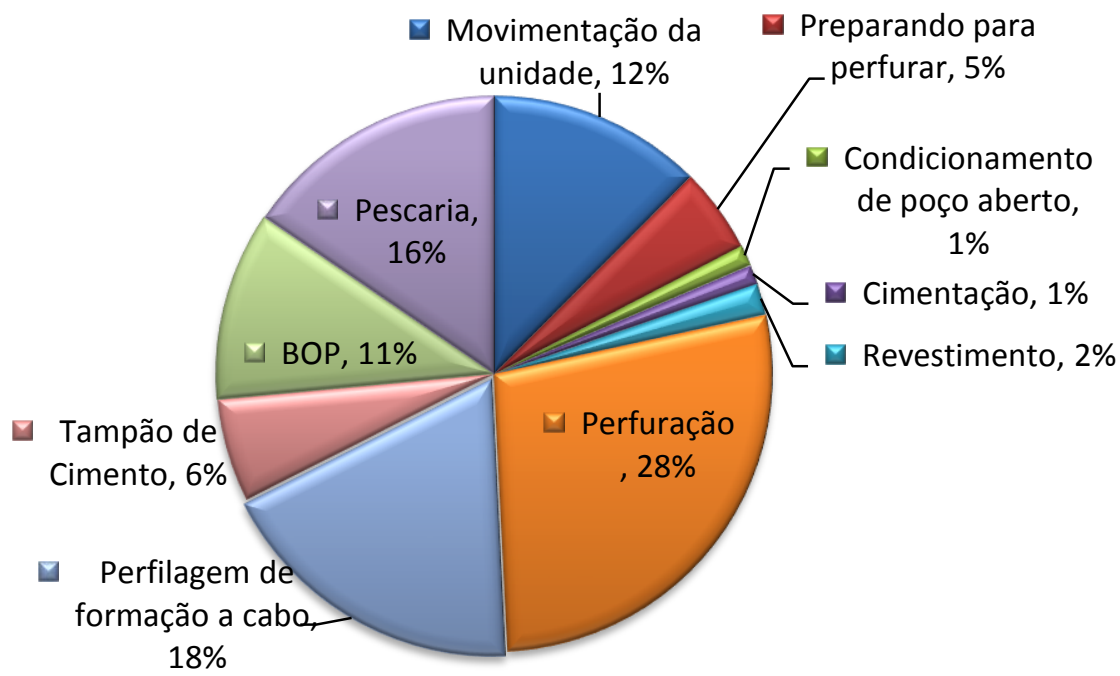

Apêndice B.4 - Gráfico do tempo de perfuração das atividades principais do poço P-002. 


\section{TP (h) e TNP (h) do poço P-002}

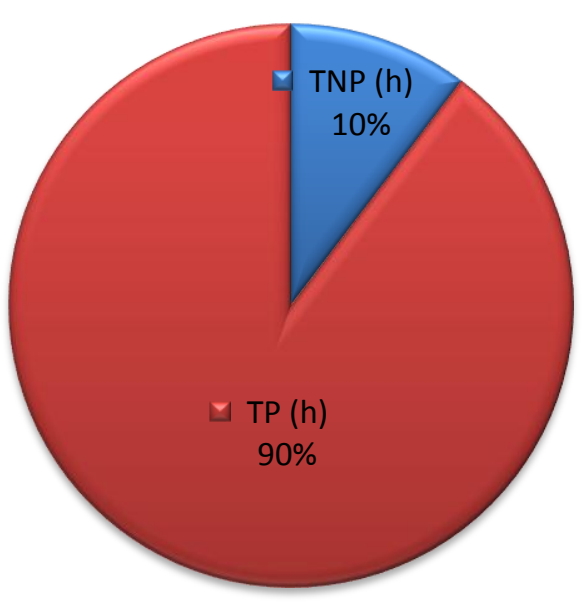

Apêndice B.5 - Gráfico do Tempo produtivo (TP) e do Tempo Não Produtivo (TNP) do poço P-002.

\section{TNP (h) nas atividades de perfuração do poço $\mathrm{P}-002$}

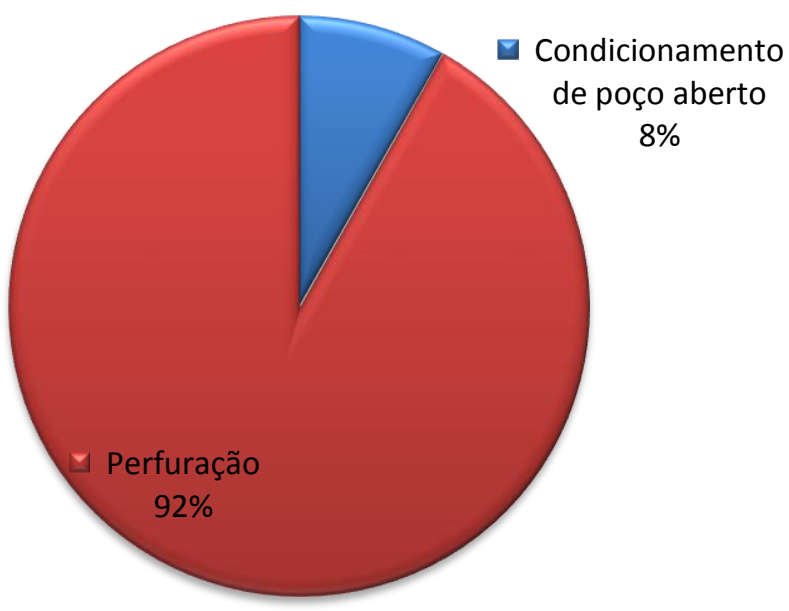

Apêndice B.6 - Gráfico do Tempo Não Produtivo (TNP) em função das atividades de perfuração do poço P-002. 
Tempo de Perfuração Total do Poço P-003

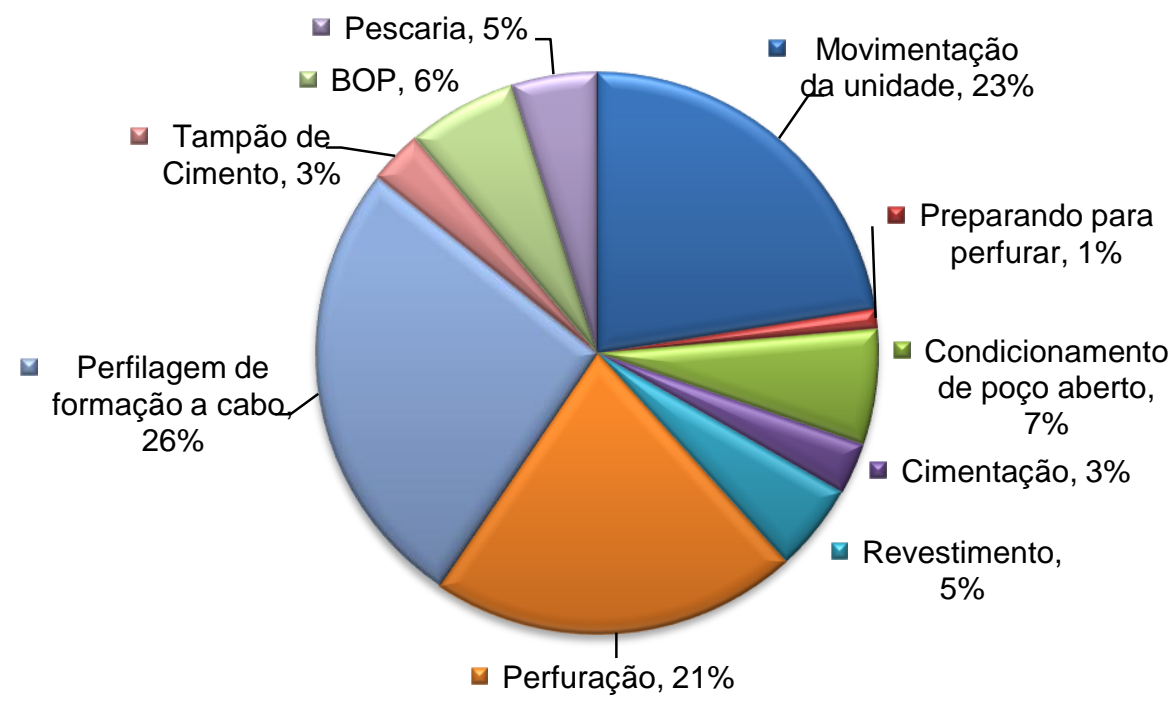

Apêndice B.7 - Gráfico do tempo de perfuração das atividades principais do poço P-003.

\section{TP (h) e TNP (h) do Poço P-003}

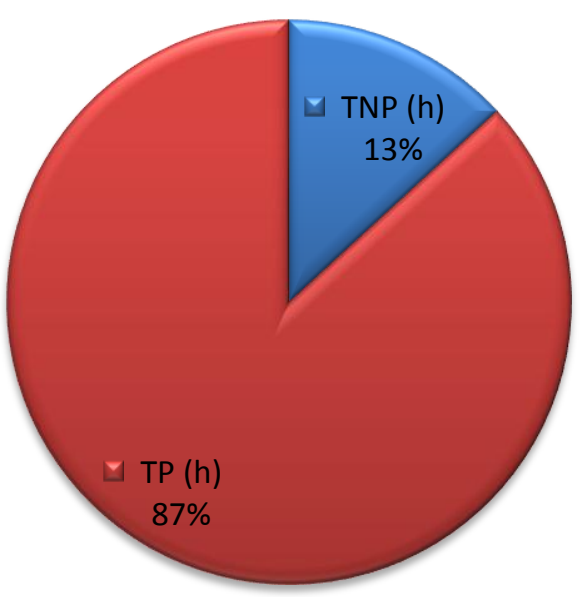

Apêndice B.8 - Gráfico do Tempo produtivo (TP) e do Tempo Não Produtivo (TNP) do poço P-003. 
TNP (h) nas atividades de perfuração do poço P-003

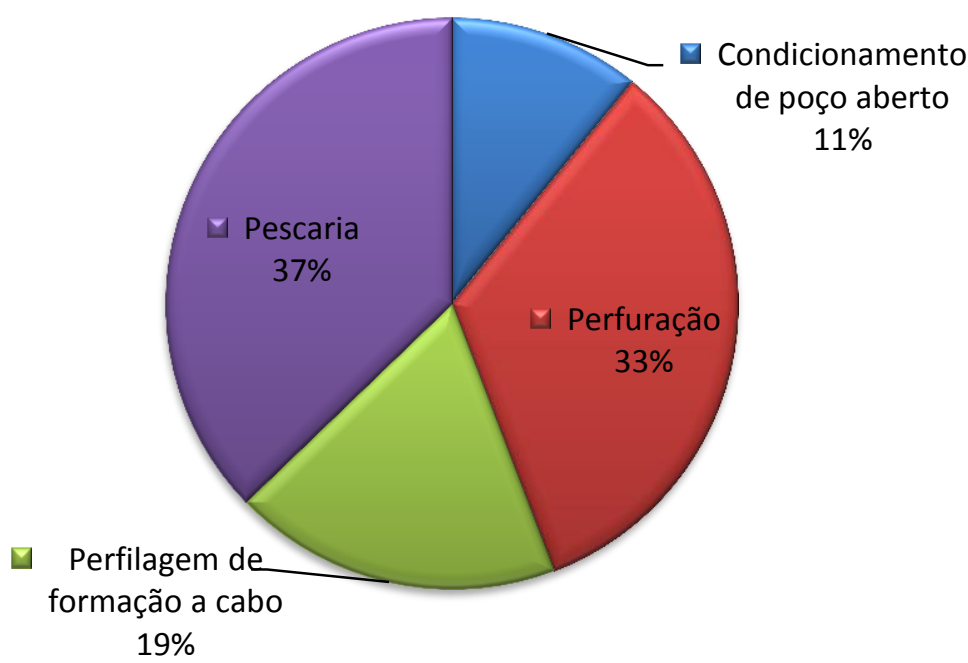

Apêndice B.9 - Gráfico do Tempo Não Produtivo (TNP) em função das atividades de perfuração do poço P-003. 


\section{Apêndice $\mathbf{C}$ Janela Operacional}

Neste capítulo serão apresentados os gráficos correspondentes às janelas operacionais dos poços P-001, P-002 e do P-003 do estudo de caso como produto final da análise de estabilidade usando o SEST ${ }^{\odot}$.

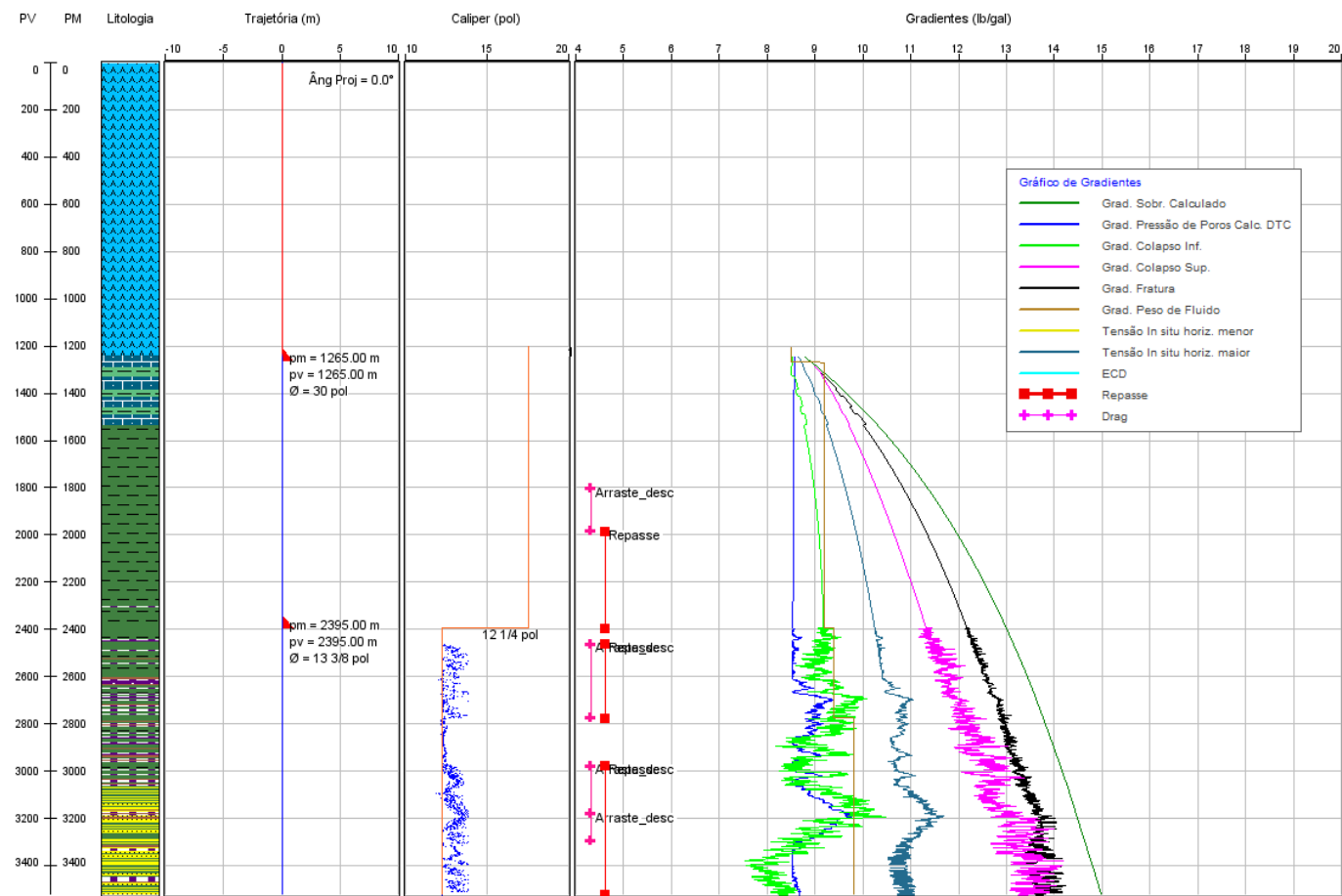

Apêndice C.1 - Janela operacional do poço P-001. 


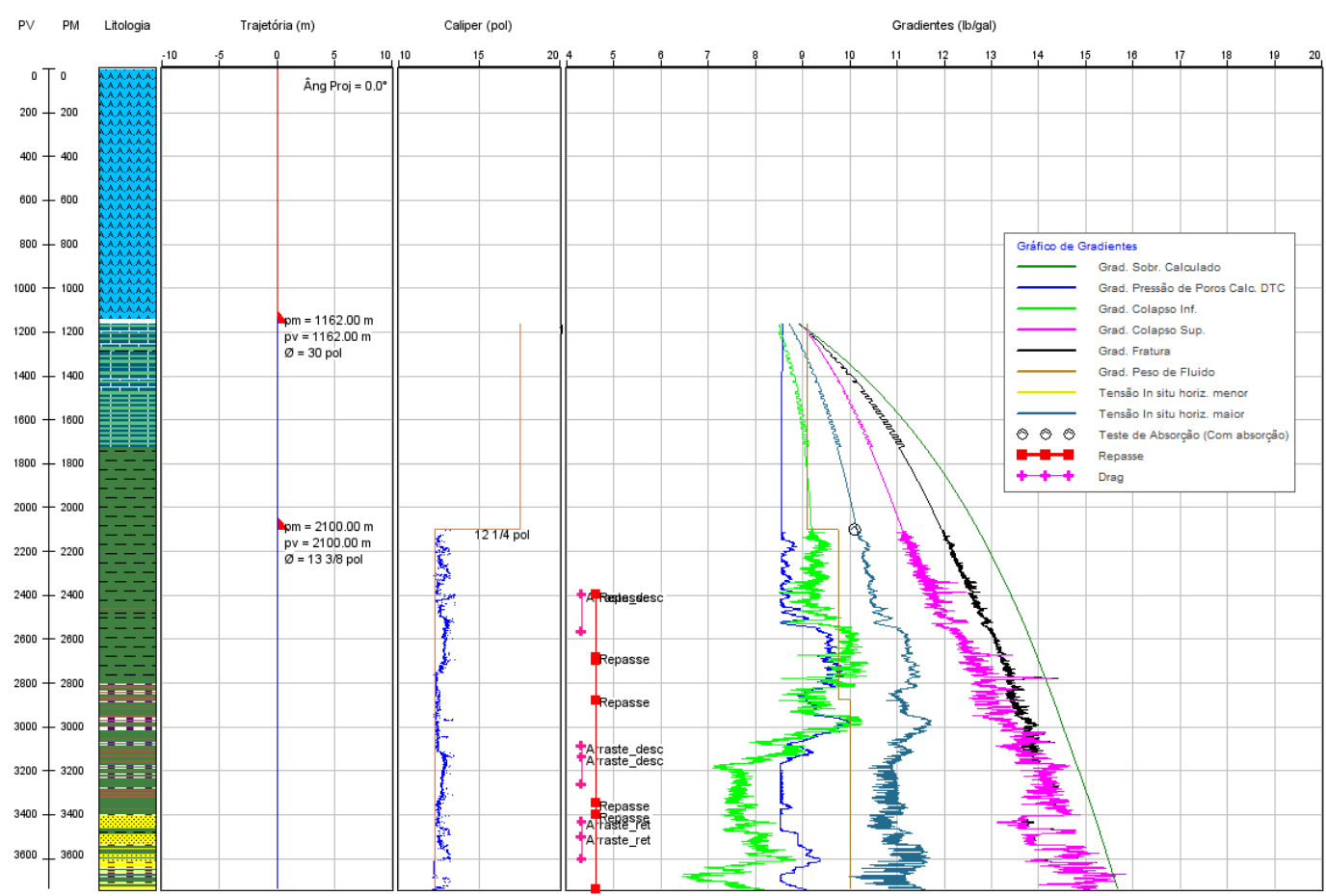

Apêndice C.2 - Janela operacional do poço P-002.

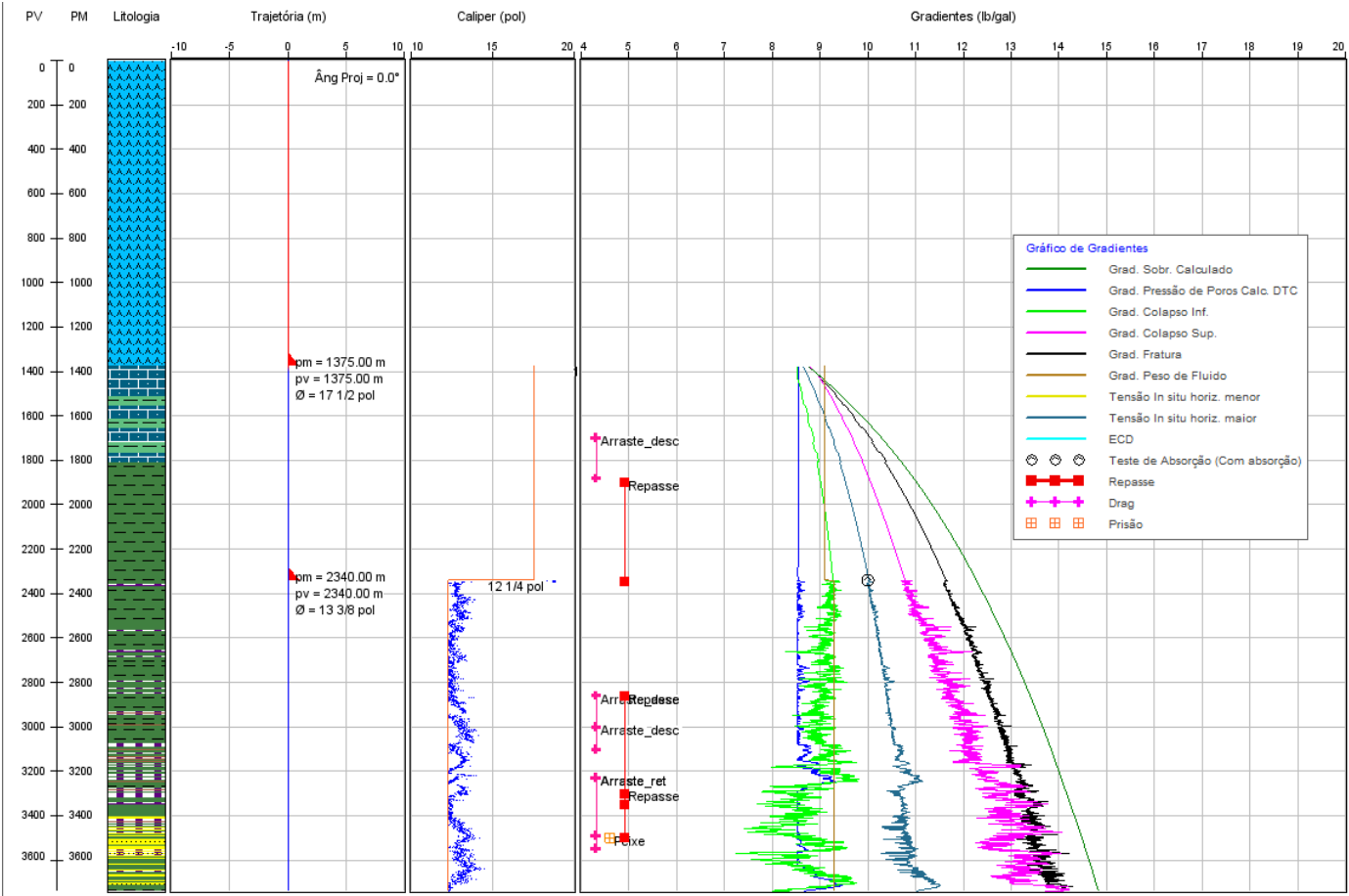

Apêndice C.3 - Janela operacional do poço P-003. 